LONDOÑO, Fernando. "Ilícito de manipulación bursátil: fenómeno y lesividad.

Aspectos de política sancionatoria".

Polít. crim. Vol. 8, No 15 (Julio 2013), Art. 3 pp. 64 - 127.

[http://www.politicacriminal.cl/Vol_08/n_15/Vol8N15A3.pdf]

\title{
Ilícito de manipulación bursátil: fenómeno y lesividad. Aspectos de política sancionatoria.
}

\author{
Dr. Fernando Londoño Martínez \\ Profesor de Derecho Penal de la Universidad Diego Portales (*) \\ fernando.londono@udp.cl
}

\begin{abstract}
"Para dar a entender el corredor sagaz que, si tiene dos mil libras que comprar, tiene veinte, compra mil; y viendo que hay otro que, o por seguirlo o por lisonjearlo, también compra, se le llega fatigado al oído y, con una voz de ansia y de recelo (mas de suerte que lo oigan los que revientan por oírlo), le pide por amor de Dios que no lo arruine, que no le altere el precio porque tiene que feriar inmensas partidas y que, si le alborota la corriente, le será imposible el viaje e indubitable la zozobra. Imagina el congreso que es afán lo que es treta, empiezan a comprar todos para recoger el avanzo que promete la disposición y, aunque no es infalible el acierto, no deja de ser muchas veces provechoso el ardid. Pidió el demonio a Eva que comiese del árbol vedado para hacerse inmortal; y es sin duda que, si ella se hubiese de hacer inmortal con el árbol, no le pediría el demonio que comiese; mas pidióle lo que a él convenía y aconsejóle lo que a él le importaba. Lo mismo hacen los demonios de nuestro infierno, jamás aconsejan sino lo que les está bien, jamás piden sino lo que les conviene, jamás persuaden sino a lo que les importa." José Penso de la Vega, Confusión de Confusiones, Ámsterdam, 1688, Diálogo Cuarto, pp. 338-339; cit. de edición contemporánea de la Universidad Europea-CEES Ediciones, Madrid, 2000, p. 258.

"'Manipulation' is 'virtually a term of art when used in connection with securities markets.' Ernst \& Ernst, 425 U.S., at 199, 96 S.Ct., at 1384. The term refers generally to practices, such as wash sales, matched orders, or rigged prices, that are intended to mislead investors by artificially affecting market activity." (judge Byron White en sentencia de la Corte Suprema de los Estados Unidos, Santa Fe Indus., Inc. v. Green, 430 U.S. 462, (1977), III).
\end{abstract}

\section{Resumen}

A partir de una revisión de la casuística comúnmente asociada al ilícito penal y administrativo de manipulación bursátil (desde una perspectiva de derecho comparado), el presente trabajo propone una caracterización y una taxonomía de la manipulación de los precios de los instrumentos financieros transados en el mercado de valores. Las soluciones se ofrecen a partir del examen de las funciones económico-financieras desempeñadas por el referido mercado, bajo el presupuesto de que sólo desde la lesividad de la conducta es posible captar criterios adecuados para una conceptualización del fenómeno manipulativo. El autor llega así a reconocer la existencia de dos entidades de manipulación, con diversos grados de lesividad: los conceptos de manipulación general y manipulación especial se proponen en ese marco. La lesividad de la manipulación bursátil se profundiza en la última sección del texto, a partir de la consideración del éthos que da vida al sistema, el que el autor caracteriza como meritocrático-comunitario. En fin, el artículo concluye extrayendo algunas conclusiones de utilidad en un plano de política sancionatoria, reconociendo el autor que se trata sólo de líneas de apertura, necesitadas por tanto de un ulterior desarrollo en un espacio diferente al del presente artículo. 
LONDOÑO, Fernando. "Ilícito de manipulación bursátil: fenómeno y lesividad. Aspectos de política sancionatoria".

\title{
Palabras clave
}

Manipulación bursátil, Mercado de Valores, Abusos de Mercado, Manipulación de precios de valores, Lesividad, Bolsa de Valores, ilícito administrativo, Ley n ${ }^{\circ}$ 18.045.

\begin{abstract}
On the basis of an analysis of categories of cases most commonly related with the criminal and regulatory offence of stock market manipulation (from the perspective of comparative law), the paper provides a characterization and taxonomy of stock-price manipulation in securities markets. The solutions are brought into light through the examination of the economical and financial functions displayed by securities markets, under the assumption that studying manipulation as a socially undesirable behavior (harm) is the one procedure in order to adequately grasp and conceptualize manipulative phenomenon. In this way, the paper illustrates two kinds of manipulative behavior within securities markets, both introducing different degrees of harm: general manipulation and special manipulation. The paper's last section enlarges the characterization of stock-price manipulation as a socially undesirable behavior, on the grounds of the ethos that gives life to the securities system, characterized by the author as meritocratic and community-oriented. The paper concludes by offering some brief and provisional insights from a sanction policy angle, acknowledging that such effort requires a further and deeper research in the matter.
\end{abstract}

\section{Key words}

Stock market manipulation, Stock market, Market Abuse, Stock-price manipulation, Harmfulness, Stock Exchange, regulatory offence, Law nº 18.045.

\section{Sumario.}

Introducción. 1.-Bosquejo del sistema de mercado de valores: sentido y funciones. 1.1.- Mercados financieros: dos grandes modelos. 1.2.- Principales aspectos problemáticos de un modelo de oferta pública de valores. 1.3.- Condiciones para el funcionamiento de un mercado de oferta pública de valores. 1.4.- Breve excurso (primera aproximación a la lesividad del fenómeno). 2.- Concepto y caracterización general de la manipulación en cuanto fenómeno: el tipo pre-normativo. 2.1. Consideraciones metodológicas. Tipologías de casos consideradas.2.2.- Una primera aproximación al fenómeno: el eficaz auxilio de la semántica: concepto general y concepto especial de manipulación (injerencia y distorsión). 2.3.- Los conceptos de manipulación a partir de la casuística: una primera verificación de los resultados provisorios a partir de la observación de algunos casos representativos. 2.3.1.- Marking the close. 2.3.2.- Pump and dump. 2.3.3.- Abusive squeeze. 2.3.4.Scalping: una clásica information based manipulation. 2.3.5.- La estabilización de precios en mercados de primera emisión. 2.3.6.- Conclusiones preliminares. 2.4.- Una primera aproximación a la lesividad del fenómeno. 2.5.- La doctrina estadounidense de la primera mitad del novecientos: una confirmación de las conclusiones preliminares. 2.6.- Profundizando en el fenómeno: una caracterización más completa de la manipulación a partir de un marco taxonómico (atendiendo principalmente al punto de vista del mecanismo medial). 2.6.1.- Perspectivas válidas para un marco taxonómico. 2.6.2.- Ulterior explicación del marco taxonómico. 2.6.3.- Una aclaración adicional: el carácter genérico de las manipulaciones informativas. 2.6.4.- La taxonomía aplicada a las 
Polit. crim. Vol. 8, № 15 (Julio 2013), Art. 3, pp. 64 - 127.

[http://www.politicacriminal.cl/Vol_08/n_15/Vol8N15A3.pdf]

principales tipologías reconocidas por el Comité de Autoridades Europeas Reguladoras de Valores (CESR). 3.- Colocando la manipulación en su contexto: las funciones del mercado de valores y la lesividad de la manipulación. Hacia una reconstrucción de los intereses jurídicos en juego. 3.1.Las funciones del mercado de valores. 3.2.- Atributos o cualidades del mercado de capitales (asociadas a las funciones precedentes). 3.3.- Los presupuestos de las funciones del mercado de valores: los factores institucionales y sociológicos que condicionan o dinamizan el despliegue de las funciones. 3.4.- Los vehículos materiales de los factores que condicionan la funcionalidad del mercado de valores. 3.5.- Algunas conclusiones preliminares. 3.6. Breve corolario aplicativo, a propósito del diseño de una política sancionatoria. Conclusiones. Propuesta de reconstrucción del fenómeno manipulativo (mecanismos y lesividad). Aspectos de política sancionatoria.

\section{Introducción}

La diferencia de aproximación entre autores de matriz anglosajona y autores de tradición europeo-continental en el tratamiento del ilícito de manipulación bursátil, ${ }^{1}$ puede esquematizarse del siguiente modo: mientras los primeros se concentran especialmente en:

(i) la descripción del fenómeno y del sistema en el que se inserta;

(ii) la explicación de la variopinta casuística subsumible bajo el título respectivo; y

(iii) la identificación de las consecuencias que una determinada subsunción podría implicar para el contexto regulado; ${ }^{2}$

(*) Me encuentro en deuda con los profesores Alessandro Bernardi y Andrea Perrone, por el incomparable espacio de trabajo y diálogo que posibilitó el presente artículo, principalmente fruto de mi estancia doctoral en Italia. Quisiera igualmente expresar mi agradecimiento a los siguientes profesores, por la generosa acogida en ese contexto: L. Bertonazzi della Val Trebbia, G. Bognetti, C. Grandi, G. Marinucci, S. Ninatti, A. Rovagnati, L. Vanoni, F. Viganò y L. Violini. Finalmente, agradezco a los colegas de la Facultad de Derecho de la Universidad Diego Portales que asistieron al seminario de discusión de papers realizado en noviembre de 2012, contexto en el que recibí valiosas observaciones relativas a un borrador del presente artículo. Naturalmente, la subsiguiente incapacidad o porfía del autor no puede resultarles imputable.

${ }^{1}$ Entiéndase por ella, en términos muy generales, todo intento por alterar (o mantener) los precios de los instrumentos financieros transados en un mercado de oferta pública de valores. La ilustración general del concepto puede resultar facilitada si se consideran los tres tipos de la legislación chilena que, paradigmáticamente, prohíben esta conducta: Ley $\mathrm{n}^{\circ} 18.045$ de Mercado de Valores: "Artículo 52.- Es contrario a la presente ley efectuar transacciones en valores con el objeto de estabilizar, fijar o hacer variar artificialmente los precios. (...). Artículo 53.- Es contrario a la presente ley efectuar cotizaciones o transacciones ficticias respecto de cualquier valor, ya sea que las transacciones se lleven a cabo en el mercado de valores o a través de negociaciones privadas. Ninguna persona podrá efectuar transacciones o inducir o intentar inducir a la compra o venta de valores, regidos o no por esta ley, por medio de cualquier acto, práctica, mecanismo o artificio engañoso o fraudulento. Artículo 61. El que con el objeto de inducir a error en el mercado de valores difunda información falsa o tendenciosa, aun cuando no persiga con ello obtener ventajas o beneficios para sí o terceros, sufrirá la pena de (...)." En lo demás, véase infra Introducción. Considérese en fin la conocida definición dada por judge White de la Corte Suprema de los EEUU en Santa Fe Indus., Inc. v. Green, 430 U.S. 462, (1977). III: "'Manipulation' is 'virtually a term of art when used in connection with securities markets.' Ernst \& Ernst, 425 U.S., at 199, 96 S.Ct., at 1384. The term refers generally to practices, such as wash sales, matched orders, or rigged prices, that are intended to mislead investors by artificially affecting market activity." Como puede advertirse, se trata de una definición que incorpora elementos que apuntan a la idoneidad de la conducta para llevar a error a los participantes en el mercado.

${ }^{2}$ Sobre el argumento, Cfr. MENGONI, Luigi, Ermeneutica e dogmatica giuridica, Milano: Giuffrè, 1996, pp. 91 y ss., quien -desde la perspectiva de la tradición europeo-continental- ofrece una muy interesante explicación sobre el por qué de la creciente influencia de la corriente de argumentación orientada a las consecuencias. 
LONDOÑO, Fernando. "Ilícito de manipulación bursátil: fenómeno y lesividad. Aspectos de política sancionatoria".

los segundos dedican un espacio considerable a:

(i) la conceptualización de los bienes (jurídicos) tutelados por las normas que prohíben la conducta; ${ }^{3} \mathrm{y}$

(ii) la exégesis y sistematización de los conceptos utilizados por el legislador al describirla o tipificarla, desde una perspectiva prioritariamente dogmática, dejando en general poco espacio para la orientación a las consecuencias. ${ }^{4}$

Ambas aproximaciones son fecundas y de utilidad en su propio ámbito, en cuanto obedecen a las necesidades y a la mentalidad propias de sus respectivos modelos normativos y jurisdiccionales.

Ahora bien, dichas aproximaciones al ilícito de manipulación bursátil plantean igualmente dificultades a quien se enfrenta a ellas desde afuera. Así, mientras la aproximación anglosajona puede lanzarnos hacia un escenario de multiforme y compleja fragmentariedad, no fácilmente aprehensible por el operador con formación exclusivamente jurídica (por más sustanciosa e inspiradora que sea la descripción del fenómeno), la aproximación europeocontinental puede ofrecernos un panorama de relativo hermetismo conceptual, eventualmente aleatorio en su rendimiento práctico y normalmente ciego a las consecuencias para el sistema objeto de regulación (por más rigurosa e intelectualmente honesta que sea la exégesis conceptual).

En extremas síntesis: si la primera aproximación nos lanza hacia el desconocido mundo de "lo especial", la segunda nos entrega al de "lo general".

Por otra parte, las descripciones legales de la conducta de manipulación bursátil -que no difieren tanto como podría pensarse entre una y otra tradición- comparten al menos una importante nota característica; a saber, la cualidad especialmente abierta o elástica de las fórmulas utilizadas para definir la conducta sancionada. Se alude así, ya a (i) una mera "idoneidad de la conducta" para alterar los precios, conduciéndolos hacia un "nivel artificial o anormal" (perspectiva de resultado), ya -más comúnmente- (ii) al empleo de

\footnotetext{
${ }^{3}$ Referencias habituales se hacen a bienes como "la integridad del mercado"; "la correcta formación de los precios del mercado"; "la confianza de los inversionistas". Al respecto, cfr. la sección tercera de este trabajo, especialmente las notas $n^{\circ} 130$ y 131 . Igualmente, cfr. infra nota $n^{\circ} 16$.

${ }^{4}$ Más allá del específico sector que nos ocupa, existirían razones de fondo -de la dogmática- para esta resistencia a la argumentación orientada a las consecuencias, como expone LUHMANN, Niklas, Sistema Giuridico e Dogmatica Giuridica, Bologna: Il Mulino, 1978, pp. 68 y ss., reconociendo en dicha corriente un peligro para la diferenciación, autonomía e imparcialidad del sub-sistema jurídico. Reconoce el citado autor la influencia del trend consecuencialista, que se va desarrollando desde hace más de un siglo (él escribe en 1974) y que intenta invertir la primacía de la orientación (dogmática y hermenéutica) desde el in-put hacia el out-put (en su terminología, out-put = la orientación hacia el futuro = la orientación según las consecuencias externas de las decisiones jurisdiccionales, es decir, su impacto fuera del sub-sistema jurídico). Luhmann identifica como actores de este trend corrientes como la jurisprudencia de los intereses, la jurisprudencia sociológica, el método teleológico de interpretación, la aproximación de la social engineering, el pensamiento realista, la preocupación por la efectivadad del derecho y, más recientemente, la demanda en pos de un empeño socio-político por parte de los juristas (cfr., LUHMANN, Sistema Giuridico, cit. nota $\mathrm{n}^{\circ}$ 4, p. 68).

${ }^{5}$ En esta línea pueden identificarse definiciones legales como las del art. 52 LMV chilena (= "efectuar transacciones en valores con el objeto de estabilizar... o hacer variar artificialmente los precios") o la
} 
Polít. crim. Vol. 8, № 15 (Julio 2013), Art. 3, pp. 64 - 127. [http://www.politicacriminal.cl/Vol_08/n_15/Vol8N15A3.pdf]

ciertos medios emparentados con el concepto de fraude en contextos de negociación bursátil $^{6}$ (como el recurso a conductas engañosas, artificios, simulaciones o ficciones en el marco de operaciones sobre valores), con o sin referencia a la idoneidad de la conducta para alterar el curso de los precios (perspectiva de medios). ${ }^{7}$

Esta textura abierta ${ }^{8}$ de las normas de prohibición de rango legal entrega una cuota importante de poder al intérprete de turno: agencia reguladora, fiscalía o tribunal que sea. Se trata de un poder que puede muy bien explicarse en razón del dinamismo y la complejidad del sector, ${ }^{9}$ más fácilmente abordable por el legislador mediante la formulación de standards. ${ }^{10}$ Ahora bien, precisamente por ello, el ejercicio de ese "poder interpretativo" -o bien derechamente "creativo", tratándose de agencias con competencia regulatoria- aparece especialmente necesitado de fundamento material y de orientación práctica. ${ }^{11}$

contenida en el art. 1.2.a de la Directiva CE 6 / 2003 sobre Abusos de Mercado (= "transacciones...que aseguren el precio...en un nivel anormal o artificial"); así como, de acuerdo a la interpretación que se le ha dado (con necesidad de prueba del carácter artificial del precio), aquella aplicable al mercado de futuros en Estados Unidos, contenida en la Sección 9 de la Commodity Exchange Act $[=7$ U.S.C. $\xi \quad 13(\mathrm{a})(2)=$ "Any person to manipulate or attempt to manipulate the price of any commodity (...)"].

${ }^{6}$ Una genealogía de esta técnica puede ya identificarse en las figuras decimonónicas de alteración de precios (agio, en castellano; aggiotaggio, en italiano), del que el art. 285 del Código Penal Chileno representa un claro ejemplo: "Los que por medios fraudulentos consiguieren alterar el precio natural del trabajo, de los géneros o mercaderías, acciones, rentas públicas o privadas o cualesquiera otras cosas que fueren objeto de contratación (...)". La relación entre esta figura y las descritas en los arts. 52 y 53 de la $L M V$ chilena es evidenciada por ETCHEBERRY, Alfredo, Derecho Penal. Parte Especial, Tomo IV, $3^{\text {a }}$ ed., Santiago: Editorial Jurídica de Chile, 1998, pp. 280-81. Un desarrollo del concepto de fraude supuesto en el art. 285 CP puede verse en HERNÁNDEZ, Héctor, "La punibilidad de la colusión (secreta) de precios en el derecho chileno", Polít. crim. Vol. 7, No 13 (Julio 2012), Art. 4, pp. 147 - 167; y MATUS, Jean Pierre, "Acerca de la actual falta de punibilidad en Chile de los acuerdos de precios", Polit. crim. Vol. 7, No 14 (Diciembre 2012), Art. 3, pp. $318-356$.

${ }^{7}$ En esta línea pueden identificarse definiciones legales como las del art. 53 LMV chilena (= inducción a la compra o venta de valores mediante "acto, práctica, mecanismo o artificio engañoso o fraudulento"); art. 1.2.b de la Directiva CE 6 / 2003 sobre Abusos de Mercado (= "transacciones u órdenes de realizar operaciones que empleen dispositivos ficticios o cualquier otra forma de engaño o maquinación”); art. 185 t.u.f. italiano (= "operaciones simuladas u otros artificios idóneos para provocar una alteración sensible del precio"); parag. 20 a (1)2 de la WpHG alemana (="conductas engañosas idóneas para influenciar los precios de valores"); y la clásica 10b SEA 1934, US Code 78j de los Estados Unidos, [= "manipulative or deceptive device (...)"].

${ }^{8}$ El concepto se debe a HART, Herbert L.A., The Concept of Law, Oxford: Oxford University Press, 1994, pp. 124 y ss.

9 Cfr. TIEDEMANN, Klaus, "Tecnica legislativa nel diritto penale economico", Riv. Trim. Dir. Pen. Ec., 2006, p. 4, quien explica el frecuente recurso del legislador a cláusulas generales en el ámbito del derecho (penal) económico a causa de la acelerada mutabilidad que caracteriza a las actividades económicas objeto de regulación: de allí entonces la necesidad de un juez -así como en sede de ley penal en blanco, de una administración- que "actualice" los contenidos de las cláusulas generales. Evidentemente esta técnica, que en el contexto del derecho económico general ofrece un rendimiento aceptable, en el derecho penal resulta problemática desde un punto de vista de legalidad.

${ }^{10}$ Precisamente normas sancionatorias amplias, elásticas, usualmente necesitadas de precisión adicional en un nivel inferior de fuentes (como acontece, en oposición a un sistema de normas estrechas, precisas o rígidas (rules)).

${ }^{11}$ Cfr. BÖCKENFORDE, Ernst-Wolfgang, Stato, costituzione, democracia, Milano: Giuffrè, 2006, p. 71, quien da cuenta del riesgo de arbitrariedad latente en la insuficiencia de los métodos tradicionales de interpretación: "Es por tanto necesario salir de estos cánones para no dejar entregada la interpretación a resultados insatisfactorios. De este modo se deberán utilizar instrumentos interpretativos complementarios, 
LONDOÑO, Fernando. "Ilícito de manipulación bursátil: fenómeno y lesividad. Aspectos de política sancionatoria".

De todo lo anterior resulta entonces el siguiente panorama problemático:

i) la base fáctica del sector es multiforme y compleja (fenómeno y casuística);

ii) las exégesis doctrinarias más a la mano en el ámbito europeo-continental suelen presentar un cuadro conceptual relativamente hermético, normalmente carente de orientación a las consecuencias (aleatoriedad);

iii) las normas sancionadoras (administrativos o penales que sean) suelen emplear términos amplios, elásticos, lo que importa entregar a los aplicadores(o reguladores de segundo grado) una dosis importante de "poder interpretativo" (o "creativo", en su caso);y

iv) a consecuencia de los factores descritos supra en i) y ii), no es infrecuente que el operador no especializado -que, ya sabemos, puede contar con un amplio poder decisorio- enfrente mayores dificultades de las deseables a la hora de aplicar las normas en cuestión.

Si ese es el diagnóstico de las dificultades, una hipótesis de colaboración en la solución muy parcial, se entiende- parece posible si se intenta responder a las siguientes interrogantes, cada una de las cuales está vinculada a las diversas aristas del problema:

i) ¿En qué contexto o sistema se insertan las conductas en estudio? La pregunta supone un bosquejo del mercado de valores;

ii) ¿Qué conductas han de considerarse en línea general como manipuladoras del mercado de valores? La pregunta supone una taxonomía de la casuística;

iii) ¿Por qué ha de prohibírseles? La pregunta supone una explicación en el plano de la lesividad; $y$

iv) ¿Qué consecuencias puede conllevar para el mercado regulado la prohibición y sanción de las aludidas conductas? La pregunta supone una perspectiva de política sancionatoria.

El iter de dichas preguntas concuerda con la estructura y el propósito del presente trabajo. En parte, éste ha sido construido a modo de círculos concéntricos, intentando ofrecer una visión progresivamente más detallada, para concluir con una de tipo sintética. Así, en una primera sección -del todo prescindible para especialistas de sector- se ofrece un bosquejo grueso del contexto o sistema en el que se inserta la conducta en estudio. En la segunda sección se plantea un principio de sistematización de la casuística común en materia de manipulaciones bursátiles. En la sección tercera se aborda de manera sistemática el problema de la lesividad de la conducta manipuladora, a partir de un estudio de las funciones y características del sistema que viene a impactar. En fin, el trabajo se cierra con una sección en la que se retoman los puntos anteriores, profundizándose en la lesividad del fenómeno a partir del éthos que da vida al sistema, concluyendo con el esbozo de perspectivas en un plano de política sancionatoria. Quisiera advertir desde ya que, por lo que se refiere a esta dimensión político-sancionatoria, se ofrecen sólo algunas líneas de apertura, requiriéndose un espacio más amplio que el presente para un desarrollo adecuado de dicha materia.

que, sin embargo, no siendo tematizados, resultan irreflexivos y carentes de control; ello da espacio a la irrupción de una (velada) arbitrariedad interpretativa" (traducción desde el italiano por el autor). 
Polít. crim. Vol. 8, № 15 (Julio 2013), Art. 3, pp. 64 - 127.

[http://www.politicacriminal.cl/Vol_08/n_15/Vol8N15A3.pdf]

Se hace en fin necesaria una última precisión relativa a la normativa de referencia y a la situación chilena en particular.

La perspectiva aquí asumida es principalmente de derecho comparado. Este punto de vista parece fecundo, dado el carácter altamente globalizado del sector bursátil, considerada especialmente la influencia que han tenido a lo menos dos importantes legislaciones. ${ }^{12} \mathrm{La}$ atención a la caracterización del fenómeno manipulativo resulta concordante con lo anterior.

Referencias puntuales se hacen a aquellos ordenamientos especialmente tenidos a la vista; a saber, la legislación chilena (principalmente la ley $n^{\circ} 18.045$ de Mercado de Valores, en adelante LMV), europea-comunitaria (Dir. CE 6/2003 sobre Abusos de Mercado [Market Abuse], en adelante Directiva $M A D)^{13}$, italiana (Testo Unico della Finanza, dlgs. n. 58 de 1998, en adelante t.u.f. n. 58), alemana (Wertpapierhandelsgesetz, en adelante $W p H G$ ), del Reino Unido (sections 118 (5-7) y 397 de la Financial Services and Markets Act 2000, en adelante FSMA) y de los Estados Unidos (principalmente la Securities Exchange Act de 1934 - en adelante $S E A^{\prime} 34$ - y normativa de segundo grado, emanada por la Securities Exchange Commission, en adelante $S E C$ ).

En cuanto a la situación chilena, se incluyen referencias especiales a los tipos e instituciones pertinentes, principalmente de la $L M V$. Los tipos paradigmáticos de manipulación bursátil se hallan descritos en los arts. 52, 53, 59 e) -en relación a los dos anteriores- y $61 \mathrm{LMV}^{14}$ Por su parte, ciertas falsedades ideológicas, en cuanto incidentes en un contexto de mercado de oferta pública de valores, pueden en concreto resultar comparables a las manipulaciones bursátiles que aquí nos ocupan, al menos por lo que se refiere a las modalidades basadas en el uso de información falsa, en su faz objetiva (cfr. infra apartados 2.3.4, 2.6 y nota al pie $\mathrm{n}^{\circ} 54$ ). Nos referimos en especial a falsedades de naturaleza societaria, de prospecto, contables o bien emanadas de calificadoras de riesgo (especialmente las hipótesis de los arts. 59 a), d), f) y g) $L M V$ y 134 de la Ley n 18.046 de Sociedades Anónimas). En general, en notas a pie de página el lector encontrará alusiones a los mencionados tipos o bien a otras instituciones de la $L M V$. Se ha utilizado dicho recurso para no romper con la estructura general del texto.

\footnotetext{
${ }^{12}$ Las legislaciones de Estados Unidos y Reino Unido por una parte, influyendo en general en la legislación del resto de los países del orbe occidental. Por la otra, la legislación comunitaria-europea - a su vez influida por las anteriores - de decisiva relevancia en su recepción por los países que hoy conforman la Unión Europea. Una armonización en este sentido ha ocurrido en el derecho bursátil, de manera especular a la que ha ido plasmándose en el derecho de las sociedades (corporate law), según dan cuenta respecto a este último derecho, HANSMANN, Henry; KRAAKMAN, Reiner, "The End of History for Corporate Law", Georgetown Law Journal, vol. 89 (2001), pp. 439 y ss. (disponible también en versión digital como paper en SSRN).

${ }^{13}$ Actualmente se encuentran en tramitación ante el Parlamento Europeo sendas propuestas de Reglamento (Com 2011, 651/3). y nueva Directiva (Com, 2011, 654/3) en materia de abusos de mercado, con la expresa exigencia de criminalización de las conductas de abuso de información privilegiado y manipulación del mercado. El proceso de revisión se suscitó a raíz de la crisis financiera iniciada en 2008. Las propuestas de Reglamento y nueva Directiva MAD datan de octubre de 2011. A diciembre de 2012 las propuestas de la Comisión Europea contaban con la aprobación de los ministros de Justicia europeos en el marco del Consejo Europeo. Cfr. http://ec.europa.eu/internal_market/securities/abuse.

${ }^{14}$ Los textos de estos artículos se encuentran parcialmente transcritos supra nota al pie $\mathrm{n}^{\circ} 1$.
} 


\section{LONDOÑO, Fernando. "Ilícito de manipulación bursátil: fenómeno y lesividad.}

Aspectos de política sancionatoria”.

En cuanto a la literatura nacional, resulta importante advertir que no nos consta la existencia de monografía o artículo de revista indexada dedicado específicamente a las manipulaciones bursátiles. ${ }^{15}$ Lo anterior puede entonces explicar la prácticamente nula referencia que aquí se hace a la literatura nacional. ${ }^{16}$ En fin, tampoco en jurisprudencia el desarrollo ha sido significativo. ${ }^{17}$ Como podrá entonces advertir el lector, la situación

15 Hasta donde se alcanza a ver, en la literatura nacional puede mencionarse sólo el comentario de jurisprudencia de ROSENBLUT, Verónica, "El denominado caso "Schwager": análisis de histórica condena por uso de información privilegiada y manipulación bursátil”, Revista Jurídica del Ministerio Público, N. 46 (marzo 2011), pp. 185-209; sp. pp. 186-189 (trabajo dedicado al análisis de la única sentencia penal de que tengamos noticia en materia de manipulación bursátil, dictada el 19 de octubre de 2010 por el $4^{\circ}$ Tribunal Oral en lo Penal de Santiago; en lo pertinente, la condena correspondió a la aplicación del art. 59 letra e) $L M V$, en relación con la conducta prohibida descrita en el inciso segundo del art. 53 de dicha ley). Por cierto, no se considera en este contexto aquella literatura dedicada al tipo penal del art. 285 del Código Penal Chileno (que tipifica la alteración de precios fraudulenta, cfr. supra nota $\mathrm{n}^{\circ} 6$ ). Es indudable que este tipo tradicional se encuentra emparentado con aquellos de manipulación bursátil y que puede aún plantearse una situación de eventual concurso aparente (resuelta en especialidad) con algunos de los tipos de manipulación bursátil de la LMV (como puede tácitamente desprenderse de ETCHEBERRY, Derecho Penal, cit. nota n6, pp. 280-281). Con todo, las características y especialidad de los tipos que nos ocupan hacen que no resulte pertinente considerar como literatura de referencia aquella (aún escasa) que se ha concentrado en el análisis del art. 285 $\mathrm{CP}$. Ni aún la renovada atención que el art. $285 \mathrm{CP}$ ha merecido de reciente entre nosotros parece suficiente para contradecir lo anterior, cuanto más si aquella ha tenido como objeto casi exclusivo argumentar en torno a la vigencia del tipo penal y a la subsunción de un caso de colusión monopólica, al alero del concepto de medios fraudulentos. Cfr. al respecto, HERNÁNDEZ, Héctor, "La punibilidad de la colusión (secreta) de precios en el derecho chileno". Polit. crim. Vol. 7, No 13 (Julio 2012), Art. 4, pp. 147 - 167; MATUS, Jean Pierre. "Acerca de la actual falta de punibilidad en Chile de los acuerdos de precios". Polít. crim. Vol. 7, No 14 (Diciembre 2012), Art. 3, pp. 318 - 356. En fin, en otro plano, vale la pena mencionar el trabajo de PARDOW, Diego, "La experiencia chilena disuadiendo ilícitos corporativos", Revista Derecho Público Iberoamericano, N. 1, 2012, pp. 55-83, el que analiza - críticamente - la actividad de la Superintendencia de Valores en el período 1990-2012 en respuesta a infracciones a deberes fiduciarios en el contexto del Mercado de Valores.

${ }^{16}$ En todo caso, se ha tenido a la vista aquella dedicada al delito de abuso de información privilegiada (arts. 60 e), 60 g) y 60 h) de la $L M V$ ), en cuanto puede resultar de interés en la conceptualización de los bienes jurídicos en juego, cuanto menos por lo que se refiere a la dimensión colectiva del interés representado por la confianza de los inversionistas en el adecuado funcionamiento del mercado de valores. Independientemente de los diversos grados de lesividad, desde esta dimensión es posible captar una unidad de sentido en la tutela del abuso de información privilegiada y la manipulación bursátil. La decisión del legislador europeo en la materia (Directiva $M A D$ ) viene a ratificar dicha conclusión (cfr. infra. sección 3.3.c. de este trabajo y especialmente la nota $\mathrm{n}^{\circ} 145$ ). Para un examen panorámico de los modelos de protección implícitos en la tipificación del abuso de información privilegiada - con una completa y actualizada revisión de la literatura nacional en lo pertinente- cfr., por todos, GARCÍA, Gonzalo, "Modelo de protección en normas administrativas y penales que regulan el abuso de Información Privilegiada en la legislación chilena". Polit. crim. Vol. 8, No 15 (2013), Art. 2, pp. 23 - 63. Por su parte, especialmente crítico de la consideración de intereses colectivos en el marco de la justificación de la prohibición y sanción del uso de información privilegiada (argumentando desde un paradigma de eficiencia informativa), cfr. RIED, José Miguel "Fundamentos de la prohibición del uso de la información privilegiada en Chile: una visión crítica", Revista Chilena de Derecho, 2004, N³1.3, pp. 439-463; sp. pp. 449 y 452.

${ }_{17}$ Por lo que se refiere a resoluciones administrativas sancionatorias, destacan las relativas al caso de la Corredora MBI por manipulación operativa (resoluciones exentas 402 y 501 de la SVS, de 8 de septiembre de 2006 y 23 de octubre de 2006, respectivamente, con sanción por infracción a los artículos 52 y 53 inciso primero de la $L M V$ ). Por su parte, el caso Schwager no dio lugar en definitiva a sanción administrativa por manipulación informativa (la resolución exenta 247 de la SVS, de 9 de junio de 2006, consideró insuficiente la prueba en materia de infracción del art. $61 \mathrm{LMV}$ ). Paradójicamente, y como ya se ha expuesto supra nota $\mathrm{n}^{\circ} 15$, el mismo caso Schwager sí fue objeto de sentencia condenatoria en sede penal por delito de 
Polít. crim. Vol. 8, № 15 (Julio 2013), Art. 3, pp. 64 - 127.

[http://www.politicacriminal.cl/Vol_08/n_15/Vol8N15A3.pdf]

nacional contrasta fuertemente con el interés que esta figura ha despertado en derecho comparado. En ese marco, este artículo se ofrece como un primer paso de cara a un futuro debate en nuestros confines.

\section{Bosquejo del sistema de mercado de valores: sentido y funciones.}

A modo de aproximación al sentido y funciones de un mercado de oferta pública de valores, en esta primera sección se expone un bosquejo de las dinámicas que le dan vida y que se hallan en las bases de su diseño normativo. ${ }^{18}$ Desde aquí podrá captarse sintéticamente la función que este mercado desempeña en una economía, así como los atributos y condiciones generales que posibilitan su correcto funcionamiento. Ubicada en esta sección inicial, esta visión sintética debería favorecer la captación del sentido y lesividad de la conducta de manipulación, aspectos que serán desarrollados con mayor detalle en las secciones centrales de este artículo. El lector especializado en el sector podrá dirigirse directamente a las secciones siguientes de este trabajo, en la medida que las generalizaciones en las que he debido incurrir no le reporten provecho.

\subsection{Mercados financieros: dos grandes modelos.}

Para materializar un proyecto, ampliar o mejorar su capacidad de producción o concretar cualquier decisión de inversión esperablemente generadora de riqueza, una empresa requiere de financiamiento. De allí que se les denomine "unidades en déficit", en cuanto aparecen necesitadas de capital, por sobre su propia capacidad de ahorro. ${ }^{19}$ Para satisfacer dicha necesidad de financiamiento, la empresa puede solicitar un crédito a una entidad

manipulación bursátil, aplicándose en la especie el tipo de manipulación del art. 59 e), en relación con el inciso segundo del art. $53 L M V$. Por cierto, cabe también mencionar en este contexto la situación del caso conocido como La Polar (SA cotizada en Bolsa) y las diversas aristas -todavía pendientes- que involucran a varios de sus ex ejecutivos (cfr. especialmente la resolución exenta 83 de la SVS, de 9 de marzo de 2012 , dirigida en contra del ex gerente general y ex Pdte. del Directorio de La Polar, Pablo Alcalde, en la que se le imputan los ilícitos del art. 59 a) y 59 f) de la $L M V$, aplicando una sanción de 25.000 UF, misma que sería confirmada el pasado 18 de abril por resolución de la Novena Sala de la I. Corte de Apelaciones de Santiago). Las imputaciones - tanto penal como administrativa- no se han referido a los tipos paradigmáticos de manipulación bursátil (arts. 52, 53, 59 e) -en relación a los dos anteriores- y 61 LMV), pero las falsedades ideológicas societarias imputadas presentan, en cuanto incidentes en un mercado de valores, una dimensión objetiva análoga a las manipulaciones bursátiles que aquí nos ocupan, al menos por lo que se refiere a las modalidades info-based (cfr. infra aparatados 2.3.4, 2.6 y nota al pie $\mathrm{n}^{\circ} 54$ ).

${ }^{18}$ En buena medida debo el iter del bosquejo a las explicaciones de Andrea Perrone, profesor de derecho comercial de la Università del Sacro Cuore di Milano, ofrecidas en el marco del curso de postgrado en Derecho del Mercado de Valores de la Alta Scuola Impresa e Società (ALTIS) de la citada Universidad, al que el aludido tuvo la gentileza de invitarme a asistir en calidad de oyente en 2005. Algunos de los elementos de dicho bosquejo pueden leerse en PERRONE, Andrea, "Información en el mercado de valores y tutela del inversor", Polít. Crim. Vol. 4, No 7 (Julio 2009), Art. 7, pp. 197-229. En lo demás, para la exposición de los elementos básicos del funcionamiento del Mercado de Valores y su regulación se han consultado especialmente: con alcance económico-financiero, ONADO, Marco, Mercati e intermediari finanziari, economia e regolamentazione, Bologna: Il Mulino, 2000, Caps. IIII, VII, VIII, XI; con alcance jurídico, COX, James D; HILLMANN, Robert W; LANGEVOORT, Donald C., Securities Regulation, Cases and Materials, New York: Aspen, 3a edición, 2001; y STEINBERG, Marc I., Understanding securities law, New York: Lexis Nexis, 2001 (3a. ed.), caps. 7, 9, 12 y 14.

${ }^{19}$ Cfr. ONADO, Marco, Economia e regolamentazione del sistema finanziario, Bologna: Il Mulino, 2004, p. 29. Véase referencia detallada y de contexto en nota $\mathrm{n}^{\circ} 102$. 
LONDOÑO, Fernando. "Ilícito de manipulación bursátil: fenómeno y lesividad. Aspectos de política sancionatoria".

bancaria. Como se sabe, dicho crédito se otorga con recursos que, en última instancia, provienen del ahorro de las personas que depositan sus dineros en el respectivo banco. A estas personas podemos denominarles "unidades en superávit", en cuanto disponen de capital por sobre su nivel de gasto. Para la entidad bancaria, el sentido lucrativo de esta operación de crédito pasa por la diferencia o spread entre la tasa de interés de captación (aquella que el Banco paga a las "unidades en superávit") y la tasa de interés del crédito (aquella que el Banco cobra a las "unidades en déficit"). Este spread se explica fácilmente. En efecto, la tasa de interés de captación es tendencialmente baja, pues en principio el riesgo que corren los depositantes es también muy bajo (riesgo de default); por otra parte, los dineros están prácticamente a su inmediata disposición, de manera que no hay una renuncia duradera al poder adquisitivo representado por el dinero (alta liquidez de los depósitos). La tasa de interés de colocación o del crédito es tendencialmente más elevada, pues en principio el riesgo que corre el acreedor bancario prestándole a la empresa es mayor (riesgo de crédito), no siendo la inversión del todo líquida (debiendo mediar una cesión de crédito).

Convengamos desde ya que, conforme al modelo ideal y sin perjuicio de los siempre discutibles márgenes de ganancia bancaria, esta dinámica es socialmente deseable y necesaria, en cuanto conecta el ahorro con la inversión, con las consiguientes ventajas asociadas..$^{20}$ En efecto, un capital que de otro modo quedaría "inmovilizado" (en poder de los ahorrantes o bien sólo generando intereses), pasa a manos de un agente (empresa) que está en condiciones -siempre en un modelo ideal, se insiste- de generar nueva riqueza con él: de producir nuevos bienes y/o servicios, de generar empleo, de contribuir con ello indirectamente- a la recaudación y gasto fiscal, etc., siguiendo en lo demás el conocido ciclo keynesiano.

Hasta aquí la dinámica y la funcionalidad de un mercado de capitales "bancocéntrico".

¿Pero qué sucedería si el flujo de los recursos financieros pasase "directamente" desde las unidades en superávit a las unidades en déficit? En otras palabras, ¿qué pasaría si los ahorrantes prestasen directamente a la empresa (= adquiriendo un bono) o bien se asociasen con ella (= recibiendo una acción), en lugar de colocar sus dineros en Bancos que luego otorgan créditos o se asocian con la empresa? La ratio lucrativa de esta dinámica es clara. En efecto, en este modelo empresas y ahorrantes comparten el spread bancario, presentándose un escenario en el que ambas partes ganan. Así, si antes -en el modelo bancocéntrico de financiamiento- el ahorrante recibía, por ejemplo, 1 de interés del Banco, ahora recibirá 3 de la empresa; por su parte, si antes la empresa pagaba 5 de interés al Banco, ahora pagará 3 a los ahorrantes. El anterior spread de 4 -que constituía la ganancia del Banco- se ha compartido así entre ahorrantes y empresa, de modo que cada parte está 2 puntos mejor que antes.

Pues bien, lo que hemos descrito en el párrafo anterior constituye el sentido económico de un modelo de oferta pública de valores, en el que las empresas -necesitadas de

\footnotetext{
${ }^{20}$ Ésta es precisamente la función central de todo mercado financiero o de capitales: vincular ahorro e inversión. Cfr. ONADO, Mercati, cit. nota ${ }^{\circ} 18$, p. 72. En igual sentido, KOSLOWSKI, Peter, The Ethics of Banking. Conclusions from the financial crisis, Dordrecht: Springer, 2011, sp. pp. 34 y 40-41.
} 
Polít. crim. Vol. 8, № 15 (Julio 2013), Art. 3, pp. 64 - 127.

[http://www.politicacriminal.cl/Vol_08/n_15/Vol8N15A3.pdf]

financiamiento- se dirigen directamente al público ahorrante, ${ }^{21}$ en busca de capital: ya emitiendo bonos (como contrapartida de un crédito), ya emitiendo acciones (por cuenta de participación en la sociedad).

La ventaja de ese modelo -respecto al bancocéntrico- es evidente: una utilidad mayor para los ahorrantes y, en principio, un costo de crédito menor para las empresas necesitadas de capital. Por otra parte, desde que se dirige al público general, este modelo cuenta con una capacidad mayor de movilización de capitales, especialmente apta para empresas que requieren de niveles tan altos de capital que difícilmente pueda ser satisfecha por uno o más bancos. Parece demasiado bueno para ser cierto. ¿Pero cuáles son sus desventajas, cuáles sus aspectos problemáticos? ¿Puede un modelo semejante funcionar realmente, sin más? ¿Qué tipo de marco institucional y normativo requiere para funcionar adecuadamente? La primera de estas preguntas será abordada en el apartado siguiente. Las otras dos serán materia del apartado 1.3. de esta primera sección.

\subsection{Principales aspectos problemáticos de un modelo de oferta pública de valores.}

Pues bien, en primer término debe hacerse notar que la mayor utilidad para los ahorrantes (accionistas o compradores de bonos) resulta una compensación de: (1) el mayor riesgo asociado; y (2), la mayor duración de la renuncia al poder adquisitivo; es decir, la menor liquidez de la inversión. ${ }^{22}$

En efecto, a diferencia del modelo bancocéntrico, aquí los dineros entregados por los ahorrantes corren mayores riesgos: riesgo de empresa (en el caso de los titulares de acciones) o riesgo de crédito (en el caso de los tenedores de bonos). En el modelo bancocéntrico el riesgo de crédito -o de empresa, en su caso- es asumido directamente por el Banco, razón por la cual recibe también una mayor utilidad. Ahora bien, este mayor riesgo no representa en sí mismo una desventaja del modelo de oferta pública, al menos no para personas propensas al riesgo: pues dicho riesgo resulta compensado por una mayor utilidad. Lo que realmente puede resultar desventajoso es el carácter difícilmente determinable de este riesgo, según se dirá de inmediato.

En efecto, un factor adicional -de tipo informativo- concurre a cualificar este "mayor riesgo" asumido por el público ahorrante en el contexto de un mercado de valores. Como se sabe, en cualquier orden de cosas quien se encuentra al interior de un determinado sistema sabe de él más que quien se ubica fuera del mismo. Existe pues una asimetría informativa estructural entre insiders y outsiders. ${ }^{23}$ Así, el propietario o el gerente general de una empresa que ofrece valores al público saben más de la misma y de sus emisiones -de sus posibilidades de utilidad en un determinado plazo, de sus deficiencias, del sector o mercado en el que se desempeñan, etc.- que el público a quien se dirige la solicitud de capital. Desde el punto de vista del público a quien se solicita capital, ¿cómo saber si se trata de una buena o mala inversión? ¿Cómo saber si el precio del capital solicitado compensa o no los riesgos

\footnotetext{
${ }^{21}$ Cfr. a título ejemplar, los arts. 1 y 4 de la $L M V$ chilena, los que definen la "oferta pública de valores".

${ }^{22} \mathrm{El}$ nivel de riesgo y la duración de la renuncia al poder adquisitivo (premio de liquidez) son elementos que conforman la tasa de interés. Cfr. ONADO, Mercati, cit. nota n 18, cap. 7, pp. 175-178, 185-186.

${ }^{23}$ Cfr. PERRONE, “Información”, cit. nota ${ }^{\circ} 18$, p. 198.
} 
LONDOÑO, Fernando. "Ilícito de manipulación bursátil: fenómeno y lesividad. Aspectos de política sancionatoria".

(unos riesgos cuya verdadera magnitud no se está en condiciones de determinar)? ${ }^{24}$ Ciertamente esta asimetría informativa también afecta al Banco al que la empresa se dirige solicitando un crédito (modelo bancocéntrico), pero es fácil captar que para remontar esta asimetría -parcialmente, al menos- el Banco posee recursos con los que el público general no cuenta. Auditorías y análisis financieros ad hoc, actualización de conocimientos previos relativos al sector, solicitudes de información, ejercicio de un mayor poder de negociación, etc., son todas medidas impracticables para el ahorrante medio individual.

En seguida, una dimensión en principio desventajosa aparece asociada a la menor liquidez de las inversiones en títulos emitidos por las empresas. En otras palabras, la renuncia al poder adquisitivo representado por el dinero es de mayor duración. Los dineros invertidos en acciones o bonos no pueden "recuperarse" tan fácilmente (ni se encuentran a inmediata disposición) como aquellos depositados en un Banco. Bajo condiciones normales, un accionista no puede imponer la disolución de la sociedad, ni un tenedor de bonos imponer un pago total inmediato. Nuevamente se trata aquí de una desventaja "compensada" con una mayor utilidad (= liquidity premium $)^{25}$, pero es preciso considerarla a la hora de valorar las características del modelo.

\footnotetext{
${ }^{24}$ Nótese que esta asimetría informativa plantea un problema vital para cualquier mercado, según demostrara en 1970 el destacado economista George Akerlof con su concepto de adverse selection, a propósito del estudio del mercado de los automóviles usados y el costo sistémico de la deshonestidad (trabajo que le valdría el premio Nobel de Economía: AKERLOF, George, "The Market for "Lemons": Quality Uncertainty and the Market Mechanism", 84 Q. J. Econ. (1970), pp. 488-500; sp. p. 495), y como luego lo hicieran Stewart Myers y el chileno Nicolás Majluf para el mercado financiero, estudiando los problemas generados en la emisión de títulos para financiar proyectos de inversión, allí donde los ejecutivos del emisor contasen con información desconocida por los inversionistas, demostrando que el precio de los títulos puede caer en ese escenario (MYERS, Stewart; MAJLUF, Nicholas (sic), "Corporate Financing and Investment Decisions When Firms Have Information that Investors Do Not Have", 13 J. Fin. Econ. (1984), pp. 187-221). El problema de selección adversa o negativa que se plantea es el siguiente: si el público inversionista no es capaz de distinguir entre ofertas convenientes y ofertas que no lo son, ni precisar las características del título emitido (si el mercado y los objetos allí transados resultan opacos a sus ojos), el costo del capital tenderá a elevarse para todos los oferentes por igual, buenos o malos que sean; lo anterior, en la medida que el inversionista, enfrentado a un escenario de incertidumbre, querrá siempre asegurar su inversión solicitando altas tasas de retorno. Con ello podría llegarse a una paradójica situación de selección adversa, en la que -como justamente indica el concepto- "sobreviven" en el mercado sólo aquellos emisores de mala calidad, los que normalmente incurren en menores costos. Aquellos emisores de buena calidad, que han invertido mayores recursos para "distinguirse" en el mercado y ofrecer un mejor producto, no estarán en condiciones de subsistir de cara al encarecimiento del capital generado por el sistemático "regateo a la baja" del público inversionista. En palabras del propio Akerlof: "Consider a market in which goods are sold honestly or dishonestly; quality may be represented, or it may be misrepresented. The purchaser's problem, of course, is to identify quality. The presence of people in the market who are willing to offer inferior goods tends to drive the market out of existence -as in the case of our automobile "lemons." It is this possibility that represents the major costs of dishonesty- for dishonest dealings tend to drive honest dealings out of the market. There may be potential buyers of good quality products and there may be potential sellers of such products in the appropriate price range; however, the presence of people who wish to pawn bad wares as good wares tends to drive out the legitimate business. The cost of dishonesty, therefore, lies not only in the amount by which the purchaser is cheated; the cost also must include the loss incurred from driving legitimate business out of existence." (op. cit. en esta nota, p. 495). Como puede advertirse, existe ya aquí un fundamento de la necesidad de regulación del mercado en una esfera de derecho público, más allá de la problemática individual asociada a la compensación. Véase el punto, con mayor detalle bibliográfico, en PERRONE, "Información", cit. nota n 18 , pp. 198 y 199.

${ }^{25}$ Cfr. ONADO, Mercati, cit. nota n ${ }^{\circ} 18$, cap. 7, pp. 179-185.
} 
Polít. crim. Vol. 8, № 15 (Julio 2013), Art. 3, pp. 64 - 127.

[http://www.politicacriminal.cl/Vol_08/n_15/Vol8N15A3.pdf]

En fin, un último aspecto problemático del modelo radica en la existencia de costos de transacción tendencialmente más elevados que aquellos del sistema bancocéntrico. En este último, el universo de oferentes de capital es acotado y todos ellos cuentan con conocimientos y procedimientos asentados en materia de concesión de créditos. Son por lo demás conocidos por los demandantes de capital y pueden operar economías de escala en contextos de negociación habituales con un mismo demandante. Esto no ocurre en principio en el modelo de oferta pública de valores, en el que el universo de oferentes de capital es, tendencialmente, tan extenso como ahorrantes dispuestos a invertir o prestar dinero a empresas. ¿Quiénes son estos ahorrantes y cómo dirigirse a ellos para solicitar capital? Los costos de transacción asociados a los procedimientos necesarios para un eficaz contacto entre oferentes y demandantes de capital resultan así comparativamente elevados.

En síntesis, hallamos problemas asociados a (1) un riesgo de inversión mayor y prácticamente indeterminable (dado un escenario de asimetría informativa difícilmente remontable), (2) un menor grado de liquidez y (3) mayores costos de transacción.

¿Significa esto que el modelo de oferta pública es ineficaz o que no puede funcionar en la práctica? La evidencia indica lo contrario. En efecto, este modelo fue creciendo en importancia desde su establecimiento moderno en torno a los siglos XVII y XVIII, ${ }^{26}$ hasta el punto que hoy resulta neurálgico para el funcionamiento de cualquier economía. La explicación debe hallarse entonces en la estructura o institucionalidad necesaria para que un modelo semejante funcione. En otras palabras: un modelo de oferta pública sólo puede funcionar bajo ciertas condiciones. Esas condiciones representan cualidades del modelo, las que deben ser preservadas para que el modelo funcione. En este punto hace su ingreso junto a otras instituciones del mundo económico- el Derecho regulador del mercado de valores y, por lo que aquí nos interesa, el derecho sancionatorio (administrativo y penal). ${ }^{27}$ En especial, el derecho sancionatorio de las manipulaciones bursátiles juega un papel importante en el plano de la preservación del modelo mediante sanciones. Se verá con detalle por qué en la tercera sección de este trabajo, pero ahora conviene no interrumpir el

\footnotetext{
${ }^{26}$ Tiende a identificarse en el desarrollo accionario de la Compañía Holandesa de las Indias Orientales, con sede en Ámsterdam, una primera fase de configuración de las modernas bolsas de valores, en los primeros años del s. XVII. Ya de 1688 data el primer texto enteramente dedicado a su configuración y funcionamiento, justamente con referencia al mercado holandés; a saber, Confusión de Confusiones, obra del escritor judíoespañol José Penso de la Vega, quien, en un formato de coloridos y doctos diálogos, ilustra sobre los tipos de operadores, las modalidades de operación y la especulación en acciones en el mercado de Ámsterdam. Nótese además que el Diálogo Cuarto incluye referencias a los ardides, trazas, sutilezas y astucias más comunes empleados para lucrar con acciones, algunos de los cuales coinciden con nuestra contemporánea manipulación de precios. Edición contemporánea en Serie “Estudios Europeos” N. 10, Universidad EuropeaCEES Ediciones, Madrid, 2000. Por otra parte y como hace ver Stuart Banner, hacia 1720 el mercado de valores era ya una institución bien establecida en Londres: cfr. BANNER, Stuart, Anglo-American Securities Regulation. Cultural and Political Roots. 1690-1860, Cambridge: Cambridge University Press, 1998, p. 14.

${ }^{27}$ Demostrando con "datos duros" el rol imprescindible del Derecho para el desarrollo de un mercado de valores (y por tanto dando cuenta de la insuficiencia de los solos mecanismos económicos del mercado), cfr. LA PORTA, Rafael; LÓPEZ-DE-SILANES, Florencio; SHLEIFER, Andrés, "What Works in securities laws?", The Journal of Finance, vol. XVI, N. 1 (2006) (disponible en versión digital en página de Andrés Shleifer, economics.harvard.edu, así como en SSRN). Asimismo, los autores hallan evidencia para demostrar que el enforcement proporcionado por el derecho privado (condiciones para indemnización de perjuicios, fundamentalmente) es más relevante que el del derecho público (administrativo regulatorio y penal) para el desarrollo de un mercado de valores.
} 
LONDOÑO, Fernando. "Ilícito de manipulación bursátil: fenómeno y lesividad.

Aspectos de política sancionatoria".

iter que hasta aquí nos condujo, y dar una rápida mirada a las principales instituciones creadas para hacer frente a las "desventajas" o problemas recién aludidos.

\subsection{Condiciones para el funcionamiento de un mercado de oferta pública de valores.}

La solución a los mencionados problemas del modelo marca la génesis de la institucionalidad económica y jurídica del mercado de valores. Gracias a estas soluciones, el modelo de oferta pública de valores puede funcionar; sin ellas, resultaría del todo inoperante.

Serán presentadas aquí muy someramente, en un orden inverso al que fueron planteadas en la sección anterior.

a.- Los costos de transacción (= tercer problema anunciado en la sección anterior) se reducen si es que se crea un espacio de interacción permanente entre oferentes y demandantes, entre emisores de valores y público inversionista. Ese espacio es, como en cualquier otro contexto comparable, el mercado: el espacio en el que oferta y demanda confluyen. Se le denomina mercado primario al existente para la colocación de los valores de primera emisión; es decir, allí donde se verifica el ingreso de capitales frescos a la empresa emisora, provenientes del público que originalmente adquiere los títulos en cuestión, en un proceso de registro público y suscripción de títulos llevado a cabo bajo la responsabilidad de bancos de inversión (conocidos en la jerga anglosajona como underwriters). ${ }^{28}$

b.- Ahora bien, una vez que los valores o títulos han sido ya colocados entre el público inversionista, se genera para los mismos un mercado secundario, en el que participan tenedores de títulos (=vendedores) e interesados en los mismos (=compradores). ${ }^{29}$ Como podrá advertirse, este mercado secundario es la solución ideada para mejorar las condiciones de liquidez de la inversión (= segundo problema anunciado en la sección anterior), en la medida que su existencia permite al titular del valor recuperar -mediante la enajenación del mismo- el poder adquisitivo originalmente cedido. El dinamismo y volumen de este mercado es favorecido por sujetos que normalmente operan en calidad de intermediarios (corredores y agentes de bolsa), ${ }^{30}$ potenciando la interacción entre oferentes y demandantes del título. ${ }^{31}$

c.- En fin, el primer problema presentado en la sección anterior -el relativo al mayor riesgo y su carácter difícilmente determinable- halla un principio de solución en una serie de mecanismos económicos y jurídicos, destinados a la superación de la asimetría informativa ubicada en la base del problema. La exposición de estos mecanismos ocupará el trecho

\footnotetext{
${ }^{28} \mathrm{Cfr}$. al respecto, COX/HILLMAN/LANGEVOORT, Securities, cit. nota $\mathrm{n}^{\circ} 18$, cap. 3 .

${ }^{29} \mathrm{Cfr}$. al respecto, COX/HILLMAN/LANGEVOORT, Securities, cit. nota $\mathrm{n}^{\circ} 18$, cap. 5. Véase a título ejemplar la definición de mercado secundario formal, contenida en la letra a) del art. 4 bis de la $L V M$ chilena. ${ }^{30} \mathrm{Cfr}$. al respecto, a título ejemplar, el art. 24 de la $L V M$ chilena.

${ }^{31} \mathrm{Si}$ estos sujetos operan negociando títulos por cuenta propia, se les denomina dealers. Si operan por cuenta de clientes, se les denomina brokers.
} 
Polít. crim. Vol. 8, № 15 (Julio 2013), Art. 3, pp. 64 - 127.

[http://www.politicacriminal.cl/Vol_08/n_15/Vol8N15A3.pdf]

restante de esta sección. Su comprensión es importante en la medida que ellos guardan directa relación con la lesividad de las manipulaciones de mercado.

c.1.- El primero de estos mecanismos obedece a una regla elemental de todo mercado regulado de valores: la mandatory disclosure. Implementada por primera vez en la legislación estadounidense como reacción a la crisis del ' $29^{32}$ y desde allí extendida a las legislaciones comparadas del sector, ${ }^{33}$ la regla obliga a las empresas que recurren a la oferta pública de valores, a revelar al mercado toda la información de que dispongan, y que pueda incidir en la valoración del título en cuestión.

Por sobre el intenso debate doctrinario que se ha suscitado en torno al fundamento y utilidad social de una regla de revelación obligatoria, ${ }^{34}$ desde siempre ha resultado evidente que esta disclosure no está en condiciones de resolver por sí sola el problema de base; en efecto, el caudal y la complejidad de la información hacen que resulte completamente imposible su asimilación por cualquier inversionista medio, de modo que el problema de la asimetría subsistirá. $^{35}$

c.2.- Ahora bien, no debe pensarse que la única información que recibe el inversionista o destinatario final es aquella cruda, en estado puro, que revela la empresa. En el mercado intervienen agentes -normalmente por mandato legal- que procesan la información, sintetizándola en aquello que resulta de relevancia para la toma de decisiones de inversión sobre los títulos emitidos por las empresas. Underwriters (bancos de inversión colocadores), auditores contables, calificadoras de riesgo y analistas profesionales son los principales agentes que intermedian información, transmitiéndola en modalidades más fácilmente aprovechables. Nótese que la intervención de las tres primeras categorías de agentes es ordenada por las leyes reguladoras del mercado, de acuerdo a todos los modelos de mercados de oferta pública de valores actualmente imperantes. Por la función de salvaguardia que desempeñan estos agentes, en la jerga de sector se les conoce como gatekeepers. Al recomendar un determinado título o inversión, ellos "prestan su reputación" al emisor, a la vez que orientan a los inversionistas en la toma de sus

\footnotetext{
${ }^{32}$ La Securities Act de 1933 (parag. 5 a 7) contiene esta regla de revelación de información.

${ }^{33} \mathrm{Cfr}$. a título ejemplar los deberes de información previstos en los arts. 9 y 10 de la $L V M$ chilena; igualmente a título ejemplar, cfr. el art. 94 del t.u.f. italiano, por lo que se refiere a los prospectos en primera emisión.

${ }^{34}$ Cfr., por todos, HERTIG, Gerard; KRAAKMAN, Reiner; ROCK, Edward, "Issuers and Investor Protection”, en: KRAAKMAN, Reiner; DAVIES, Paul; HANSMANN, Henry; HERTIG, Gerard; HOPT, Klaus; KANDA, Hideki; ROCK, Edward (Dirs.), The Anatomy of Corporate Law. A Comparative and Functional Approach, New York: Oxford University Press, 2004, sección 8.2.4, pp. 204-207. En este plano, considérense especialmente las tesis contrapuestas de EASTERBROOK, Frank H.; FISCHEL, Daniel, "Mandatory Disclosure and the Protection of Investors", 70 Virginia Law Review 669 (1984) y COFFEE Jr., John C, Market Failure and the Economic Case for a Mandatory Disclosure System, 70 Virginia Law Review 717 (1984).En cuanto al debate en el campo económico sobre el rol de una regulación legal en general (más allá de la regla de mandatory disclosure), una panorámica sintética de tres grupos de posiciones (noregulación; pro regulación con énfasis en derecho privad; y pro regulación con énfasis en derecho público) se halla expuesta en LA PORTA/LÓPEZ-DE-SILANES/SHLEIFER, "What Works", cit. nota n 27, pp. 1-3.

${ }^{35}$ Por lo demás, en principio nada obsta a que las empresas divulguen, simultáneamente, información falsa. Las medidas sancionatorias buscan justamente introducir un desincentivo para la divulgación de información falsa.
} 
LONDOÑO, Fernando. "Ilícito de manipulación bursátil: fenómeno y lesividad. Aspectos de política sancionatoria".

decisiones, "señalizando" un determinado producto financiero con una determinada apreciación de riesgo y/o estimación de rentabilidad.

El proceso de determinación de la entidad del riesgo - problema desde el que comenzamos en la subsección anterior- se ve así favorecido. El inversionista no se encuentra ya sólo con la información en su fuente, sino con los "comentarios" generados por terceros (expertos) a partir de la misma. Así como en cualquier grupo humano hay quienes saben más y quienes saben menos, y en general resulta de utilidad para los segundos seguir los consejos de los primeros, así también el seguimiento de los intermediarios informativos tiende a mejor el juicio del público inversionista.

\subsection{Breve excurso (primera aproximación a la lesividad del fenómeno).}

Pues bien, llegados a este punto, ya habrá quien piense que lo anterior es válido sólo en la medida que el intermediario informativo o gatekeeper realice correctamente su lectura (negligencia excluida), se mantenga leal a su rol institucional, sea objetivo en las recomendaciones y no ceda indebidamente a un conflicto de interés en el mismo. Por cierto, el modelo expuesto supone esa lealtad u objetividad como condición para su correcto funcionamiento. ${ }^{36} \mathrm{El}$ modelo supone que el intermediario calificará con nota alta a quien lo merece por su valor de inversión, y no por desidia (= culpa o negligencia) o porque previamente ha tomado una posición en el título en cuestión, de modo que se beneficiará con el alza de su precio, con total independencia del real valor de inversión del título (= dolo).

El modelo es sin duda elitista/meritocrático. Es decir, el seguimiento de quienes tienen mejores conocimientos es deseable en el marco del sistema. Con todo, está también en su éthos el que la actividad meritoria se ejerza de modo que favorezca a los demás participantes; de manera "comunitariamente responsable", podría decirse. El mejor conocimiento debe emplearse de un modo que también resulte provechoso para el público inversionista.

Este punto será abordado con detalle en las secciones tercera y última del presente trabajo, pero es adecuado anticipar aquí una importante conclusión en materia de lesividad de las conductas de manipulación bursátil; ello, aún antes de definirlas con detalle, como se hará en la sección siguiente.

Así pues, si relacionamos los pasajes anteriores con la función central de todo mercado financiero -según expuesta supra 1.1, como la vinculación de ahorro e inversión en pos de la generación de riqueza- pueden ya advertirse las primeras notas de lesividad de las conductas de que trata el presente trabajo: quien, en un contexto de mercado primario, aporta información falsa de relevancia o hace una falsa recomendación, incrementa el riesgo de que recursos financieros (=ahorro) se destinen a proyectos de inversión

\footnotetext{
${ }^{36}$ De hecho, buena parte de los escándalos financieros más notables de las últimas décadas (Enron, por todos) han sido posibles gracias a la intervención de gatekeepers desleales en el ejercicio de su función institucional.
} 
Polít. crim. Vol. 8, № 15 (Julio 2013), Art. 3, pp. 64 - 127.

[http://www.politicacriminal.cl/Vol_08/n_15/Vol8N15A3.pdf]

comparativamente menos lucrativos(o que derechamente vayan a pérdida). En esta sintética idea radica la dañosidad social de las falsedades informativas en el mercado primario. ${ }^{37}$

¿Y qué hay de una falsa recomendación en un mercado secundario? ${ }^{38}$ Allí no operan transferencias de dinero a los emisores, sino entre inversionistas, vendedores y compradores del título. Como se verá de inmediato, allí la dañosidad se explica desde la función desempeñada por el precio del instrumento transado. Justamente con esta última idea estamos ya en condiciones dar el último paso de esta primera sección.

Cabe recordar que nuestro punto de partida ha sido el de la ardua evaluación del riesgo de la inversión, en un escenario de asimetría informativa, y el consiguiente riesgo de selección adversa a él vinculado (cfr. supra nota $\mathrm{n}^{\circ} 24$ ). Los instrumentos o mecanismos que colaboran en la solución de este problema son -recordemos- (1) la regla de revelación (mandatory disclosure) y (2) la intermediación informativa realizada por los gatekeepers.

c.3.- El precio de mercado constituye el último de estos mecanismos; y lo hace en la medida que, de acuerdo a la hipótesis de eficiencia informativa planteada por Eugene Fama $^{39}$ (efficient capital markets hypothesis), el precio tiende a incorporar en sí las informaciones disponibles, reflejándolas. En efecto, "el volumen y la concentración de los intercambios, conjuntamente con la participación de sujetos altamente calificados y en condiciones de explotar economías de escala, le permiten al mercado financiero expresar precios que tienden a reflejar completamente todas las informaciones disponibles". 40

Los precios entonces "informan", "hablan", operan cual signos: deberían ellos -y su fluctuación- estar en condiciones de decirnos "algo" sobre las características del producto de que se trata. El ejemplo más a la mano es muy eficaz y posiblemente más de algún lector lo habrá experimentado. Considérese el mercado del vino. Sin otro medio más que la referencia del precio solicitado en un establecimiento comercial, un comprador no entendido en vinos podrá identificar calidades de vino - cuanto menos ciertos tramos- y decidir en función de ello el destino del gasto a realizar; pagando por ejemplo un alto precio si busca agasajar a los comensales en el marco de una importante cena; o bien uno inferior si busca un vino corriente, de consumo diario. El precio servirá entonces como una primera -pero posiblemente bastante eficaz- guía de captación del "valor" del vino. Todo ello sin necesidad de consultar directamente a un sommelier (= analista financiero), revisar una guía

\footnotetext{
${ }^{37}$ Considérese a título ejemplar la letra f) del art. 59 LMV chilena, en virtud de la cual se tipifican falsedades ideológicas introducidas en el contexto de un mercado primario de oferta pública de valores.

${ }^{38}$ Cfr. la situación evocada en la frase del "Confusión de Confusiones" con la que se presenta este trabajo.

39 FAMA, Eugene F., "Efficient Capital Markets: A Review of Theory and Empirical Work", 25 J. Fin. (1970), pp. 383 y ss. (disponible digitalmente en stuwww.uvt.nl). Al respecto, un trabajo de referencia obligada en el campo jurídico es el de GILSON, Ronald J.; KRAAKMAN, Reinier H., "The Mechanism of Market Efficiency", $70 \mathrm{Va}$. L. Rev. (1984), 549 y ss. Ha sido intensa entre los economistas la discusión en cuanto a si esta hipótesis halla comprobación en la realidad o no, pero en cualquier caso podría aceptarse que se trata de una "tendencia" (cuanto menos de carácter relativo) y que por tanto el nivel de eficiencia se ve incrementado o disminuido dependiendo de una serie de variables, como el volumen de las transacciones, la calificación de los operadores que transan en bolsa, el flujo de la información en el mercado y la calidad de la misma. Véase en este sentido, PERRONE, "Información”, cit. nota n 18, pp. 201-203.

${ }^{40}$ PERRONE, "Información”, cit. nota n 18, p. 199.
} 
LONDOÑO, Fernando. "Ilícito de manipulación bursátil: fenómeno y lesividad. Aspectos de política sancionatoria".

con calificación o recomendaciones de vino (=calificadora de riesgos), ni aún leer la etiqueta para conocer detalles del producto (=prospectos de información, informes contables, etc.).

Sobre cómo puede operar esta eficiencia informativa en el mercado que aquí nos ocupa, muy ilustrativa resulta la explicación de Andrea Perrone:

“(...) considérese, por ejemplo, la hipótesis de un inversionista que haya desarrollado específicas investigaciones con respecto a la potencia económico-lucrativa del sector de las utilities y que, en consecuencia, decida adquirir acciones de una sociedad que cotiza en bolsa, especializada en la producción de energía eléctrica "limpia". Si los respectivos volúmenes son suficientemente elevados, la experiencia demuestra cómo el precio de las acciones comienza a subir, hasta colocarse rápidamente en un nuevo punto de equilibrio, coherente con la perspectiva de rendimiento revelada a partir de la información que se halla en el origen de la decisión de inversión."

Hallamos así un mecanismo que coopera en la superación de la asimetría informativa. Una suerte de "atajo" para el inversionista. Lo anterior, siempre bajo la premisa de que el precio en un mercado -el punto de equilibrio entre oferta y demanda en un momento dado- es el producto de la intensa interacción de operadores racionales, todos los cuales realizan transacciones de sentido económico, con razones de inversión que se fundan en (nuevos) conocimientos/informaciones relativas al potencial valor/riesgo asociado al título/emisor. ${ }^{42}$ De allí entonces las razones para "tomar en serio" el precio, cual vehículo informativo.

Esta cualidad informativa de los precios hace que sobre ellos el inversionista deposite una confianza importante. En este sentido, en palabras de Eugene Fama, el "mercado ideal" aquél cuyos precios representan un indicador confiable para el inversionista- es:

"aquél en el que los precios suministran señales correctas para la distribución de recursos: esto es, un mercado en el que las empresas pueden adoptar decisiones de producción-inversión, mientras que los inversionistas pueden elegir entre valores que representan participación en las actividades de las empresas, bajo la premisa de que en todo momento los precios de los valores "reflejan completamente" [fully reflect] toda la información disponible." 43

\footnotetext{
${ }^{41}$ PERRONE, “Información”, cit. nota n 18, pp. 200-201.

${ }^{42}$ No se pasa por alto que en las operaciones de un inversionista racional pueden también concurrir meras razones de liquidez o cobertura, que por tanto no se fundan directamente en nuevos conocimientos o informaciones relativas al potencial valor del título/emisor. Ya en un plano argumentativo superior, considérese en todo caso el carácter incompleto del modelo de "comportamiento racional" tradicional en las ciencias económicas. La consideración de los límites cognitivos y las variables ético-normativas de los operadores desempeña un rol en este plano, conforme ha sido evidenciado a partir de los trabajos de economía del comportamiento de autores como Daniel Kahneman, Paul Slovic y Amos Tvesky (Judgment Under Uncertainty: Heuristics and Biases, Cambridge, 1982), Amartya Sen ("Rational Fools: A Critique of the Behavioral Foundations of Economic Theory”, 6 Phil. \& Pub. Aff. (1977), pp. 317-344) y -especialmente por lo que se refiere a la dimensión ética- Peter Koslowski (Principles of Ethical Economy, Dordrecht, 2001).

${ }^{43}$ FAMA, "Efficient Capital Markets ", cit. nota ${ }^{\circ}$ 39, p. 383.
} 
Polít. crim. Vol. 8, № 15 (Julio 2013), Art. 3, pp. 64 - 127.

[http://www.politicacriminal.cl/Vol_08/n_15/Vol8N15A3.pdf]

Mientras más informado, abierto y competitivo sea un mercado, mayores serán las posibilidades de que el precio refleje eficientemente la información sobre las características del producto. ${ }^{44}$ En este sentido - para seguir con el ejemplo propuesto- no es comparable el precio de un vino debutante en un establecimiento comercial (que puede estar en gran medida determinado por el precio de venta del propio productor), que el de un vino ya probado y que tiene un nivel de demanda probada en el tiempo. Mientras la atribución de un precio puede ser algo arbitraria en el primer caso (el resultado de un mercado tan acotado como el que determina un equilibrio entre la oferta del productor y la demanda del supermercado), en el segundo será el resultado de un equilibrio entre ofertas y demandas sostenidas en el tiempo, lo que nos dice algo sobre la apreciación de un universo más amplio de personas y, por tanto, indirectamente, algo más respecto a la calidad del vino (incluyendo atributos ajenos a la calidad intrínseca del producto, como es el caso de la visibilidad de la marca y su posicionamiento en el mercado).

El mercado de valores resulta entonces un contexto especialmente idóneo para la verificación de esta cualidad informativa, considerado el volumen de las transacciones y la calificación de los agentes que allí intervienen. Difícilmente un precio resultará allí el banal producto de la apreciación de dos partes desinformadas.

En fin, nótese que cuanto se ha dicho respecto a la eficiencia informativa de los precios no se ha predicado sólo de la información verdadera, es decir, aquella que realmente se corresponde con el valor de inversión del producto financiero (riesgo y esperable rentabilidad). También la información incorrecta o falsa es incorporada en el precio, reflejada por él, en la medida que aquella ha dado pie a las respectivas transacciones: ya llevando a compras del título, si se trata de erróneas o falsas buenas noticias acerca del esperable rendimiento de la empresa; ya conduciendo a ventas del título, si se trata de erróneas o falsas malas noticias acerca del esperable rendimiento de una empresa. Una calificación de riesgo falsa o erróneamente optimista es idónea para mejorar el precio de un instrumento financiero como lo es un bono, por ejemplo. Las falsas o erróneas buenas noticias implícitas en la calificación se han incorporado así en el precio del bono (=baja tasa de interés). ¿Y qué refleja ese precio o esa baja tasa de interés? Buenas noticias, en circunstancias que no las hay...

Si se considera además que sobre la cualidad informativa del precio el participante en el mercado deposita su confianza para la adopción de decisiones, se comprende entonces que el propio precio resulte un medio especialmente idóneo para defraudar al inversor. La expectativa informativa que el precio despierta, aparece así cual factor criminógeno. En este sentido considérese, por ejemplo, que el alza de un precio de cierre -causado por un afán manipulador- será normalmente leído por el mercado como "buenas noticias" (sobre la base de la confianza en la valencia informativa del precio), lo que a su turno invitará a nuevos participantes a comprar el título, con la consiguiente alza sucesiva del precio; y con el consiguiente incremento del riesgo de que el manipulador alcance su propósito.

\footnotetext{
${ }^{44}$ Cfr. GILSON/KRAAKMAN, "The Mechanism", cit. nota n 39, pp. 549 y ss. Considérese especialmente la situación de las formas de eficiencia semi-fuerte y fuerte.
} 
LONDOÑO, Fernando. "Ilícito de manipulación bursátil: fenómeno y lesividad.

Aspectos de política sancionatoria".

Con lo dicho hasta aquí se está en condiciones de responder la pregunta con la que se cerraba la subsección anterior: ¿Qué sucede en el caso de una recomendación mendaz en un mercado secundario? ¿En qué radica su lesividad?

Pues bien, supuesta la efectiva acogida de la falsa recomendación (por quien la recibe directamente y por quienes lo imitan), ${ }^{45}$ el precio del instrumento recomendado tenderá a elevarse en el mercado respectivo. Hasta aquí, nada más que una manifestación de la "eficiencia informativa". Una dimensión material del problema se alcanza si se considera que dicha alza no se funda en antecedentes "reales", que se correspondan con el estado o posibilidades de rendimiento del emisor o del título. El nuevo precio se aleja así del valor de inversión del título.

¿No es acaso problemático que ahora, gracias a la errónea recomendación, la sociedad emisora "valga más" que antes? ¿No es acaso problemático que un inversionista "pague en exceso", sin un fundamento alineado con una razonable expectativa de lucro?

Aquí no se trata de una deficiencia informativa (la información fluye correctamente, incorporándose en el precio), sino de una deficiencia distributiva: el resultado es una ineficiente asignación de recursos financieros. ${ }^{46}$ Por otra parte, considerada una dimensión global-consecuencial, un mercado en el que los precios bajen o suban en función de expectativas carentes de fundamento real caerá -en un mediano o largo plazo- en desprestigio. ${ }^{47}$ Cuanto menos los inversionistas adversos al riesgo se retraerán y mirarán hacia otras formas de inversión, diversas a las que procura el mercado de oferta pública de valores.

El desarrollo de estos aspectos -la explicación de la lesividad-merece un tratamiento más detallado y será materia de la sección tercera de este trabajo. Con lo dicho entonces se cierra esta primera sección, cuyo único objetivo era -se insiste- el de abonar el terreno para una más fácil lectura de las dos siguientes. Así, presentado el contexto en el que se inserta la conducta en estudio, toca ahora definirla a partir de sus características, para luego intentar una taxonomía de la misma.

\section{Concepto y caracterización general de la manipulación en cuanto fenómeno: el "tipo pre-normativo".}

En esta segunda sección se procurará describir la manipulación bursátil -la manipulación de los precios de los instrumentos financieros cotizados en el mercado de valores ${ }^{4}{ }^{48}$ en cuanto fenómeno, es decir, así como tiende a manifestarse en el mundo de los hechos. No se tratará entonces de identificar el alcance o contenido preciso de un determinado tipo legal, vigente en uno u otro ordenamiento jurídico. Ese esfuerzo deberá ser abordado en

\footnotetext{
${ }^{45}$ Considérese la situación engañosa descrita en la cita de la obra de José Penso de la Vega con la que se abre el presente trabajo. Por lo que se refiere a la $L M V$ chilena, considérense las conductas subsumibles bajo el inciso final del art. 53 o el art. 61.

${ }^{46}$ Este aspecto será abordado con detalle en la tercera sección de este trabajo.

${ }^{47}$ Cfr. infra sección 3.3. c) del presente trabajo.

${ }^{48}$ En adelante, salvo indicación contraria, simplemente manipulación.
} 
Polit. crim. Vol. 8, № 15 (Julio 2013), Art. 3, pp. 64 - 127.

[http://www.politicacriminal.cl/Vol_08/n_15/Vol8N15A3.pdf]

otra sede. Se intentará aquí delinear lo que podría considerarse -si se excusa la expresióncomo un tipo pre-normativo de manipulación bursátil. ${ }^{49}$

\subsection{Consideraciones metodológicas. Tipologías consideradas.}

Para la identificación del material de estudio -definiciones de manipulación y casos pertinentes- se han considerado algunos conocidos reportes de la ciencia económicafinanciera. ${ }^{50}$ Con todo, no se ha podido detener allí el análisis. Pese a que el escenario

${ }^{49}$ Es evidente, en todo caso, que la manifestación de un fenómeno humano como el objeto del presente estudio aparezca históricamente condicionada. Con ello se quiere decir que ciertas manifestaciones son inconcebibles fuera de una determinada forma de mercado bursátil, la que a su vez es inconcebible fuera de un determinado desarrollo social, económico y tecnológico. De allí que no pueda más que intentarse la identificación del fenómeno manipulativo así como ha tendido a manifestarse hasta ahora. Lo anterior no obsta por cierto a la posibilidad de captación de determinadas dinámicas "estables", presentes en todas las categorías de casos observados. Ello no es sino lo que aquí se ha entendido justamente con la idea de fenómeno.

${ }_{50}$ Así, por ejemplo, AGGARWAL, Rajesh K.; WU, Guojun, "Stock Market Manipulation - Theory and Evidence", SSRN, 2003, disponible en http://papers.ssrn.com/sol3/papers.cfm?abstract id=474582 Seguramente se trata del más comprensivo de los estudios económico-financieros tenidos a la vista. Se sirve como insumo de los casos perseguidos por la SEC americana en la década de los 90. Aunque se concentra en la manipulación trade based, incluye referencia a las más diversas tipologías de manipulación. Como sea, este trabajo no se propone tanto la caracterización del fenómeno manipulativo como el estudio de las condiciones de mercado que lo favorecen/inhiben (la presencia de information seekers/arbitrageurs; el grado iliquidez), así como de los principales signos/efectos asociados a las conductas manipulativas); AGGARWAL, Rajesh; PURNANANDAM, Amiyatosh; WU, Guojun, "Underwriter Manipulation in Initial Public Offerings", SSRN, 2005, disponible en www.csom.umn.edu/Assets/62572.pdf o en http://papers.ssrn.com (estudio que da cuenta de una específica práctica manipulativa - de tipo trade based- cual es la que deriva de los tie-in agreement frecuentemente utilizados por los underwriters en las IPOs durante la década del 90); ALLEN, Franklin, GALE, Douglas, "Stock-Price Manipulation", Rev. Fin. Stud. (1992), n. 5, p. 503 y ss. (si bien uno de los estudios más comprensivos - al menos por cuanto se refiere al marco teórico y la presentación general del fenómeno: caracterizándolo en general como el ejercicio de influencia artificial en los precios de los valores (cfr. p. 503 y ss) - en definitiva se concentra sólo en la denominada actual trade based manipulation); CHATTERJEA, Arkadev; JARROW, Robert, "Market Manipulation, Price Bubbles, and a Model of the U.S. Treasury Securities Auction Market", The Journal of Financial and Quantitative Analysis, 1998-Jun, Vol. 33, pp. 255-289 (dedicada a la caracterización de una específica modalidad de cornering y squeezing en el mercado de los bonds del tesoro americano); FELIXSON, Karl; PELLI, Anders, "Day end returns - stock price manipulation”, Journal of Multinational Financial Management, 1999, Vol. 9, pp. 95-127 (dedicado a la caracterización de la manipulación actual trade based de los precios de cierre); FINNERTY, John D., "Short Selling, Death Spiral Convertibles, and the Profitability of Stock Manipulation", SSRN, 2005, disponible en http://papers.ssrn.com/sol3/papers.cfm?abstract id=687282 (dedicado al fenómeno de las short sales como (eventual) forma de manipulación trade based); JARROW, Robert, "Market Manipulation, Bubbles, Corners, and Short Squeezes", The Journal of Financial and Quantitative Analysis, 1992-Sep., Vol. 27, pp. 311-336; JARROW, Robert, "Derivative Security Markets, Market Manipulation, and Option Pricing Theory", The Journal of Financial and Quantitative Analysis, 1994, Vol. 29, pp. 241-261; JIANG, Goulin; MAHONEY, Paul G.; MEI, Jianping, "Market manipulation: a comprehensive study of stock pools", Journal of Financial Economics, 2005, vol. 77, pp. 147-170 (el que se avoca al estudio del fenómeno de las stock pools de la década del 20 en EEUU); KUMAR, Praveen; SEPPI, Duane J., "Futures Manipulation with 'Cash Settlement'”, The Journal of Finance, 1992-Sep., Vol. 47, pp. 1485-1502 (quienes se concentran en las actual trade based manipulations en el contexto del mercado de futuros y su correspectivo mercado spot); MAHONEY, Paul G., "The Stock Pools and the Securities Exchange Act", J. Fin. Econ., n. 51 (1999), p. 343 y ss. (dedicado a la caracterización de los trading pools activos en el mercado americano antes del crack de 1929); MERRICK Jr., John J., NAIK, Narayan Y., YADAV, Pradeep K., "Strategic trading behavior and price distortion in a manipulated market: anatomy of a squeeze", Journal of Financial Economics, 2005, vol. 
LONDOÑO, Fernando. "Ilícito de manipulación bursátil: fenómeno y lesividad. Aspectos de política sancionatoria".

planteado por dicha ciencia ofrece un panorama rico en caracterizaciones de las conductas, la selección del reporte de los casos no necesariamente se condice con categorías de relevancia para nuestros propósitos (como la lesividad, por ejemplo). Por otra parte, no es fácil hallar en la ciencia económica-financiera perspectivas lo suficientemente amplias como para comprender una parte significativa de las tipologías de conductas manipulativas. Esto es así porque sus estudios no tienen por vocación pretensiones de generalidad, ni menos la elaboración de definiciones o descripciones comprensivas. Más bien, se concentran en tipologías muy específicas de conducta, teniendo normalmente como propósito la descripción de su fisiología e incidencia en ámbitos delimitados. ${ }^{51}$ En fin, en ocasiones la ciencia económica selecciona los casos de estudio de entre aquellos previamente reportados como contrarios a la regulación (sancionados administrativamente, por ejemplo). Lo anterior nos reenvía entonces a la perspectiva jurídico-legal para la identificación de los casos. Esta última sí presenta un escenario adecuado para los propósitos de selección del material a analizar. Su naturaleza y fines se condicen con requerimientos de cobertura general. Sus puntos de partida positivos son normalmente el resultado de la interacción de un universo mayor de sujetos. En fin, el ámbito jurídico-legal ofrece un punto de partida superior por lo que se refiere a los criterios de relevancia implícitos en una u otra decisión conceptual.

En lo demás, el método aquí seguido es familiar al empleado por el comparatista. ${ }^{52}$ En primer lugar, no se ha partido de un único concepto hipotético, sino de un panorama de conceptos hipotéticos. Dichos conceptos son los correspondientes al contenido de determinadas descripciones de conducta o tipos legales de manipulación vigentes en ciertos ordenamientos jurídicos considerados relevantes para estos efectos. ${ }^{53}$ Dichos ordenamientos son: [1] el ordenamiento comunitario-europeo (Directiva $M A D$ 6/2003 y la normativa europea complementaria), [2] italiano (principalmente los arts. 185 e 187 ter t.u.f. n. 58 y 501 C.P. it), [3] del Reino Unido (sections 118 (5-7) y 397 de la FSMA 2000), [4] alemán (parag. 20a, 38 e 39 WpHG), [5] de los Estados Unidos de América (principalmente las sections 9(a)1-6 y 10(b) SEA'34) y [6] chileno [arts. 52, 53 y 61 de la $L M V$, preferentemente; si bien se han tenido también en cuenta algunos tipos de falsedad ideológica, afines en sede objetiva a las modalidades de manipulación informativa; a saber, art. 59 letras a), d) f) y g)]. Los tipos legales seleccionados no se agotan en los tipos penales, sino que comprenden también los administrativos.

77, pp. 171-218 (específicamente avocado al estudio de una conducta manipulativa de tipo squeeze en el contexto del mercado de futuros sobre obligaciones en Londres); VAN BOMMEL, Jos, "Rumors", The Journal of Finance, 2003-Aug., vol. LVIII, No. 4, pp. 1499-1519 (el que se ocupa de la caracterización de un tipo de manipulación info based -como la difusión de rumores- típicamente por pequeños inversionistas informados).

${ }^{51}$ Véase la nota precedente.

${ }^{52}$ Sobre el método comparado en general, cfr. BOGNETTI, Giovanni, Introduzione al diritto costituzionale comparato: il metodo, Torino, 1994; igualmente BOGNETTI, Giovanni, L'apporto della comparazione alla scienza giuridica / contributi originali di Giovanni Bognetti (raccolti a cura di R. Sacco), Milano, 1980.

${ }^{53}$ En la selección de estos ordenamientos puede reconocerse una dosis de arbitrariedad. La selección sin embargo ha obedecido a criterios de relevancia objetivos: ya porque se trata de los ordenamientos que antes y en mayor grado han desarrollado el argumento específico (Reino Unido y EEUU), ya porque se trata de ordenamientos con una fuerte tradición dogmático-penal (Alemania e Italia) y, en fin, porque se trata de la normativa de sector más incisiva y reciente en el ámbito europeo (normativa comunitaria). 
Polít. crim. Vol. 8, № 15 (Julio 2013), Art. 3, pp. 64 - 127. [http://www.politicacriminal.cl/Vol_08/n_15/Vol8N15A3.pdf]

Es decisivo hacer presente que el contenido general de estos tipos ha sido apreciado también a partir del examen de los casos que suelen atribuirse a los tipos; pues no sólo el conocimiento del alcance de la regla echa luz sobre los casos, sino que también el conocimiento de los casos esclarece el contenido de la regla. De este modo, en la búsqueda de un tipo pre-normativo de manipulación se ha intentado incorporar la casuística a modo de complemento del panorama de definiciones o conceptos que se deprenden de las legislaciones consideradas, así como de los respectivos comentarios doctrinarios.

En este contexto, el universo de tipologías de casos consideradas en este estudio comprende las siguientes, todas ellas de frecuente alusión en la literatura consultada: tradebased manipulations o manipulaciones operativas, ${ }^{54}$ information-based manipulations o manipulaciones informativas, ${ }^{55}$ action-based manipulations, ${ }^{56}$ wash trades, ${ }^{57}$ painting the tape, improper matched orders, marking the close, abusive squeeze, excessive bid-ask spreads, pump and dump, trash and cash, concealing ownership, difusión de información

${ }^{54}$ Ésta y las dos siguientes tipologías -information-based y action-based-corresponden a las tres principales categorías en las que se suelen clasificar las diversas tipologías manipulativas, en atención al medio material empleado como mecanismo de obtención del resultado esperado; a saber, trade-based manipulations, si la manipulación se ha perseguido mediante negociaciones u órdenes de negociación (reales o simuladas) en un mercado relevante, es decir, operando directamente a través de las fuerzas del mercado (oferta y demanda); information-based manipulations si la manipulación se ha perseguido mediante la difusión de informaciones falsas de cualquier naturaleza, es decir, operando sólo indirectamente a través de las fuerzas del mercado; action-based manipulations si la manipulación se ha perseguido mediante comportamientos humanas engañosos ejecutados en un contexto externo al mercado (diversas por tanto a las negociaciones u órdenes de negociación), como puede ser por ejemplo simular el cierre de un importante establecimiento perteneciente a una sociedad cotizada en bolsa (para luego reabrirlo pocos días después, una vez que los precios de las respectivas acciones han bajado a causa de la percepción negativa que el cierre ha generado en el mercado). Es fácil advertir que en realidad esta tercera categoría carece de especificidad, debiendo entenderse como completamente absorbida - desde el punto de vista relevante para la clasificación- por la categoría de las information-based manipulations: pues también las informaciones falsas son ocasionadas por comportamientos humanos y puesto que el criterio decisivo para la clasificación se halla en el medio material utilizado como mecanismo manipulativo; en ambos casos el mecanismo se radica en la información, ya directa o explícitamente (a partir de manifestaciones de expresión, como declaraciones o escritos), ya cual reflejo de otros comportamientos humanos diversos a las directas manifestaciones de expresión. La clasificación elaborada por el CESR en el documento guía CESR 04-505b (recepcionado en Italia en la Comunicación CONSOB $n$. DME/5078692 del 29-11-2005) confirma por lo demás la posición que aquí se ha defendido: una clara hipótesis action-based -me refiero a la descrita en la hipótesis b) del apartado 4.14 del documento CESR- es colocada bajo el título relativo a las modalidades information-based. La tripartición trade-information-action based fue por primera vez utilizada como tal en el importante trabajo de ALLEN/GALE, "Stock-price", cit. nota n ${ }^{\circ} 50$, p. 505 y ss. Desde entonces ha gozado de gran difusión, siendo seguramente la clasificación más extendida actualmente en los círculos especializados, tanto del ámbito jurídico como económico (cfr. por todos, AGGARWAL/WU, "Stock Market Manipulation", cit. nota n 50). En Italia fue introducida en el contexto penalista por FABRIZIO, S.; TROVATORE, G., art. 181 (Comentario), en: RABITTI BEDOGNI, Carla, (Dira.), Il testo unico della intermediazione finanziaria: commento al d. lg. 24 febbraio 1998, $n$. 58, Milano, 1998, p. 1001, aunque interpretando la categoría de las action-based manipulations como comprensiva de las tipologías consistentes en operaciones ficticias o simuladas, lo que en mi entender no puede desprenderse del trabajo de Allen y Gale. Siempre en Italia, la tripartición fue retomada por VIZZARDI, Matteo, "Manipolazione del mercato: un "doppio binario" da ripensare?", Riv. it. dir. proc. pen., 2007, pp.704-731, incluyendo una adecuada aclaración del punto relativo al contenido atribuido por Allen y Gale a las action-based manipulations.

${ }^{55}$ Véase nota precedente.

${ }^{56}$ Véase nota 54, relativa a las manipulaciones operativas (trade based manipulations).

${ }^{57}$ Para ésta y las sucesivas tipologías, véase la nota siguiente. 
falsa o engañosa, inserción de órdenes de negociación sin la intención de ejecutarlas, constitución de un piso mínimo en el curso de los precios; negociaciones ejecutadas con la intención de incidir en los precios de un mercado relacionado (de derivados, por ejemplo), abrir una posición y cerrarla inmediatamente después de haberla revelado al público, ${ }^{58}$ cornering, ${ }^{59}$ punching the settlement price, ${ }^{60}$ tie-in agreements en el contexto de un Initial Public Offering o IPO, ${ }^{61}$ estabilización, ${ }^{62}$ buy-back programmes o programas de recompra, ${ }^{63}$ pegging, ${ }^{64}$ trading pools y trading syndicates, ${ }^{65}$ totuing, $^{66}$ rigged trades, ${ }^{67}$

58 Todas las precedentes -desde wash sale en adelante- son tipologías identificadas y descritas por el CESR
como eventualmente subsumibles bajo la Directiva MAD: cfr. Doc. guide-lines CESR 04-505 b, parag. 4.10 y
ss. Sin perjuicio de reenviar de inmediato a las descripciones contenidas en el referido documento del CESR,
se hace presente que varias de estas modalidades comisivas serán objeto de estudio más adelante en el curso de este trabajo.

${ }^{59}$ Se trata de una tipología basada en el ejercicio de un poder de mercado en perjuicio de los short sellers llamados a cumplir con obligaciones derivadas de sus posiciones en un mercado de futuros u otros instrumentos derivados. El manipulador opera de manera de controlar una parte relevante del mercado de los instrumentos financieros o bienes subyacentes objeto de la obligación de distribución por parte de los short sellers, colocándose en consecuencia en condiciones de dictar el precio a pagar por los short sellers para evitar el incumplimiento contractual. Cfr. MARKHAM, Jerry W., "Manipulation of Commodity Futures Prices -- The Unprosecutable Crime", Yale J. Reg., n. 8 (1991), p. 283; AVGOULEAS, Emilios, The Mechanics and Regulation of Market Abuse. A legal and Economic Analysis, Oxford: Oxford University Press, 2005, p. 150 y ss. Para mayor detalle, cfr. McDERMOTT, Edward T., "Defining Manipulation in Commodity Futures Trading: The Futures 'Squeeze'”, Nw. U.L. Rev., 1979, vol, 74, pp. 202 y ss.; VAN SMITH, M., "Preventing the Manipulation of Commodity Futures Markets: To Deliver or Not to Deliver", Hastings L.J. (1981), 32, pp. 1569 y ss. Haciendo ver la inexistencia de un consenso respecto al real alcance de expresiones como corner o squeeze, y concentrándose en su lugar en el concepto de manipulación de naturaleza monopólica, cfr. EASTERBROOK, Frank H., "Monopoly, Manipulation, and the Regulation of Futures Markets", The Journal of Business, 1986, Vol. 59, n. 2, pp. 103-127, p. 106.

${ }^{60}$ Otro tipo de manipulación basada en el ejercicio de un poder de mercado, en el que se procura alterar el precio de cash settlement de los futuros, por la vía de operaciones manipuladoras en el mercado spot. En lo específico, hallándose el manipulador en una posición long en un mercado de futuros, se trata de comprar en el mercado spot de manera de alzar el precio de settlement. Cfr. KUMAR/SEPPI, "Futures Manipulation", cit. nota $\mathrm{n}^{\circ} 50, \mathrm{p} .1486$.

${ }^{61}$ Se trata de una modalidad manipulativa en virtud de la cual los underwriters obtienen el alza de los precios de instrumentos asociados a una IPO (initial public offering = oferta pública inicial o primera oferta pública de valores), por la vía de amarrar los acuerdos de asignación de los lotes de los respectivos instrumentos a la condición de que los clientes adquieran los mismos en el aftermarket. Cfr. AGGARWAL/PURNANANDAM/WU, "Underwriter Manipulation”, cit. nota n 50 .

${ }^{62}$ Más que una tipología o modalidad comisiva singular, se trata de una categoría comprensiva de una serie de tipologías manipulativas cuya nota común es el intento de sostener el precio de un instrumento financiero en un determinado nivel, en la mayoría de los casos a modo de defensa contra tendencias o presiones a la baja (presiones de venta) en el mercado primario o, en general, en contextos de ofertas o distribuciones de dimensiones significativas. Es reconocida tanto en el sistema europeo como en el americano como una categoría excepcionalmente no sancionable, supuesto el cumplimiento de determinadas condiciones previstas por el propio ordenamiento: cfr. art. 7 Directiva $M A D$ y Reglamento de la Comisión Europea 2273-2003; para el sistema americano, cfr. fundamentalmente la section 9(a)6 de la SEA (=15 USCS § 78i(a)6 del 2005) y la denominada Regulation M (=Rules 100-105, en 17 CFR 242.101-105), y para una explicación general de las mismas, cfr. LOSS, Louis; SELIGMAN, Joel, Securities Regulation, versión digital Lexis.com, 2004 (3a. ed.), cap. 10-E.

${ }^{63}$ Análogas consideraciones a las efectuadas con respecto a la estabilización cabe hacer para los buy-back programmes e issuer repurchases; sin embargo a diferencia de la anterior, no se trata de conductas per se manipulativas (desde un punto de vista fenomenológico, se entiende) sino que se trata sólo de hipótesis indiciarias de una eventual manipulación: una especie "peligro de manipulación". Como en el caso de la 
Polít. crim. Vol. 8, № 15 (Julio 2013), Art. 3, pp. 64 - 127. [http://www.politicacriminal.cl/Vol_08/n_15/Vol8N15A3.pdf]

market power manipulation, ${ }^{68}$ contract based manipulation, ${ }^{69}$ offsetting trade-based
manipulation, ${ }^{70}$ y omisión de comunicación de información relevante o price sensitive.

estabilización, el sistema europeo exime los buy-back programmes de sanción bajo condiciones bien precisas: cfr. art. 7 Directiva MAD y Reglamento de la Comisión Europea 2273-2003.

${ }^{64}$ Se refiere a una específica modalidad de estabilización, habitual en el mercado americano con anterioridad al crack de 1929 (cfr. TWENTIETH CENTURY FUND, INC., The Security Markets, New York, 1935, cap. 13, p. 458), aunque la expresión suele usarse también para referirse en modo genérico a la estabilización. Otro tanto cabe decir del denominado fixing. La legislación americana las contempla expresamente en la ya referida section 9(a)6 de la SEA (= 15 USCS § 78i(a)6 del 2005).

${ }^{65}$ Con dichas expresiones se alude en general a las diversas modalidades de consorcio o pactos de banqueros y operadores -habituales en el mercado americano pre-'29- y que tenían como propósito la estabilización o bien -derechamente- la manipulación de los precios de los instrumentos financieros. En cuanto asociaciones con finalidades manipulativas o estabilizadoras, comprenden en si una serie de modalidades o técnicas manipulativas distintas, desde las clásicas informaciones falsas o publicidades engañosas, hasta las más sofisticadas manipulaciones operativas. Al respecto, cfr. Twentieth Century Fund, p. 456 y ss., con una precisa descripción del concreto modus operandi de la manipulación operativa ejecutada en el contexto de las trading pools; para mayor detalle, defendiendo el carácter tendencialmente no manipulativo de los trading pools pre-'29 y su utilidad económica, cfr. MAHONEY, "The Stock Pools", cit. nota n 50, p. 343 y ss.

${ }^{66}$ Otra modalidad manipulativa frecuente en los EEUU pre'29, consistente en un conjunto de maniobras de naturaleza informativa, como el recurso a publicidad engañoso, la correría o diseminación de rumores, la divulgación de análisis o recomendaciones tendenciosas. Al respecto, cfr. TWENTIETH CENTURY FUND, INC., The Security Markets, cit. nota $n^{\circ}$ 64, pp. 472 y ss.; y LOSS/SELIGMAN, Securities Regulation, cit. nota $\mathrm{n}^{\circ}$ 62, cap. 10-A A, "Classic Portrait of Market Manipulation".

${ }^{67}$ No se trata de una específica modalidad comisiva sino de una categoría que comprende las diversas formas de manipulación operativa en las que interviene un neto factor de engaño: como las wash trades, matched orders, pump and dump, trash and cash, etc. Esta categoría se coloca como distinta de aquella de las market power manipulations, en las que la manipulación es también de naturaleza operativa, pero que no se caracterizan por un actuar engañoso, sino más bien por el clamoroso abuso de un poder de mercado, como típicamente es el caso de los corners, los squeezes o los tie-in agreements en el contexto de una IPO. Las rigged trades y las market power son las dos categorías de manipulaciones operativas identificadas por MARKHAM, "Manipulation of Commodity", cit. nota n ${ }^{\circ} 59$, pp. 283 y 284.

${ }^{68}$ Véase la nota precedente.

${ }^{69}$ No se trata en rigor de una modalidad comisiva de manipulación, sino de una categoría comprensiva de aquellas manipulaciones cuyo provecho económico se radica en una mejora en las condiciones de ejecución de un contrato preexistente, en el se ha estipulado un determinado precio de mercado como precio de ejecución contractual (precio de mercado que precisamente ha sido alterado por el manipulador). La contrapartida de esta categoría debería hallarse en las manipulaciones offsetting trade-based, en las que el provecho económico es el resultado de la ejecución de operaciones en sentido opuesto a aquellas previamente ejecutadas con miras manipuladoras o bien en sentido opuesto al sentido de la información falsa o engañosa utilizada: como cuando se venden los instrumentos cuyo precio ha sido previamente elevado por operaciones o informaciones tendientes al alza o, al opuesto, cuando se adquieren instrumentos cuyo precio ha sido previamente deprimido por operaciones o informaciones tendientes a la baja. Cfr., por todos, THEL, Steve, "\$ 850,000 in Six Minutes -- The Mechanics of Securities Manipulation”, Cornell L. Rev., n. 79 (1994), pp.247 ss. La distinción entre una clase y otra de manipulaciones es relevante desde el punto de vista de deterrence: pues el segundo tipo de provecho expone al agente a un riesgo y un costo elevados con respecto al primero tipo de provecho. Al respecto, cfr. el conocido trabajo de FISCHEL, Daniel R.; ROSS, David J., "Should the Law Prohibit "Manipulation" in Financial Markets?", Harv. L. Rev., n. 105 (1991), pp. 503 y ss., y la contundente réplica de THEL, “\$ 850,000 in Six", op. cit. supra en esta nota.

${ }^{70}$ Véase nota precedente.

71 Corresponde a un tipo omisivo de manipulación informativa. No debe confundirse con una conducta activa, consistente en la entrega de información incompleta o tendenciosa (contexto en el que se omite información relevante). Su tratamiento jurídico no es uniforme en los diversos ordenamientos, siendo mayoritaria la tendencia a no considerarlo una manipulación propiamente tal, aplicándose en general las específicas sanciones que derivan de la violación de las reglas de mandatory disclosure. Aunque no 
LONDOÑO, Fernando. "Ilícito de manipulación bursátil: fenómeno y lesividad. Aspectos de política sancionatoria".

Para recabar provecho de la casuística no basta por cierto exponerla, sino que es necesario sistematizarla. Evidentemente, ello se logra en la medida que se identifican criterios rectores para distinciones válidas, que expliquen y disuelvan las superposiciones y den sentido de pertenencia a las diversas categorías. Los siguientes constituyen algunos de los problemas que en este plano cabe superar. ¿En qué medida la recurrente sistematización trade-based/information-based/action-based ${ }^{72}$ (en adelante sistematización medial) es compatible con aquella que reconoce una tipología como la contract-based ${ }^{73}$ ¿En qué medida la sistematización medial resulta suficiente? ¿Dónde radica la distinción entre definiciones de manipulación intent-based y effect-based ${ }^{74}$ o entre manipulaciones fraudbased y market power-based $?^{75}$ Por otra parte, ¿cómo se conjugan las sistematizaciones conocidas (la medial principalmente) con la summa divisio acogida por la Directiva MAD $6 / 2003 ?^{76}$ ¿Hasta qué punto ellas se concilian con la casuística empleada por el Comité de Autoridades Europeas Reguladoras de Valores (en adelante, CESR = Committee of European Securities Regulators) $?^{77}$ En fin, ¿en qué medida las sistematizaciones dan

expresamente abordada por el ordenamiento comunitario $M A D$, es mencionada como ejemplo -aunque ulteriormente no desarrollada- en la presentación de las tipologías information based por el citado documento CESR 04-505b y su cobertura puede advertirse en la propuesta de Directiva MAD de 30.5.200 - COM (2001). Mientras que su tipicidad penal -a título de manipulación bursátil, se entiende- puede ser discutible en otros ordenamientos relevantes, su tipicidad es expresa en el ordenamiento alemán (WpHG parag. 20a (1) 1: Ümstände entgegen bestehenden Rechtsvorschriften zu verschweigen). En el ordenamiento estadounidense no sería subsumible ni aún bajo la muy vaga section 10(b) de la SEA (15 USCS $\S 78 j$ ), complementada por la regulación SEC, regla 10b-5 (17 CFR 240.10b-5), en la medida que lo sancionado allí no es tanto una auténtica omisión como la emanación (conducta activa) de un statement incompleto y, por tanto, engañoso (misleading): "Employment of manipulative and deceptive devices. It shall be unlawful for any person, directly or indirectly, by the use of any means or instrumentality of interstate commerce, or of the mails or of any facility of any national securities exchange, (...) (b) To make any untrue statement of a material fact or to omit to state a material fact necessary in order to make the statements made, in the light of the circumstances under which they were made, not misleading (...)". Al respecto, cfr. la importante sentencia Santa Fe Indus., Inc. v. Green, 430 U.S. 462, 477 (1977).

${ }^{72} \mathrm{Cfr}$. lo expuesto supra en nota 47.

${ }^{73}$ Cfr. supra nota 62.

74 Distinción operativa en el plano probatorio, dando contenido al genérico concepto de manipulación empleado por la legislación estadounidense para el mercado de futuros. Al respecto, cfr. la reconstrucción del debate en el trabajo de PERDUE, Wendy C., "Manipulation of futures markets: redefining the offense", Fordham L. Rev., n. 56 (1987), pp. 345 y ss., definiendo la manipulación como una conducta antieconómica o irracional, de no contarse ex ante con la obtención de un efecto en el precio de mercado como resultado de dicha conducta (cfr. op. cit, p. 401). Sobre este concepto se volverá más adelante.

${ }^{75}$ Cfr. el ya citado MARKHAM, "Manipulation of Commodity", cit. nota n 59, pp. 283 y 284.

${ }^{76}$ A saber, desde el punto de vista medial material, la distinción entre transacciones [art. 1, 2 a) y b)] e informaciones [art. 1, 2 c) - aunque en parte subsumible en la letra b), como lo demuestra la ejemplificación del CESR 04-505b]; y, desde el punto de vista de la conducta, entre transacciones falsas o engañosas [art. 1, 2 a) primera hipótesis], posicionamiento de los precios [art. 1, 2 a) segunda hipótesis], transacciones artificiosas [art. 1,2 b) ] y diseminación de información falsa o engañosa [art. 1, 2 c) ].

${ }^{77}$ Instancia técnica y de consulta en la materia, que hasta fines de 2010 agrupaba a las diversas autoridades nacionales reguladoras de mercados de valores en el marco de la Unión Europea. Su sucesora - a partir de enero de 2011 - es el ESMA (European Securities and Markets Authority), entidad europea ya no sólo técnico-consultiva, sino connotada de directos poderes de regulación sobre el sector. En 2004 el CESR elaboró un documento guía de tercer nivel (documento 04-505 b =Market Abuse Directive.Level 3 - First set of Cesr guidance and information on the common operation of the Directive". Ref: CESR/04-505b.) en el que se asociaban concretas tipologías de manipulación a las diversas definiciones de la Directiva $M A D$. Se trata, de hecho, de una propuesta hermenéutica, elaborada a partir de tipos de casos subsumibles en las diversas 
Polít. crim. Vol. 8, № 15 (Julio 2013), Art. 3, pp. 64 - 127. [http://www.politicacriminal.cl/Vol_08/n_15/Vol8N15A3.pdf]

cuenta de la distinción jurídicamente más relevante: a saber, entre manipulaciones sancionables y manipulaciones exentas de sanción? ${ }^{78}$ ¿Puede identificarse una diferencia estructural o permanente entre estas dos categorías? ¿Por qué -es decir, en base a qué características del fenómeno- los ordenamientos tienden a excluir la punibilidad de ciertas modalidades de manipulación, en lugar de otras? Éstas son todas preguntas cuya solución parece exigir un intento de superación de las elaboraciones disponibles. ${ }^{79}$

En lo demás, el método utilizado para alcanzar dicho objetivo es sencillo e intuitivo: a partir del examen de las descripciones y casos vinculados a los correspondientes tipos legales -lo que constituye el denominado panorama de (pre)conceptos- se ha intentado elaborar una taxonomía de las diversas manifestaciones del fenómeno manipulativo; es decir, una suerte de cuadro general de las tipologías y categorías principales, siguiendo fundamentalmente criterios de relevancia hermenéutica, tales como la lesividad, la modalidad medial y la necesidad preventiva o de disuasión. Se intenta, en fin, elaborar un concepto de manipulación capaz de capturar aquello que constituiría el núcleo de todas las

definiciones de manipulación de nivel comunitario. Con posterioridad, en 2007 y 2009, el CESR publicó otros dos sets de guías complementarias de la primera (docs. 06-562b y 09-219).

${ }^{78}$ Me refiero ante todo a la problemática de las tipologías eventualmente exentas como la estabilización o los programas de recompra, así como, en general, las prácticas de mercado aceptadas (arts. 8 y 2 de la Dir. $M A D)$.

${ }^{79}$ Mi hipótesis es que esta relativa falta de claridad en el plano fenomenológico y taxonómico explica en parte la vaguedad en el plano legislativo, a nivel de tipicidad. Ciertamente no basta para demostrar esta conexión echar mano a legislaciones penales - como la italiana- que tradicionalmente han ofrecido descripciones típicas amplias (recurriendo a elementos descriptivos elásticos como el carácter artificioso o fraudulento de las conductas manipulativas), pues es normal que dicha técnica conlleve un grado de opacidad significativo. Puede en cambio servir para ilustrar el punto hacer ver las oscuridades imperantes en una legislación como la del Reino Unido, cuya tradición se halla seguramente más emparentada con el fenómeno manipulativo en su especificidad. En efecto, no obstante dicha familiaridad con la fenomenología del caso, la regulación del Reino Unido ofrece tipos administrativos y penales recíprocamente asimétricos y fragmentarios, resultando arduo identificar con seguridad qué tipologías fenomenológicas son reconducibles a cada uno de ellos (lo que resulta especialmente grave en el caso del tipo penal). Esta crítica ha sido precisamente expuesta por AVGOULEAS, The Mechanics, cit. nota $n^{\circ}$ 59, pp. 308 y 312; sp. p. 312. Por lo que se refiere a Alemania, tampoco allí la situación es alentadora, ni ha cambiado mayormente a partir de la recepción de la Directiva $M A D$; en efecto, más allá de las dudas que existen respecto a la cobertura de la prohibición en general, los criterios de distinción entre la punibilidad penal y la vía administrativa resultan en concreto - sin perjuicio de la objetiva claridad del texto legal (§ 38(2) WpHG: criterios de tipicidad subjetiva (dolo) y de resultado) - de ardua e insegura aplicación. En doctrina, cfr. especialmente, MOOSMAYER, Klaus, "Straf- und bußgeldrechtliche Regelungen im Entwurf eines Vierten Finanzmarktförderungsgesetzes, Wistra (2002), n. 5, pp. 161-170; SCHMITZ, Roland, "Der strafrechtliche Schutz des Kapitalmarkts in Europa", ZStW, 2003, n.115, pp. 501-538; SORGENFREI, Ulrich, "Zum Verbot der Kurs- oder Marktpreismanipulation nach dem 4. Finanzmarktförderungsgesetz”, Wistra (2002), n. 9, pp. 321-331; SORGENFREI, Ulrich, §§ 20a, 38 I nr. 4, 39 WpHG (Comentario), en: PARK, Tido (Coord.), Kapitalmarkt Strafrecht. Handkommentar, Baden Baden: Nomos-Verlag-Ges, 2004, pp. 210-270; TIEDEMANN, Klaus, Wirtschaftsstrafrecht: Besonderer Teil, Köln: Heymanns, 2006, pp. 158-162; TRIPMAKER, Stefan, "Der subjective Tatbestand des Kursbetrugs", Wistra (2002), n. 8, pp. 288-292; VOGEL, Joachim, "Kurspflege: Zulässige Kurs- und Marktpreisstabilisierung oder straf- bzw. ahndbare Kurs- und Marktpreismanipulation? ”, WM, 2003, n. 51-52, pp. 2437-2445.; VOGEL, Joachim, $\S \S 20 a$, 38-40b (kommentar), en: ASSMANN, H.D.; SCHNEIDER, U.H., Wertpapierhandelsgesetz Kommentar, Köln: Otto Schmidt, 2006, pp. 727 y ss. y 1669 y ss.; ZIOUVAS, Dimitris, "Das Neue Recht gegen Kurs- und Marktpreismanipulation im 4. Finanzmarktförderungsgesetz", en ZGR, 2003, p. 113 y ss.; ZIOUVAS, Dimitris; WALTER, Tonio, "Das neue Börsenstrafrecht mit Blick auf das Europarecht - zur Reform des § 88 BörsG -", WM, 2002, n. 29, pp. 1483-1488. 
LONDOÑO, Fernando. "Ilícito de manipulación bursátil: fenómeno y lesividad. Aspectos de política sancionatoria".

manifestaciones: el fenómeno en cuanto tal. La expresión tipo pre-normativo alude precisamente a ese núcleo. ${ }^{80}$

Sin anticipar aquí el concepto a que se llegará, bastará adelantar un aspecto central de las conclusiones del presente trabajo. Considerando la lesividad y los intereses en juego como criterios taxonómicos fundamentales, no existiría un único concepto de manipulación, sino dos posibles conceptos jurídicamente relevantes. Además, dichos conceptos se hallan en una relación de género/especie.

Como se verá enseguida, la atención al uso común o general de la voz manipulación proporcionará una clave de lectura sintética e iluminadora a este respecto.

\subsection{Una primera aproximación al fenómeno. El eficaz auxilio de la semántica: concepto general y concepto especial de manipulación (injerencia y distorsión).}

Un anticipo de la conclusión arriba adelantada -la dualidad de conceptos del fenómeno manipulativo, en una relación de género/especie- puede encontrarse atendiendo simplemente al uso lingüístico de la voz manipulación. ¿En qué sentido se usa dicha expresión en el lenguaje común? ¿A qué se alude normalmente cuando se dice que tal o cual persona manipulan esto o aquello? ¿En qué medida la consideración del objeto de la acción manipuladora cambia la valoración relativa a la conducta?

Conviene responder gradualmente.

Una primer sentido de la voz manipular posee una connotación marcadamente negativa. Así, se dice que se manipula o que se verifica una manipulación allí donde una persona ejerce una injerencia indebida o desleal en un determinado ámbito de personas o cosas. Se trata de una injerencia que puede considerarse, según los casos, innatural, artificiosa, deslealmente interesada, distorsionadora, etc. En fin, se trata de una forma de injerencia o control reñida con la consideración debida al objeto de la acción; reñida con la verdad, el bien o el razonable interés de un determinado valor (de allí la idea de distorsión). A esta acepción hace referencia la Real Academia Española cuando define manipular como "intervenir con medios hábiles $\mathrm{y}$, a veces, arteros, en la política, en el mercado, en la información, etc., con distorsión de la verdad o la justicia, y al servicio de intereses particulares". ${ }^{81}$ Resulta claro que este concepto parece inmediatamente aplicable al campo que aquí nos ocupa. En efecto, la idea no es lejana a buena parte de los conceptos elaborados por la doctrina.

\footnotetext{
${ }^{80}$ La tentativa de elaborar un concepto de manipulación capaz de comprender y dar razón de las diversas manifestaciones del fenómeno y que a la vez sea utilizable en la práctica, constituye un esfuerzo recurrente en la literatura americana especializada, particularmente en el campo de las manipulaciones en los mercados de futuros. Por todos, confrontar los trabajos de EASTERBROOK, "Monopoly", cit. nota n 59; PERDUE, "Manipulation", cit. nota ${ }^{\circ} 74 ;$ FRIEDMAN, Richard D., "Stalking the squeeze: understanding commodities market manipulation", Mich. L. Rev., n. 89 (1990), pp. 30-68; MARKHAM, "Manipulation of Commodity", cit. nota $\mathrm{n}^{\circ}$ 59, y PIRRONG, Craig, "Commodity Market Manipulation Law: A (Very) Critical Analysis and a Proposed Alternative”, Wash. \& Lee L. Rev., n. 51 (1994), pp. 945 y ss.

81 Tercera acepción: cfr. Diccionario de la Real Academia Española, versión digital disponible en http://www.rae.es.
} 
Polít. crim. Vol. 8, № 15 (Julio 2013), Art. 3, pp. 64 - 127.

[http://www.politicacriminal.cl/Vol_08/n_15/Vol8N15A3.pdf]

Sin embargo, esto no puede ser todo, pues si la manipulación fuese siempre una acción reñida con la verdad o el bien del objeto, no se advierte cómo podría reconocerse la legitimidad o incluso auspiciarse la práctica de conductas manipulativas. Con ello estoy aludiendo al grueso de las conductas de estabilización que se ejecutan en los contextos de primera emisión y a otras prácticas de mercado aceptadas de las que me ocuparé más adelante (infra 2.3.5.) ¿Cómo es que la semántica puede auxiliarnos en este punto?

Pues bien, la expresión manipular puede usarse también en un sentido diverso; en principio positivo, aunque cuanto menos neutro. Así, manipular es ejercer injerencia, control o dominio sobre una determinada realidad. Precisamente un aspecto de la dignidad humana es su capacidad de injerir en lo real, de modelar la realidad conforme a lo que advierte como deseable, estimable. Las manos son precisamente la primera "herramienta" de la que el hombre -desde tiempos remotos- se ha servido para modificar su entorno. De allí justamente la etimología de la palabra. De esta acepción da precisamente cuenta la $R A E$ en primer término: manipular es "operar con las manos o con cualquier instrumento". 82

De manera que manipular es siempre injerir, ejercer una forma de control o dominio sobre una determinada realidad. Con ello se alude a un manipular genérico. Ahora bien, dicha injerencia puede ser positiva o no, puede o no ser conforme al ser del objeto al que se aplica, puede o no distorsionarlo. La connotación negativa de manipulación -aquella que posiblemente nos viene a la mente primero- sería entonces una especie perteneciente a una categoría más amplia.

Estas sencillas consideraciones pueden de inmediato iluminar el por qué determinadas hipótesis de manipulación pueden no necesariamente aparecer como reprobables o indeseables: ¡pues la injerencia en si no lo es! No toda manipulación es sinónimo de distorsión.

Ahora bien, alguien podría todavía observar: ¿no existen acaso ámbitos en los que la injerencia o el ejercicio de control es en sí reprobable o indeseable? ¿La valoración de la injerencia no depende acaso de la cualidad o condición del objeto sobre el que recae la misma? En efecto, allí donde el objeto de la acción manipuladora es un sujeto, allí donde se trata de ejercer un domino o control sobre un agente libre, la reprochabilidad ético-social de la conducta constituirá en principio la regla general. La manipulación aplicada a objetos en sentido estricto- puede ser considerada en principio valiosa o bien neutra; no en cambio si ella se ejerce sobre un ser humano. También aquí el lenguaje común resulta de auxilio, pues es un hecho que jamás podrá considerarse positiva (ni aún neutra) una formulación como: "X suele manipular a sus amigos". Ella conlleva necesariamente un juicio de desvalor. Las personas no deben ser manipuladas -en el sentido de pretender anular en ellas un espacio de libertad- y todo intento en esa dirección es comúnmente considerado indeseable y, como tal, socialmente reprochado. ${ }^{83}{ }_{-}^{84}$

\footnotetext{
82 Primera acepción: cfr. Diccionario de la Real Academia Española, versión digital disponible en http://www.rae.es.

${ }^{83}$ La cuarta acepción del verbo manipular se orienta en parte en este sentido: "mezclarse en los [negocios] ajenos" (cfr. Diccionario de la Real Academia Española, versión digital disponible en http://www.rae.es).
} 
LONDOÑO, Fernando. "Ilícito de manipulación bursátil: fenómeno y lesividad. Aspectos de política sancionatoria".

¿Y qué decir del mercado a este respecto? ¿No se extiende acaso la cualidad de libre también al mercado, de manera que a su respecto las tentativas de injerencia, control o dominio deberán ser consideradas en principio o a priori como indeseables? ${ }^{85}$ ¿Cómo puede decirse entonces que con respecto al mercado existe un espacio para la manipulación legítima, benigna o deseable?

La argumentación se vuelve aquí más compleja y necesitada de aportes adicionales de carácter técnico. Ciertamente no puede ya bastar el recurso a la semántica y parece preciso dar un nuevo paso en el desarrollo del presente trabajo. Con todo, puede desde ya adelantarse que: (1) persona y mercado no pueden colocarse en un plano equivalente desde este punto de vista, pues mientras en la primera la libertad constituye una constante ontológica - estructural, si se quiere-, en el caso del mercado ella constituye una aspiración ideal, una cualidad deseable conforme a un determinado modelo, pero no siempre verificable en concreto: una cualidad eventual, asociada a la idea de que el mercado está conformado por un flujo de comportamientos (ofertas y demandas) ejecutados por agentes inteligentes y estructuralmente libres. De allí entonces que la reprochabilidad de la manipulación ejercida sobre personas y sobre mercados no pueda colocarse en un mismo plano. (2) Con todo, resulta indudable que las injerencias o formas de control del mercado deterioran lo (poco o mucho) que pueda haber de libre en aquél. Si la libertad, como hemos dicho, es un atributo deseable (ideal) de los mercados, entonces no puede negarse que toda injerencia o tentativa de control del mercado (de control de las fuerzas en él imperantes) deberá ser en principio estimada como no deseable (porque potencialmente lesiva). No será entonces una acción a priori neutra como puede serla la de manipular un objeto diverso cualquiera. En este sentido, puede hablarse de la manipulación del mercado como de una conducta preliminarmente indeseable (idea cercana a la de tipicidad pre-normativa); en otras palabras, como una conducta cuya legitimidad o benignidad constituirá más bien una excepción, a demostrarse en concreto.

No conviene sin embargo abusar del limitado espacio de trabajo que ofrece la semántica en este contexto.

Puede entonces concluirse este apartado diciendo que, atendiendo al lenguaje corriente, se han identificado dos conceptos de manipulación igualmente válidos: uno general y otro especial. Un primer concepto alude a la genérica injerencia (o grado de control) ejercida por un agente sobre una determinada realidad (en adelante denominada manipulación en sentido general). Un segundo concepto, especie del anterior, alude a manipulación como injerencia o control distorsionador, desviante; a saber, una injerencia o control que aleja al objeto de su condición real (en adelante denominada manipulación en sentido especial). Manipulación entonces como mera injerencia/control y manipulación como distorsión/desviación. Dijimos además que allí donde la realidad manipulada esté constituida por agentes libres, la calificación de las conductas manipulativas va acompañada - conforme al lenguaje común- de una connotación negativa. Desde las

\footnotetext{
${ }^{84}$ Como puede haberse advertido, se reconoce una sintonía entre lenguaje común y valoraciones éticosociales comunes.

${ }^{85}$ Una ilustración clara y sintética de la idea de mercado libre se halla en NOVAK, Michael, The Spirit of Democratic Capitalism, Lanham, 1991, pp. 104 y ss. Sobre el contenido de esta obra se volverá más adelante.
} 
Polít. crim. Vol. 8, № 15 (Julio 2013), Art. 3, pp. 64 - 127.

[http://www.politicacriminal.cl/Vol_08/n_15/Vol8N15A3.pdf]

personas al mercado puede extenderse una analogía en este plano; pero no deja de ser precisamente ello: una analogía. Deben por tanto respetarse ciertas diferencias o matices a este respecto. Cuáles son estas diferencias y qué tratamiento merecen, es algo que deberá ser respondido en lo sucesivo.

\subsection{Los conceptos de manipulación a partir de la casuística: una primera verificación de los resultados provisorios a partir de la observación de algunos casos representativos.}

Toca ahora analizar en qué medida puede hablarse de manipulación como injerencia o como distorsión atendiendo - ya no a la mera semántica- sino a la observación de algunas manifestaciones o tipologías fácticas, seleccionadas ${ }^{86}$ en cuanto uniformemente consideradas como manipulativas por los diversos ordenamientos legales de referencia. ${ }^{87}$ Probablemente el camino más sencillo y a la vez fructífero está dado por el recurso a algunos de los casos o tipologías reconocidas por el CESR en el documento-guía de tercer nivel $04-505 b^{88}$

Recordemos que si nuestra hipótesis es correcta, todos los casos podrán ser descritos recurriendo a la fórmula de la injerencia o control, mientras que algunos podrán además ser caracterizados como casos de injerencia o control distorsionador. Evidentemente la fórmula debe concebirse no sólo en términos de resultado alcanzado (una injerencia o una distorsión efectivas), sino también en términos de resultado perseguido (la intención o la tentativa de injerencia o distorsión). En lo demás, las apreciaciones se harán necesariamente en abstracto, en base a una tipología estandarizada.

\subsubsection{Marking the close.}

Considérese en primer lugar el denominado marking the close (marcar el precio de cierre). Conforme a la descripción contenida en la aludida guía del CESR sobre operaciones preliminarmente comprendidas por la Directiva $M A D$ (CESR/04-505b),

\footnotetext{
${ }^{86}$ Las tipologías o manifestaciones expuestas a continuación constituyen una muestra representativa de otros tantos que se han tenido a la vista. Además de haber revisado cada una de las tipologías CESR (según se dará cuenta infra en tabla bajo el apartado 2.6.4.), se han tenido especialmente en cuenta los principales casos y tipologías reportados por la siguiente literatura (económica y jurídica): AGGARWAL/WU, "Stock Market", cit. nota $\mathrm{n}^{\circ}$ 50; ALLEN/GALE, "Stock-Price", cit. nota $\mathrm{n}^{\circ}$ 50; BERLE, Adolf. A. Jr., "Stock Market Manipulation", Colum. L. Rev., n. 38 (1938), pp. 393 y ss.; FISCHEL/ROSS, "Should the Law", cit. nota ${ }^{\circ}$ 69; EASTERBROOK, "Monopoly", cit. nota n 59; JENNINGS, Richard W.; MARSH Jr., Harold; COFFEE Jr. John. C.; SELIGMAN, Joel, Securities Regulation, Cases and Materials, New York: Matthew Bender, 1998 (8a. ed.), cap. 11 y 18, pp. 673 y ss. y 1582 y ss.; LOSS/SELIGMAN, "Securities Regulation", cit. nota $\mathrm{n}^{\circ}$ 62, cap. 10; MARKHAM, "Manipulation of Commodity", cit. nota $\mathrm{n}^{\circ} 59$; MATHIAS, James, "Manipulative Practices and the Securities Exchange Act", U. Pitt. L. Rev. (1936), n. 3, pp. 7 y ss.; PERDUE, "Manipulation of futures", cit. nota $\mathrm{n}^{\circ} 74$; POSER, Norman, "Stock Market Manipulation and Corporate Control Transactions", U. Miami L. Rev., n. 40 (1986), pp. 671 y ss.; y THEL, “\$ 850,000 in Six”, cit. nota n 69.

${ }^{87} \mathrm{Cfr}$. lo expuesto supra en el precedente apartado 2.1 .

${ }^{88}$ Market Abuse Directive. Level 3 - First set of Cesr guidance and information on the common operation of the Directive. Ref: CESR/04-505b. Recepcionados en Italia a nivel administrativo por la Comunicación CONSOB n. DME/5078692 del 29-11-2005.
} 
LONDOÑO, Fernando. "Ilícito de manipulación bursátil: fenómeno y lesividad. Aspectos de política sancionatoria".

"esta práctica consiste en la compra o venta de valores o contratos derivados al cierre
del mercado, en un intento deliberado por alterar el precio de cierre del valor o
contrato derivado. Esta práctica puede tener lugar en una fecha cualquiera de
intercambio bursátil, pero se asocia especialmente a fechas como las de expiración de
futuros/opciones o las correspondientes a la valoración o puntuación de índices o
fondos [portfolio] trimestral o anualmente consolidados". 89

Realizando operaciones poco antes de la hora de cierre del mercado de bolsa, el agente se coloca ciertamente en condiciones mejores para injerir en la determinación del último precio. ${ }^{90}$ Es decir, el agente se coloca en condiciones para asumir una posición de relativo control sobre una de las dos fuerzas del mercado (oferta o demanda). Lo anterior, en la medida que, restando poco tiempo para el cierre, la posibilidad de una injerencia reequilibradora de terceros se reduce considerablemente. Si el precio es el producto de la interacción de los diversos participantes en el mercado, ${ }^{91}$ allí donde se reduzca el espacio de participación de muchos - por razones de tiempo, como en este caso- se aumentarán las posibilidades de injerencia en el producto (precio) de aquellos pocos que sí se hallan en condiciones de acceder al espacio de participación. No es otra cosa lo que sucede en el marking the close. Sobre si acaso puede aquí hablarse también de distorsión (al menos en un plano de tentativa o de evento perseguido), es algo que debe juzgarse en concreto, en atención a las razones que inspiran al agente en su accionar. Así, si éste reconoce en los instrumentos un valor (contingente) igual o cercano a 10 (consolidado por el mercado en un período relevante de tiempo), no se ve entonces cómo pueda excluirse la hipótesis de distorsión, allí donde se disponga a comprar ingentes cantidades a un precio igual a 20 . Un agente económico-racional no se comporta de este modo (pues optará por comprar maximizando su margen de ganancia), salvo que espere obtener un provecho a partir de una externalidad o de una circunstancia extrínseca a su participación en el mercado. ${ }^{92}$ Por ahora digamos entonces que el marking the close no se asocia necesariamente a la manipulación especial o distorsión, pero ciertamente resulta en abstracto compatible con la misma.

\subsubsection{Pump and dump.}

Examinemos ahora la tipología denominada pump and dump (inflar y descargar), cuya descripción por el CESR reza:

"Esta práctica consiste en la toma o apertura de una "posición larga" [long position] en un determinado título para luego proceder a realizar adicionales actividades de compra y/o a difundir información falsa positiva u optimista respecto al título, con miras a

\footnotetext{
${ }^{89}$ Traducción por el autor desde el inglés, a partir de su formulación en el punto 4.12 a) del CESR/04-505b.

90 Se trata de una injerencia normalmente asociada a una forma de lucro contract-based; es decir, obteniéndose ganancias a partir del impacto que el precio de cierre tiene en el cálculo de precios o factores de pago en el marco de una determinado contrato, previamente celebrado por el manipulador o un agente relacionado.

${ }^{91}$ Cfr. BERLE, Adolf A., "Liability for Stock Market Manipulation”, Colum. L. Rev., n. 31 (1931), pp. 264 y ss.; p. 267.

92 Como puede ser el caso de las contract-based manipulations, en las que el agente obtiene provecho desde que la determinación de la entidad de un derecho u obligación contractual dependen del precio de cierre en una determinada fecha. Cfr. PERDUE, "Manipulation of futures", cit. nota $\mathrm{n}^{\circ} 74$, pp. 345 y ss. Igualmente, cfr. THEL, "\$ 850,000 in Six", cit. nota ${ }^{\circ} 69$.
} 
Polit. crim. Vol. 8, № 15 (Julio 2013), Art. 3, pp. 64 - 127.

[http://www.politicacriminal.cl/Vol_08/n_15/Vol8N15A3.pdf]

lograr el incremento del precio del mismo. Otros participantes del mercado son llevados a error por el precio resultante, atraídos así a comprar el título. El manipulador vende luego su posición al precio inflado". 93

Aquí no hace falta mayor análisis para reconocer la injerencia. Por la vía del engaño, el agente obtiene un control sobre las actividades de participantes en el mercado. Estos participantes incrementan la demanda por el título, en la creencia de que existen buenas noticias relativas a los mismos. El incremento de la demanda eleva el precio del título. Ya no es directamente el poder económico del agente el que condiciona el resultado de la interacción de las fuerzas del mercado -como en el precedente caso marking the close-sino el poder económico aportado por terceros incautos o ignorantes del presupuesto aportado por el agente. Es por cierto una hipótesis de manipulación general. En cuanto a si además se plantea una manipulación especial, debe decirse que la distorsión será la regla, pero tampoco en este caso puede considerarse necesaria. Aunque en la práctica resulta muy extraño, puede concebirse el caso de quien "engaña" a terceros participantes en el mercado para llevarlos a ejercer su fuerza económica en el sentido y grado que él -con correcta y mejor información- reconoce apropiado. En este caso el agente se sustituye a los terceros en la valoración del instrumento -imponiendo, a través del engaño, la propia- pero nada obsta a que sus valoraciones puedan en concreto resultar certeras, mientras que aquellas asumidas por los terceros revelarse inadecuadas. Así sucederá en el caso del manipulador que considere que el precio correcto (=valor de inversión) de un determinado instrumento es cercano a 15 (mientras que el mercado lo reconoce sólo en 10) y que proceda a manipular el precio hacia el alza, con el fin de evitar que la compañía emisora del título se vea financieramente castigada por lo que considera una errónea apreciación del mercado. Si su apreciación relativa al valor de inversión fuese acertada, no podría por cierto hablarse de manipulación distorsionadora, pero no por ello su conducta dejaría de ser manipulativa en términos de injerencia.

Digámoslo en términos más plásticos: si se engaña a alguien que se halla en error, puede obtenerse su objetivo acercamiento a lo intersubjetivamente reconocido como correcto, pero ese acercamiento se revelará impersonal, no libre, no participado.

\subsubsection{Abusive squeeze.}

Examinemos en tercer lugar una tipología clásica de los mercados de derivados, como es el abusive squeeze. El CESR lo ha definido como:

Aquel que "involucra a un sujeto o a varios con una influencia significativa sobre la demanda, la oferta o los mecanismos de distribución de un determinado instrumento financiero y/o producto subyacente a un instrumento derivado, quien o quienes abusan o explotan su posición dominante de manera de distorsionar sustantivamente el precio al que otros deben entregar, recibir o aplazar la entrega del instrumento o producto en cumplimiento de sus obligaciones contractuales (debe notarse que la misma interacción de oferta y demanda puede $-\mathrm{y}$ a menudo lo hace- conducir a una contracción del mercado para el instrumento, pero esto no significa por si mismo

\footnotetext{
${ }^{93}$ Traducción por el autor desde el inglés, a partir de su formulación en el punto 4.13 b) del CESR/04-505b.
} 
LONDOÑO, Fernando. "Ilícito de manipulación bursátil: fenómeno y lesividad. Aspectos de política sancionatoria".

manipulación del mercado; ni tampoco la sola posesión de una influencia significativa sobre la oferta, la demanda o los mecanismos de distribución de un instrumento o producto constituye por sí sola manipulación del mercado).".94

Es evidente que la esencia de esta tipología radica en la idea de injerencia o control; a saber, el control de una de las fuerzas del mercado (la oferta), de manera de poder imponer (squeeze: estrujar) un determinado precio a los demandantes (típicamente short sellers). Es la hipótesis manipulativa más cercana a una conducta contraria a la libre competencia o monopólica. Más difícil resulta decidir sobre si hay además manipulación especial. La definición CESR utiliza precisamente la expresión distort. Con todo, la respuesta no es fácil, pues mediante el efectivo control de la oferta, el manipulador ha generado una mutación real; es decir, en el mundo real. De allí que no pueda en principio decirse que el precio impuesto (abusivamente "estrujado") se aleja o no se condice con las condiciones actuales de la oferta o del mercado. El mercado, así como se halla configurado en ese momento -esto es, en el puño del manipulador- viene a dar con un precio que efectivamente refleja esa condición. El manipulador, "apropiándose" de la oferta, ha alterado la realidad subyacente (el valor del instrumento demandado por los short sellers) y el precio se conforma perfectamente a esa nueva realidad. El precio la refleja adecuadamente: es el precio impuesto por quien tiene de facto el poder para imponerlo.

Nótese que la situación no es diversa al caso de un agente que proceda a destruir o a retirar de mercado importantes partidas del bien sobre el que recae la oferta. ${ }^{95}$ Aquí en efecto el bien -que antes abundaba- resulta ahora escaso. El precio será entonces correspondientemente superior. ¿No podrá entonces verse jamás una manipulación especial en estos casos? La respuesta sin embargo debe ser afirmativa. La realidad hipotética aquella que habría podido existir de no haber mediado la toma de control- debe primar por sobre la nueva realidad modelada por el agente. La violación de un deber de no injerencia abusiva -se asume el carácter normativo de la libertad del mercado como presupuesto de sistema- no puede ciertamente cancelar lo que ha llegado a ser; pero si ese deber ha de tener un sentido racional, entonces no podrá obviarse el respectivo juicio de no correspondencia. Así, podrá decirse que el precio ha sido conducido (manipulado) de manera de alejarlo del nivel que razonablemente habría sido esperable dadas las condiciones anteriores a la violación del deber. Se capta en todo caso que la clave está en una correcta definición del deber, de modo que la relación entre "abuso" y "distorsión" no resulte artificiosa o meramente circular.

\subsubsection{Scalping: una clásica information based manipulation.}

Consideremos ahora una clásica manipulación informativa, así como descrita por el CESR:

"Difusión de información de mercado falsa o engañosa a través de los medios de comunicación, incluyendo internet o por cualquier otro medio (en algunas

\footnotetext{
${ }^{94}$ Traducción por el autor desde el inglés, a partir de su formulación en el punto 4.12 c) del CESR/04-505b.

${ }^{95}$ Cfr. la hipótesis b) del apartado 4.14 del documento CESR 04-505, equivalente a la letra b) del apartado 4 de la Comunicación CONSOB n. DME/5078692 del 29-11-2005. Se trata de una hipótesis catalogable como action-based.
} 
Polít. crim. Vol. 8, № 15 (Julio 2013), Art. 3, pp. 64 - 127.

[http://www.politicacriminal.cl/Vol_08/n_15/Vol8N15A3.pdf]

jurisdicciones esto es conocido como 'scalping'). Esta acción es realizada con la intención de mover el precio de un título, de un contrato derivado o del activo subyacente en una dirección que resulta favorable a la posición sostenida o a la transacción planificada por la persona que difunde la información". 96

Que se trate aquí de una modalidad de injerencia no puede ponerse en duda: las fuerzas del mercado se mueven en el sentido perseguido por el agente, alimentadas por la información que éste suministra. Se trata además de un caso de distorsión, por excelencia. En efecto, el precio se mueve en el sentido opuesto al correspondiente; así, por ejemplo, si se tratase de una sociedad financieramente frágil y poco productiva, la información falsa será idónea para inducir al mercado a cotizar sus acciones a mejor precio (o bien a asignarle una tasa de interés más baja a sus bonos); por el contrario, una sociedad robusta y productiva podrá verse penalizada con un peor precio para sus acciones (o bien con una tasa de interés más elevada para sus bonos). La asignación de los recursos obedecerá entonces a una "lógica ilógica": una distorsión, precisamente.

\subsubsection{La estabilización de precios en mercados de primera emisión.}

Resulta por fin indispensable referirse a aquella hipótesis que los ordenamientos jurídicos tienden a reconocer como preliminarmente lícita o no sancionable, pese a tratarse propiamente de una forma de manipulación. ${ }^{97}$ ¿En qué sentido lo es y por qué ha de legitimarse bajo determinadas condiciones?

Según reza el considerando 11 del Reglamento (CE) No. 2273/2003:

"Las operaciones de estabilización tienen principalmente el efecto de proporcionar apoyo para el precio de una oferta de los valores de que se trate durante un tiempo limitado, si se producen bajo presión de las ventas, aliviando de este modo esa presión generada por los inversores a corto plazo y manteniendo un mercado ordenado de los valores de que se trate." 98

Como se puede comprender, este "apoyo" al precio de los valores ofrecidos se traduce en una instancia de control de un segmento de las fuerzas del mercado primario, marcando una clara forma de injerencia. Así, los estabilizadores operan negociaciones con el fin de evitar

\footnotetext{
${ }^{96}$ Traducción por el autor desde el inglés, a partir de su formulación en el punto 4.13 b) del CESR/04-505b.

${ }^{97}$ Por lo que se refiere a la situación chilena, la autorización es explícita en el inciso segundo del art. 52 de la $L M V$, con el reenvío de rigor a fuentes de rango administrativo emanadas por la autoridad reguladora; a saber, por de pronto, la Circular $N^{\circ} 1644$ de la Superintendencia de Valores y Seguros. Véase igualmente la normativa Market-Maker de la Bolsa de Comercio de Santiago. Ilustrativas resultan en la especie las "Reglas para prevenir y combatir el uso de información privilegiada y la manipulación de mercado", elaboradas por los Comité de Regulación y Autorregulación de las Bolsas de Comercio de Santiago y Electrónica de Chile, de abril de 2009, apartado V. $1 . \quad$ B. $\quad$ Disponible en http://www.bolsadesantiago.com/Normativas $\% 20$ Comite $\% 20$ Regulacion/Reglas $\% 20$ sobre $\% 20$ informaci $\%$ C3 $\%$ B3n $\% 20$ privilegiada.pdf.

${ }^{98}$ Dando cuenta de la ratio económica de la tipología, el considerando 11 prosigue: "Esto es del interés de los inversores que hayan suscrito o comprado esos valores en el contexto de una distribución importante, así como de los emisores. De esta manera, la estabilización puede contribuir a aumentar la confianza de inversores y emisores en los mercados financieros." (REGLAMENTO (CE) No 2273/2003, considerando 11).
} 
LONDOÑO, Fernando. "Ilícito de manipulación bursátil: fenómeno y lesividad. Aspectos de política sancionatoria".

la depresión de los precios de los instrumentos distribuidos, allí donde se produzca un desequilibrio entre oferta y demanda, normalmente a causa del gran número de títulos emitidos y las ulteriores ventas de especuladores a la baja (short sellers). Es un control que se realiza "en el interés del mercado" y en respeto por lo que se considera como un adecuado valor de inversión del título por primera vez emitido. Con todo, lo anterior no muta su estructura objetiva de naturaleza manipulativa.

La especulación y las presiones de venta pueden deprimir el precio de los instrumentos en primera emisión, lo que -en la medida que tiende a ser estructural- implicaría un fuerte desincentivo para el recurso al mercado de valores como opción de financiamiento de las empresas. Se hace necesario entonces justificar una injerencia en defensa del propio interés en el desarrollo de los mercados de valores. En principio ningún interviniente puede arrogarse el control de bienes públicos, pero si el bien corre peligro, entonces puede ser en interés de muchos, el control por unos pocos (siempre que dicho control se ajuste al marco de legitimidad previamente acordado, por cierto). El precio de un instrumento bursátil (y, por extensión, el interés en el desarrollo del propio mercado de valores) es este "bien público" que puede correr peligro si es entregado a la espontánea suerte de las mecánicas y fuerzas operativas en contextos de primera emisión (en los que el lado de la oferta puede exceder al de la demanda).

Es evidente entonces que estamos en presencia de una modalidad manipulativa en sentido general (injerencia). Pero debería resultar igualmente evidente que en la estabilización no hay distorsión; al menos no en principio, así como autorizada o legitimada, en consonancia con un precio que se ha juzgado como adecuado al valor d inversión del instrumento. Es para salvar el interés del mercado que se confieren poderes estabilizadores; si ellos se abusan -si la estabilización se utiliza para conducir al mercado a precios "inadecuados"sólo entonces podrá hablarse de distorsión.

De lo dicho hasta aquí se desprende naturalmente que para que la estabilización pueda reputarse manipulativa sólo en sentido general (y no como forma de distorsión), ella debe cumplir con determinadas condiciones, normalmente fijadas en abstracto por ley o por las autoridades reguladoras (y luego autorizadas en concreto por las mismas). La legislación europea por ejemplo dispone tres categorías de condiciones: ${ }^{99}$ temporales (estabilización autorizada sólo en determinados períodos), informativas (estabilización autorizada sólo si comunicada al público) y de nivel de precios (estabilización autorizada sólo si funcional a un determinado precio, previamente determinado). ${ }^{100}$

Interesa destacar, antes de cerrar este punto, que la problemática de la estabilización introduce nuevamente el problema del valor real o correcto de los instrumentos bursátiles. Así, allí donde la estabilización se mueva fuera de un determinado rango de precio (previamente valorado, autorizado y comunicado sobre una base objetiva), allí podrá eventualmente imputarse manipulación en sentido especial (distorsión).

\footnotetext{
${ }^{99}$ Art. 7 y ss. REGLAMENTO (CE) No 2273/2003

100 Para las condiciones imperantes en el modelo americano en el marco de la Regulation M, cfr. LOSS/SELIGMAN, Securities Regulation, cit. nota ${ }^{\circ}$ 62, cap. 10-E. Por lo que se refiere a la situación chilena, véase la nota $n^{\circ} 97$ de este trabajo.
} 
Polít. crim. Vol. 8, № 15 (Julio 2013), Art. 3, pp. 64 - 127.

[http://www.politicacriminal.cl/Vol_08/n_15/Vol8N15A3.pdf]

\subsubsection{Conclusiones preliminares.}

Una primera aproximación al fenómeno a partir de la observación de algunos casos o tipologías consideradas especialmente representativas parece demostrar que la manipulación se manifiesta siempre como (i) injerencia/control en la formación de los precios; $\mathrm{y}$, en determinados casos, adicionalmente como (ii) injerencia/control distorsionador de los precios. A la primera manifestación se le ha denominado aquí manipulación en sentido general; a la segunda, manipulación en sentido especial.

\subsection{Una primera aproximación a la lesividad del fenómeno.}

Hasta aquí se ha expuesto una representación del concepto de manipulación, obtenida a partir del análisis de algunas tipologías de casos. Así se ha llegado a los conceptos de manipulación en sentido general y de manipulación en sentido especial.

Ahora bien, si se atiende ya al plano de la lesividad -vinculando la manipulación y su impacto en el mercado- ${ }^{101}$ es posible afirmar que a la primera forma de manipulación puede asociarse, preliminarmente, una incidencia negativa en las condiciones de libertad y de paridad del mercado (por vía de la injerencia o control), mientras que a la forma de manipulación especial puede enlazarse -adicionalmente- una lesividad en el plano de las condiciones de inteligencia e integridad del mercado (por vía de la distorsión del precio con respecto al valor real o valor de inversión).

Dicho en términos menos sintéticos: la manipulación especial (distorsionadora) se sitúa como una lesión a la capacidad (=inteligencia) del mercado para asignar eficientemente los recursos financieros desde las unidades en superávit a las unidades en déficit. A esa capacidad de asignación eficiente de recursos financieros suele denominársele eficiencia distributiva (=allocative efficiency, en la terminología anglosajona de sector). ${ }^{102}$

\footnotetext{
${ }^{101}$ Considérese aquí lo expuesto en la primera sección de este trabajo, por lo que se refiere a la descripción del sentido y funciones del mercado de valores.

${ }^{102}$ Cfr. sobre el concepto de eficiencia distributiva, sintéticamente, PERRONE, "Información", cit. nota n ${ }^{\circ}$ 18, pp. 197 y ss. Entendida como la capacidad "to allocate funds to higher valuing users", cfr. EASTERBROOK, Frank. H.; FISCHEL, Daniel. R., The Economic Structure of Corporate Law, Cambridge: Cambridge University Press, 1991, p. 299. Una explicación muy clara de la idea de "efficienza allocativa" se halla también en ONADO, Marco, Economia e regolamentazione, cit. nota n¹8, pp. 24-30: “Conectando al sujeto ahorrante con aquél que invierte, el sistema financiero cumple una función de asignación [de capital] extremadamente importante. En efecto, este sistema distribuye principalmente recursos (poder de adquisición) que serán utilizados para producir bienes y recursos en el futuro. De este modo se alimenta el corazón del proceso de crecimiento de un sistema económico. Es, por tanto, crucial que los recursos sean asignados; es decir, destinados a un uso capaz de maximizar el crecimiento futuro." (op. cit., pp. 24-25) (...) "Emitiendo los instrumentos representativos de deuda necesarios para cubrir el propio déficit financiero, las empresas obtienen recursos que pueden ser utilizados para adquirir maquinarias y establecimientos que en futuro aumentan la capacidad productiva y las utilidadas" (...) "Los recursos que las empresas obtienen para invertir, son el fruto de opciones adoptadas por inversionistas individuales que deciden invertir su proprio activo del balance en títulos emitidos por la sociedad $x$ antes que por la sociedad $y$, o bien son opciones de bancos que deciden conceder préstamos a ciertas empresas en lugar de a otras. En este sentido, el sistema financiero cumple la función de asignación [de capital] (...) (op. cit., p. 29). Y luego todavía: “Con su comportamiento, los operadores del sistema financiero deciden qué decisiones de inversión pueden materializarse y cuáles no. En consecuencia, el corazón del proceso económico - es decir, la acumulación del capital - depende del
} 
LONDOÑO, Fernando. "Ilícito de manipulación bursátil: fenómeno y lesividad. Aspectos de política sancionatoria".

Por su parte, la capacidad o idoneidad de la manipulación especial (distorsionadora) para afectar la dimensión de la eficiencia distributiva puede describirse con excepcional eficacia del siguiente modo, a partir de una formulación más general que Easterbrook y Fischel desarrollan al explicar la relación entre fraude y daño en la economía:

"Las fuentes de daño [harm] corresponden a las respectivas reducciones en la eficiencia distributiva [allocative efficiency] de la economía. Así, una incompleta o inexacta entrega de información relativa a las inversiones, conduce a las personas a invertir en los proyectos equivocados; se gastarán más recursos de los necesarios para producir bienes y servicios. Por otra parte, una incompleta o inexacta entrega de información puede enviar señales erróneas sobre el riesgo, y esto distorsiona la posibilidad de elección entre inversión y consumo."

¿Lo afirmado en este apartado lleva a pensar que sólo la manipulación especial resulta indeseable, porque lesiva? La respuesta ya se ha anticipado esquemáticamente supra 2.2: si el mercado se concibe como una entidad libre y si esa libertad es también presupuesto de una aspiración igualitaria, entonces también la mera manipulación general o no distorsionadora aparecerá como indeseable, porque potencialmente lesiva. En este segundo supuesto se trata en todo caso de una lesividad de connotación menos sustantiva.

Conviene ahora dar cuenta de un antecedente que viene a confirmar la validez de estas conclusiones preliminares.

\subsection{La doctrina estadounidense de la primera mitad del novecientos: una confirmación de las conclusiones preliminares.}

Resulta interesante verificar si los mencionados resultados son compatibles con la visión de la primera doctrina estadounidense que se ocupó del argumento. ${ }^{104} \mathrm{Me}$ refiero

funcionamiento del sistema financiero. Sobre éste, por tanto, pesa la responsabilidad de asegurar que los recursos sean destinados a los usos más eficientes (aquellos que maximizan la productividad esperada del capital o, dicho en otros términos, la rentabilidad esperada de las empresas financiadas" (op. cit. p. 29; traducción desde el italiano por el autor). Por su parte, en ONADO, Mercati, cit. nota n 18 , p. 359 y ss., se halla una explicación de las principales formas de eficiencia del mercado de capitales: (1) informativa: "cuando en cada momento los precios de los títulos reflejan completamente y en modo correcto todas las informaciones disponibles" (p. 363, 364, op. cit.); (2) valorativa o fundamental: "se entiende como la capacidad de los precios de representar el valor neto de los flujos de caja esperados" (p. 367, op. cit.) (3) distributiva [allocativa]: la idea de que "los recursos provenientes de las unidades en surplus deben ser colocados a disposición de los proyectos que representan la máxima rentabilidad esperada” (p. 370, op. cit.). Cfr. tb. ALLEN, William T., "Securities Markets as Social Products: The Pretty Efficient Capital Market Hypothesis", 28 Iowa J. Corp. L. p. 556.

103 EASTERBROOK/FISCHEL, The Economic Structure, cit. nota n 102, p. 324: "The (...) sources of harm are related reductions in the allocative efficiency of the economy. One is that incomplete or inaccurate disclosure about investments leads people to invest in the wrong projects. They will spend "too much" in resources to produce goods and services. The other is that incomplete or inaccurate disclosure can send the wrong signals about risk, and this distorts the choice between investment and consumption".

${ }^{104} \mathrm{El}$ énfasis en la doctrina estadounidense de la primera mitad del siglo XX se justifica desde que en ese período se verificó una primera reflexión profunda acerca de las razones de la legislación que orgánicamente se ocupó de la regulación del mercado de valores tras el desastre del '29. (SA 1933 y SEA 1934). En todo caso vale la pena advertir que en los desarrollos doctrinarios posteriores -contemporáneos- no he hallado tesis que contradigan el punto que aquí se pretende demostrar. 
Polít. crim. Vol. 8, № 15 (Julio 2013), Art. 3, pp. 64 - 127.

[http://www.politicacriminal.cl/Vol_08/n_15/Vol8N15A3.pdf]

principalmente a aquella doctrina de los años '30 del novecientos, fuertemente sensibilizada por los acontecimientos del crack del '29. Puede considerársele sin duda como la literatura fundacional en el sector, habida cuenta de la notable influencia que habrían de tener sobre el ulterior desarrollo del campo los cuerpos legales materia de dicha doctrina; a saber, la Securities Act de 1933 y la Securities Exchange Act de $1934 .^{105}$

Considérese por ejemplo este decisivo pasaje de la Columbia L. Rev. Note de 1934:

"La manipulación, así como usualmente es ejecutada, se desentiende del valor de inversión de un instrumento y realiza una divergencia entre ese valor y el precio. Con todo, bajo la teoría de que el precio ha de determinarse por el regateo en un mercado libre, no es necesaria la consideración de esos elementos, desde que cualquier interferencia en el precio habrá de desaprobarse, con prescindencia de una correlación con el valor de inversión. En los Estados Unidos las cortes adoptan esta lógica en su rechazo a requerir al gobierno prueba sobre el "valor real" de los instrumentos manipulados o bien de un perjuicio concreto para los compradores; pero desde que el perjuicio debe acreditarse en el marco de una acción civil, toca allí hacerse igualmente cargo del valor real". 106

El pasaje citado demuestra la coexistencia de dos fenómenos. Por una parte la operación de una "divergencia entre valor de inversión (real) y el precio" y por la otra una restricción del "mercado libre", que opera sin perjuicio de la demostración de una divergencia entre precio y valor real. Estos dos fenómenos denunciados coinciden precisamente con los conceptos de manipulación especial (en el que la distorsión radica precisamente en un alejamiento del precio con respecto al valor real o valor de inversión) y manipulación general (en el que la sola injerencia altera las condiciones -o presupuestos- de libertad y paridad del mercado).

Otra fuerte confirmación de la visión aquí manifestada puede también hallarse en AA. VV., Market Manipulation and the Securities Exchange Act (Comment), en Yale L.J., n. 46, 1937, pp. 624-625, en el que igualmente se aprecia la dicotomía injerencia/desviación y la consecuente dicotomía en el plano de la lesividad. No se trata en todo caso -ni allí ni en la Columbia Note de 1934- de una tentativa de conceptualización explícita en el anotado

\footnotetext{
${ }^{105}$ En el marco de esta literatura tradicional estadounidense, cfr. especialmente AA. VV., "Manipulation of the Stock Markets under the Securities Laws (Note)", U. Pa. L. Rev., n. 99 (1951), pp. 651 y ss.; AA. VV., "Market Manipulation and the Securities Exchange Act (Comment)", Yale L.J., n. 46 (1937), pp. 624 y ss.; AA. VV., "Regulation of Stock Market Manipulation (Comment)", Yale L.J., n. 56 (1947), pp. 509 y ss.; AA.VV., "Illegality of Stock Market Manipulation (Note)", Colum. L. Rev. (1934), vol. 34, pp. 500 y ss.; BERLE, "Liability", cit. nota $n^{\circ}$ 91, pp. 264 y ss.; BERLE, "Stock Market", cit. nota n 86, pp. 393 y ss.; MATHIAS, "Manipulative Practices", cit. nota $\mathrm{n}^{\circ}$ 86, pp. 7 y ss.; MOORE, James M.; WISEMAN, Frank M., "Market Manipulation and the Exchange Act", U. Chi. L. Rev., n. 2 (1934), pp. 46 y ss.

${ }^{106}$ AA.VV., "Illegality", cit. nota $\mathrm{n}^{\circ} 105$, p. 505. El original reza: "Manipulation, as usually conducted, disregards the investment value of the stock and works a divergence between that value and price. However, under the theory that price is to be set by higgling in a free market, these elements need not be considered since any tampering with price would have to be disapproved regardless of a correlation with investment value. In the United States the courts adopt this rationale in their refusal to require proof by the government of the "real value" of stock manipulated or of actual damage to buyers. But since damage must be shown in a civil action, real value must there be dealt with."
} 
LONDOÑO, Fernando. "Ilícito de manipulación bursátil: fenómeno y lesividad.

Aspectos de política sancionatoria".

sentido, de manera que, si alguno lo tiene, el mérito del presente trabajo puede identificarse con una puesta en evidencia de la referida distinción conceptual. ${ }^{107}$

\subsection{Profundizando en el fenómeno: una caracterización más completa de la manipulación a partir de un marco taxonómico (atendiendo principalmente al punto de vista del mecanismo medial).}

Lo dicho en los apartados precedentes, especialmente en el apartado 2.3., hace necesaria una caracterización más completa de las modalidades o tipologías de manipulación. Se trata aquí precisamente de proponer lo que se había anticipado: una taxonomía del fenómeno a modo de un marco general en el que colocar las diversas tipologías a partir de criterios de selección relevantes.

En términos esquemáticos, puede proponerse el siguiente marco taxonómico de conductas de manipulación:

\subsubsection{Perspectivas válidas para un marco taxonómico.}

\section{a) Distinción conforme a lesividad.}

Como ya se ha expuesto, puede aquí distinguirse entre injerencia o control (manipulación general) y distorsión o desviación (manipulación especial). Mediante las formas de mero control se alteran las condiciones de libertad $e$ igualdad del mercado (lesividad marcadamente formal). Mediante las formas de distorsión se alteran las condiciones de inteligencia del mercado, lo que en definitiva viene a afectar la eficiencia en la distribución o asignación de los recursos financieros.

b) Distinción conforme al mecanismo abstracto de actuación de la manipulación bursátil (el mecanismo de interacción entre conducta y precio).

El control sobre los mecanismos de formación de los precios puede ejercerse por vía indirecta (mediata) o directa (inmediata). La vía indirecta representa una forma de control a través de terceros participantes en el mercado; a su vez, ella puede operar (=mecanismo) bajo dos modalidades diversas: mediante formas de engaño/falsedad ${ }^{108}$ o por la vía de un abuso de posición de poder de mercado. ${ }^{109} \mathrm{El}$ control directo se ejerce mediante un poder de mercado; es decir, actuando en el precio directamente, mediante operaciones del propio agente o relacionados. ${ }^{110}$

\footnotetext{
${ }^{107}$ En un plano diverso, resulta muy interesante hacer notar que, según da cuenta el propio pasaje de la Columbia Note de 1934 supra transcrita, el concepto general de manipulación -la idea de que los presupuestos de acceso a un libre mercado han sido alterados- habría permitido a las cortes estadounidenses eludir la (compleja) prueba de la divergencia entre valor real y precio, al menos por lo que se refiere a las finalidades de la jurisdicción penal. Podría entonces encontrarse en sede práctica-probatoria el fundamento de la distinción.

${ }^{108}$ Como en el caso del ya descrito scalping o como es habitual en los esquemas de pump and dump: supra 2.3.2.

${ }^{109}$ Como en el caso de los aludidos squeezes o corners: supra 2.3.3.

${ }^{110}$ Como en el caso del ya descrito marking the close: supra 2.3.1.
} 
Polít. crim. Vol. 8, № 15 (Julio 2013), Art. 3, pp. 64 - 127.

[http://www.politicacriminal.cl/Vol_08/n_15/Vol8N15A3.pdf]

Nótese la existencia de una tendencial correlación entre falsedad/engaño (como mecanismo de actuación) y distorsión o desviación (en el plano de la lesividad). ${ }^{111}$

\section{c) Distinción conforme al concreto medio empleado en la manipulación bursátil.}

Conforme al medio concreto empleado en la tentativa de alteración de los precios, puede distinguirse entre la manipulación informativa (=info \& action based) -que opera siempre por vía mediata, de acuerdo a la clasificación anterior- y la manipulación operativa o manipulación mediante transacciones (=trade based), que puede operar tanto por vía inmediata (en casos de poder de mercado), como por vía mediata (tratándose de transacciones idóneas para engañar al mercado o inducir a los inversionistas a tomar posiciones respecto al título en cuestión). ${ }^{112}$

d) Conforme al mecanismo de obtención de provecho o lucro.

Aquí es posible distinguir entre aquellas manipulaciones en las que el agente busca alcanzar el provecho de manera extrínseca al mercado (manipulaciones contract based) y aquellas en las que el provecho es alcanzado de modo intrínseco al mercado (manipulaciones no contract based, lucrativas en función del directo mayor valor de las posiciones alcanzadas o del spread resultante de los respectivos intercambios u offsetting trades). ${ }^{113}$

\subsubsection{Ulterior explicación del marco taxonómico.}

Conviene ahora desarrollar una breve explicación de lo que hasta aquí se ha planteado sólo esquemáticamente.

No pueden captarse los efectos (lesividad) sin referencia a las causas o mecanismos de actuación, y es en este plano que se intenta aquí una más completa caracterización de las tipologías de manipulación aludidas en los puntos (ii) y (iii) precedentes.

Si toda manipulación bursátil es representativa de -cuanto menos- una tentativa de injerencia/control sobre la formación de los precios de los instrumentos transados en Bolsa, entonces una primera clasificación útil se obtiene a partir de la captación de los mecanismos de injerencia. Concretamente: ¿cómo se puede injerir en la formación de los

\footnotetext{
${ }^{111}$ Considérese sin embargo el caso de la AMP (=accepted market practice) denominada "valuation transaction on the bond market on the Vienna Stock Exchange", en el que esta relación no se da, en la medida que las transacciones ficticias -en el sentido de ejecutadas por una misma parte en calidad de compradoravendedora, sin por tanto la intención de tomar una posición respecto al instrumento o título- no conducen a una alteración del precio considerado adecuado al valor del instrumento. Puede hallarse una explicación detallada de esta AMP en http://www.esma.europa.eu/system/files/AMP_Austria.pdf, context en el que se reconoce que "members of the Vienna Stock Exchange are allowed to carry out a "Valuation transaction" by acting for both the buyer and the seller in government bonds and in bonds where they are the issuer or are closely related to the issuer, in order to provide the market with a reference price".

${ }^{112}$ Cfr. explicación en nota ${ }^{\circ} 54$ de este trabajo. En Chile, el caso de la Corredora MBI puede encuadrarse bajo esta categoría. Cfr. resoluciones exentas 402 y 501 de la SVS, de 8 de septiembre de 2006 y 23 de octubre de 2006, respectivamente, con sanción por infracción a los artículos 52 y 53 inciso primero de la $L M V$.

${ }^{113}$ Cfr. explicación adicional en notas $n^{\circ} 69$ y 70 de este trabajo.
} 
LONDOÑO, Fernando. "Ilícito de manipulación bursátil: fenómeno y lesividad. Aspectos de política sancionatoria".

precios? Si los precios son el resultado de la interacción entre oferentes y demandantes (=concurrentes en el mercado), entonces es posible injerir en los mismos básicamente: (a) condicionando la conducta de oferentes/demandantes; (b) colocándose el propio agente como oferente/demandante; es decir, mediante el ejercicio de un poder de mercado (market power).

Ahora bien, la primera modalidad ofrece a su vez dos formas alternativas: pues es posible condicionar/inducir (manipular) la conducta de terceros (participantes del mercado en este caso) ya por (a.1) injerencia en los presupuestos cognitivos de su actuación (engaño, básicamente), ya por (a.2) constricción o abuso de posición.

Al primer tipo (a.1) pertenecen siempre las denominadas info based manipulations o manipulaciones informativas (=descritas en el art. 1.2.c. de la Directiva MAD). ${ }^{114}$ Desde esta perspectiva -es decir, considerando el mecanismo de injerencia o control sobre los precios- es posible redefinir las info based manipulations como deceptive based o manipulaciones mediante formas de engaño. De allí que también las action based manipulations ${ }^{115}{ }^{116}$-a saber, manipulaciones realizadas mediante acciones engañosas o artificiosas, ejecutadas fuera del mercado, en el seno de la empresa o en el "mundo real"puedan considerarse igualmente como una especie del género info based. Pero aún más: desde esta perspectiva también algunos esquemas de actual trade based manipulations $(=\text { descritos en el art. 1.2.a.i de la Directiva } M A D)^{117}{ }^{118}$-típicamente asociables a las modalidades de poder de mercado o de injerencia directa (supra b)- pueden aparecer descritas como deceptive-based o info-based. Lo anterior, en cuanto las transacciones transmiten siempre información al mercado. ${ }^{119}$ Sería por ejemplo el caso de una conducta de pump and dump puramente operativa (sin recurso a información o publicidad falsa), en

\footnotetext{
${ }^{114}$ En Chile, el art. 61 de la $L V M$ describe una conducta encuadrable en esta categoría: “Artículo 61. El que con el objeto de inducir a error en el mercado de valores difunda información falsa o tendenciosa, aun cuando no persiga con ello obtener ventajas o beneficios para sí o terceros, sufrirá la pena de (...)". La conducta descrita en la segunda parte del inciso segundo del art. 53 de dicha ley es igualmente reconducible a esta categoría: “(...) ninguna persona podrá (...) inducir o intentar inducir a la compra o venta de valores, regidos o no por esta ley, por medio de cualquier acto, práctica, mecanismo o artificio engañoso o fraudulento". En fin, las hipótesis de falsedad informativa de las letras a) y f) del art. 59 de la $L M V$ - si bien insertas en cánones de figuras de mera falsedad informativa, no necesariamente manipuladoras del mercado secundario y primario, respectivamente - pueden muy bien asociarse a esta categoría, según se ha ya expuesto en la Introducción de este trabajo.

${ }^{115} \mathrm{Cfr}$. explicación en nota 54 de este trabajo, con referencia a ALLEN/GALE, "Stock-Price", cit. nota $n^{\circ} 50$.

${ }^{116}$ En Chile, comprendidas en principio por la segunda parte del inciso segundo del art. 53 de la $L V M$ : “( ...) ninguna persona podrá (...) inducir o intentar inducir a la compra o venta de valores, regidos o no por esta ley, por medio de cualquier acto, práctica, mecanismo o artificio engañoso o fraudulento.”.

${ }^{117}$ Cfr. explicación en nota $n^{\circ} 54$ de este trabajo, con referencia a ALLEN/GALE, "Stock-Price", cit. nota $n^{\circ}$ 50 .

${ }^{118}$ En Chile, claramente comprendidas por la prohibición general del inciso primero del art. 52 de la $L V M$ : "Artículo 52.- Es contrario a la presente ley efectuar transacciones en valores con el objeto de estabilizar, fijar o hacer variar artificialmente los precios.".

${ }^{119}$ Cfr. los casos reportados en ALLEN/GALE, "Stock-Price", cit. nota n 50 y AGGARWAL/WU, "Stock Market", cit. nota $\mathrm{n}^{\circ}$ 50. Una explicación clásica y heurística de los mecanismos de actuación de transacciones e informaciones en la formación de los precios puede hallarse en GILSON/KRAAKMAN, "The Mechanism", cit. nota $n^{\circ} 39$.
} 
Polít. crim. Vol. 8, № 15 (Julio 2013), Art. 3, pp. 64 - 127.

[http://www.politicacriminal.cl/Vol_08/n_15/Vol8N15A3.pdf]

la que el agente alcanza su objetivo mediante la burbuja especulativa que sus propias transacciones causan en la cotización del título. ${ }^{120}$

Por su parte, la segunda modalidad de condicionamiento de las conductas de los participantes del mercado (a.2) es la constricción o abuso de posición. A ella es posible reconducir las hipótesis de price fixing, como lo son los corners y squeezes ${ }^{121}$ (=comprendidas en el art. 1.2.a.ii de la Directiva $M A D$ ).

Por fin, como se ha anticipado, es posible injerir directamente en la formación de los precios, en calidad de demandantes/oferentes en el mercado (b). Aquí ya no hay un condicionamiento de la conducta de terceros; simplemente se toma una posición de cara a una conducta libre o pre-ordenada de un tercero (contraparte en la operación), con miras a alcanzar un determinado nivel de precio. Es decir, se interviene en el mercado y se ejerce un poder en el mismo con miras a la modificación de un precio. Así, se compra o se vende en el mercado de manera de conducir el precio hasta el nivel deseado. Es lo que sucede con las denominadas actual trade based manipulations. ${ }^{122}$

Si las hipótesis descritas en (a) reclaman una semejanza -figurativa, se entiende- con modalidades de perjuicio patrimonial o apropiación autolesivas, que operan con colaboración o interacción de la víctima (estafa, paradigmáticamente), aquí en (b) la analogía es con la figura de hurto, pues opera una "apropiación directa y clandestina" del precio. La figura ya descrita de marking the close responde a este esquema.

Cabe en todo caso considerar aquí una sub-especie de (b); a saber, la posibilidad de injerir en la formación de los precios no ya asumiendo una posición de demandante/oferente, sino (b.i) aparentando que se ha asumido una posición semejante. Obedecen a este esquema las manipulaciones basadas en formas de engaño (deceptive based manipulations) del tipo transacciones ficticias o simuladas (=fictious trade based, como por ejemplo wash sales y matched orders). ${ }^{123}$

a) Excurso: operaciones lícitas y operaciones manipulativas.

En este contexto, cabe aludir brevemente a un aspecto de tradicional preocupación doctrinaria y práctica en relación con las formas puras de manipulación operativa descritas en (b) (actual trade based). ¿Cómo distinguir entre transacciones reales pero manipulativas y transacciones lícitas, en las que se ejerce poder de mercado, en sí idóneo para alterar los precios de mercado (por ejemplo, atendido el volumen de las operaciones o

\footnotetext{
${ }^{120} \mathrm{Cfr}$. descripciones de casos semejantes en AGGARWAL/WU, "Stock Market",cit. nota $\mathrm{n}^{\circ} 50$; y en ALLEN/GALE, "Stock-Price", cit. nota $\mathrm{n}^{\circ} 50$.

${ }^{121} \mathrm{Cfr}$. explicación supra apartado 2.3 .3 (abusive squeeze) y nota $\mathrm{n}^{\circ} 59$ (cornering).

${ }^{122}$ Cfr. explicación en nota $n^{\circ} 54$ de este trabajo. Es importante recordar en todo caso que, como se ha dicho, la actual trade based pueden también ofrecer rasgos de deceptive o fraud based. Cfr. casos reportados por ALLEN/GALE, "Stock-Price", cit. nota n 50 y AGGARWAL/WU, "Stock Market", cit. nota n 50.

${ }^{123}$ En principio subsumibles el art. 1.2.b. de la Directiva MAD. En la legislación chilena, con seguridad cubiertas en parte bajo el inciso primero del art. 53 de la $L V M$ chilena: "Artículo 53.- Es contrario a la presente ley efectuar cotizaciones o transacciones ficticias respecto de cualquier valor, ya sea que las transacciones se lleven a cabo en el mercado de valores o a través de negociaciones privadas."
} 
LONDOÑO, Fernando. "Ilícito de manipulación bursátil: fenómeno y lesividad. Aspectos de política sancionatoria".

las condiciones pactadas)? Quien -por legítimos motivos de necesidad de liquidezrequiere enajenar rápidamente grandes volúmenes de valores de un determinado emisor, puede representarse que sus ventas conducirán los precios a la baja (lo que -dicho sea de paso- le resultará perjudicial, de modo que tenderá a distribuir las ventas en un período mayor de tiempo). Si pese a ello ejerce abruptamente su poder de venta en el mercado, provocando una caída del precio, ¿incurre en una manipulación de tipo operativa?

Convengamos que la distinción entre operaciones lícitas y operaciones reales manipuladoras ha sido desde siempre problemática, probatoriamente al menos. Esa es la razón por la que algunos autores han incluso renunciado a reconocer la tipicidad de este tipo de conductas. ${ }^{124}$ Con todo, la distinción es posible -al menos conceptual y descriptivamente- y así lo han reconocido en general los ordenamientos dominantes, ya basando la distinción en (i) una exigencia subjetiva especial (=intención trascendente manipuladora); ${ }^{125}$ o bien (ii) a partir de una exigencia objetiva, relativa al carácter anormal o artificial del nivel de precio perseguido o alcanzado. ${ }^{126}$

Otra parece la sede más idónea para abordar el punto en detalle y tomar una posición definitiva al respecto, pero a título preliminar parece de recibo la tesis objetivizadora de la intención manipulativa, propuesta por Wendy C. Perdue para el mercado de futuros en Estados Unidos. ${ }^{127} \mathrm{La}$ intención trascendente manipuladora es allí reformulada como ausencia de una racionalidad económica explicable más allá de la persecución de un determinado nivel de precio. Esta tesis -ideada como alternativa a la tesis objetiva imperante para el mercado de futuros estadounidense bajo la forma de la acreditación del precio artificial o anormal-se desprende de la definición de manipulación ofrecida por la citada autora; a saber, "conducta que, en ausencia de un efecto en el precio del mercado, sería antieconómica o irracional". ${ }^{28}$ Como puede advertirse, la reconducción al (no) hallazgo de una razón económica que explique la operación resulta -especialmente- en una objetivización de la intención manipuladora del precio: su contracara objetiva. ${ }^{129}$

\footnotetext{
${ }^{124}$ Cfr. MUCCIARELLI, Francesco, “Aggiotaggio", en: ALESSANDRI, Alberto (Dir.), Il nuovo diritto penale delle società, Milano: Ipsoa, 2002, pp. 421-440, negando la tipicidad de este tipo de conductas bajo la legislación italiana vigente a la época de su comentario, considerando especialmente la imposibilidad de distinguir estas conductas de otras tantas lícitas, igualmente idóneas para alterar los precios del mercado.Cfr. igualmente, MUSCO, Enzo, I nuovi reati societari, Milano: Giuffrè, 2001, pp. 175 y ss.

${ }^{125}$ Así, en general, la técnica empleada en la sección 9 a SEA 1932 (=15 USCS $\S 78 i$, Manipulation of security prices), con referencia al "propósito para inducir a comprar o vender" valores. Similar técnica exhibe el inciso segundo del art. 53 de la $L M V$ chilena (=inducción a la compra o venta). En la misma línea, el artículo 52 de la $L M V$ chilena, que prohíbe efectuar transacciones "con el objeto de" efectuar alteraciones artificiales en los precios (si bien la referencia a la artificialidad parece colocarnos en un marco objetivo).

${ }^{126}$ Supuesta la no concurrencia de un motivo legítimo, al amparo de una práctica de mercado aceptada (=AMP, accepted market practice), como acontece en general en la esfera europea a partir del art. 1.2 a) i y ii de la Directiva $M A D$; o bien reconduciendo la prueba de la manipulación a la acreditación de un precio "artificial" o "anormal", como sucede en la práctica estadounidense para el mercado de futuros, al alero de la prohibición de manipulación contenida en la Sección 9 de la Commodity Exchange Act [=7 U.S.C. $\S$ $13(\mathrm{a})(2)]$.

${ }^{127}$ Cfr. PERDUE, "Manipulation of futures", cit. nota $\mathrm{n}^{\circ} 74, \mathrm{pp} .393$ y ss.

128 PERDUE, "Manipulation of futures", cit. nota $\mathrm{n}^{\circ}$ 74, p. 393: "manipulation as conduct that would be uneconomical or irrational, absent an effect on market price".

${ }^{129}$ En todo caso resulta problemático el tratamiento probatorio de esta tesis. Sabido es que la prueba del hecho negativo resulta tendencialmente diabólica para el acusador; pero por otra parte una radical inversión de la
} 
Polít. crim. Vol. 8, № 15 (Julio 2013), Art. 3, pp. 64 - 127.

[http://www.politicacriminal.cl/Vol_08/n_15/Vol8N15A3.pdf]

2.6.3. Una aclaración adicional: el carácter genérico de las manipulaciones informativas.

Dado que toda acción humana en el mercado (=trade) o fuera del mercado (=action) es traducible en información por vía refleja, todas las tipologías son reconducibles -por idoneidad objetiva y sin perjuicio del problema del dolo- a la categoría de manipulaciones informativas (=info-based). Esto es particularmente claro en las operaciones ficticias y en las operaciones reales que operan sobre la base de un esquema generador de burbuja. ${ }^{130}$ Posiblemente eso explica que en la guía de nivel 3 de regulaciones derivadas de la $M A D$ europea (CESR- 04-505b), se haga presente que los ejemplos pueden valer para una o más hipótesis descrita en la $M A D$.

Por el contrario, la manipulación meramente informativa jamás será reconducible a formas de injerencia directa o de power market; pues con la mera información no puede asumirse una posición en el mercado.

2.6.4. La taxonomía aplicada a las principales tipologías reconocidas por el Comité de Autoridades Europeas Reguladoras de Valores (CESR).

Cerrando esta segunda sección, se da cuenta de la correspondencia entre la taxonomía propuesta y cada una de las tipologías de manipulación descritas por el CESR, en el documento guía de tercer nivel 04-505b. Para una mejor ilustración se ha recurrido a la siguiente tabla esquemática:

Nota explicativa de la tabla.

Las tipologías corresponden a las incorporadas en el documento CESR 04-505b. ${ }^{131}$ Se señala con una "X" el mecanismo medial conforme a la específica descripción ofrecida por el CESR (lo que en principio coincide con el tipo de mecanismo medial de acuerdo a la intención del agente). Con una "Ea" se señala el mecanismo que eventualmente puede operar en forma adicional, sin perjuicio de la intención del agente. En la caracterización de la tipología (primera columna), se incluye la referencia a la norma preliminarmente de cobertura en la propia Directiva MAD.

\begin{tabular}{|c|c|c|}
\hline \multirow[t]{2}{*}{$\begin{array}{c}\text { Conductas Level } 3 \text { MAD: CESR 04- } \\
505 \text { b, parag. } 4.10 \mathrm{ss}\end{array}$} & \multicolumn{2}{|c|}{$\begin{array}{l}\text { Mecanismo operativo de la } \\
\text { manipulación }\end{array}$} \\
\hline & $\begin{array}{l}\text { Mediante el condicionamiento de } \\
\text { oferentes/demandantes } \\
\text { (a) }\end{array}$ & $\begin{array}{l}\text { Condicionamiento } \\
\text { directo del precio } \\
\text { (en calidad - real o } \\
\text { aparente - de } \\
\text { oferente/demandante) }\end{array}$ \\
\hline
\end{tabular}

carga de la prueba resultaría constitucionalmente inaceptable. Podría sí abrirse un espacio para una inversión dinámica (no inicial), en la medida que el hallazgo de una "razón económica" se trate cual motivo "justificado", a modo de los safe harbor del derecho anglosajón (como las prácticas de mercado aceptadas o AMP = accepted market practices). Ello se reconduciría, en nuestro sistema, a la acreditación de la justificante del ejercicio legítimo del derecho.

${ }^{130}$ Ambas formas muy presentes en los trading pools y short sales manipuladores observados en la crisis bursátil de 1929 en Estados Unidos. Una descripción viva del fenómeno histórico en Twentieth Century Fund, Inc., The Security Markets, New York: The Fund, 1935, cap. 13. Ilustrativo también, LOSS/SELIGMAN, Securities Regulation, cit. nota ${ }^{\circ} 62$, cap. 10.

${ }^{131}$ Recogidas en Italia en virtud de Comunicazione Consob n. DME/5078692 del 29 novembre 2005. 


\section{LONDOÑO, Fernando. "Ilícito de manipulación bursátil: fenómeno y lesividad.}

Aspectos de política sancionatoria".

\begin{tabular}{|c|c|c|c|}
\hline & & & (b) \\
\hline & $\begin{array}{l}\text { Mediante } \\
\text { engaño (difusión } \\
\text { de información) } \\
\text { (a.1) }\end{array}$ & $\begin{array}{l}\text { Mediante abuso } \\
\text { de posición de } \\
\text { poder de } \\
\text { mercado } \\
\text { (a.2) }\end{array}$ & \\
\hline \multicolumn{4}{|l|}{$\begin{array}{l}\text { Género } 4.11 \text { False / Misleading } \\
\text { Transactions }=\text { Transacciones falsas } / \\
\text { engañosas (art. 1.2.a.i } M A D=\text { art. 187- } \\
\text { ter, 3a tuf. italiano) }\end{array}$} \\
\hline $\begin{array}{l}\text { Wash trades }=\text { Transacciones ficticias } \\
\text { o simuladas }\end{array}$ & $\mathbf{X}$ & & $\mathbf{E a}$ \\
\hline $\begin{array}{l}\text { Painting the tape }=\text { adulterar el registro } \\
\text { de las operaciones }\end{array}$ & $\mathbf{X}$ & & $\mathbf{E a}$ \\
\hline $\begin{array}{l}\text { Improper matched order }=\text { ordenes de } \\
\text { operación calzadas o cruzadas }\end{array}$ & $\mathbf{X}$ & & Ea \\
\hline $\begin{array}{l}\text { Placing orders with no intention of } \\
\text { executing them = colocación de } \\
\text { órdenes sin la intención de ejecutarlas }\end{array}$ & $\mathbf{X}$ & & Ea \\
\hline \multicolumn{4}{|l|}{$\begin{array}{l}\text { Género } 4.12 \text { Price Positioning }= \\
\text { fijación de precios (art. 1.2.a.ii } M A D= \\
\text { art. 187-ter, 3b tuf. italiano) }\end{array}$} \\
\hline $\begin{array}{l}\text { Marking the close }=\text { marcación del } \\
\text { precio de cierre }\end{array}$ & Ea & & $\mathbf{X}$ \\
\hline $\begin{array}{l}\text { Colluding in the after market of an } \\
\text { Initial Public Offer = colusión en el } \\
\text { mercado secundario, tras una oferta } \\
\text { pública de primera emisión }\end{array}$ & $\mathbf{X}$ & & $\mathbf{X}$ \\
\hline $\begin{array}{l}\text { Abusive Squeeze }=\text { compresión } \\
\text { abusiva de mercado }\end{array}$ & & $\mathbf{X}$ & $\mathbf{E a}$ \\
\hline $\begin{array}{l}\text { Creation of a floor in the price pattern } \\
=\text { creación de una banda mínima en el } \\
\text { iter o curso de los precios }\end{array}$ & $\mathbf{E a}$ & & $\mathbf{X}$ \\
\hline $\begin{array}{l}\text { Excessive bid-ask spreads = Spreads o } \\
\text { diferencia excesiva en precios de } \\
\text { compra/venta }\end{array}$ & Ea & $\mathbf{X}$ & $\mathbf{X}$ \\
\hline $\begin{array}{l}\text { Trading on one market to improperly } \\
\text { position the price of a financial } \\
\text { instrument on a related market = } \\
\text { efectuar transacciones en un mercado } \\
\text { para influir indebidamente en el precio } \\
\text { de un instrumento financiero en un } \\
\text { mercado dependiente o relacionado }\end{array}$ & $\mathbf{E a}$ & & $\mathbf{X}$ \\
\hline \multicolumn{4}{|l|}{$\begin{array}{l}\text { Género } 4.13 \text { Transactions involving } \\
\text { fictitious devices/deception }= \\
\text { Transacciones que emplean } \\
\text { dispositivos ficticios o cualquier otra } \\
\text { forma de engaño (art. 1.2.b MAD = art. } \\
\text { 187-ter, 3c tuf. italiano) }\end{array}$} \\
\hline $\begin{array}{l}\text { Concealing ownership }=\text { disimulación } \\
\text { de la titularidad }\end{array}$ & $\mathbf{X}$ & & \\
\hline $\begin{array}{l}\text { Dissemination of false or misleading } \\
\text { market information through media = } \\
\text { difusión de información de mercado } \\
\text { falsa o engañosa, a través de los } \\
\text { medios de comunicación }\end{array}$ & $\mathbf{X}$ & & \\
\hline Pump and dump = inflar y descargar & $\mathbf{X}$ & & $\mathbf{E a}$ \\
\hline Trash and cash $=$ desacreditar y cobrar & $\mathbf{X}$ & & $\mathbf{E a}$ \\
\hline $\begin{array}{l}\text { Opening position and closing it } \\
\text { immediately after its public disclosure }\end{array}$ & $\mathbf{X}$ & & \\
\hline
\end{tabular}


Polít. crim. Vol. 8, № 15 (Julio 2013), Art. 3, pp. 64 - 127.

[http://www.politicacriminal.cl/Vol_08/n_15/Vol8N15A3.pdf]

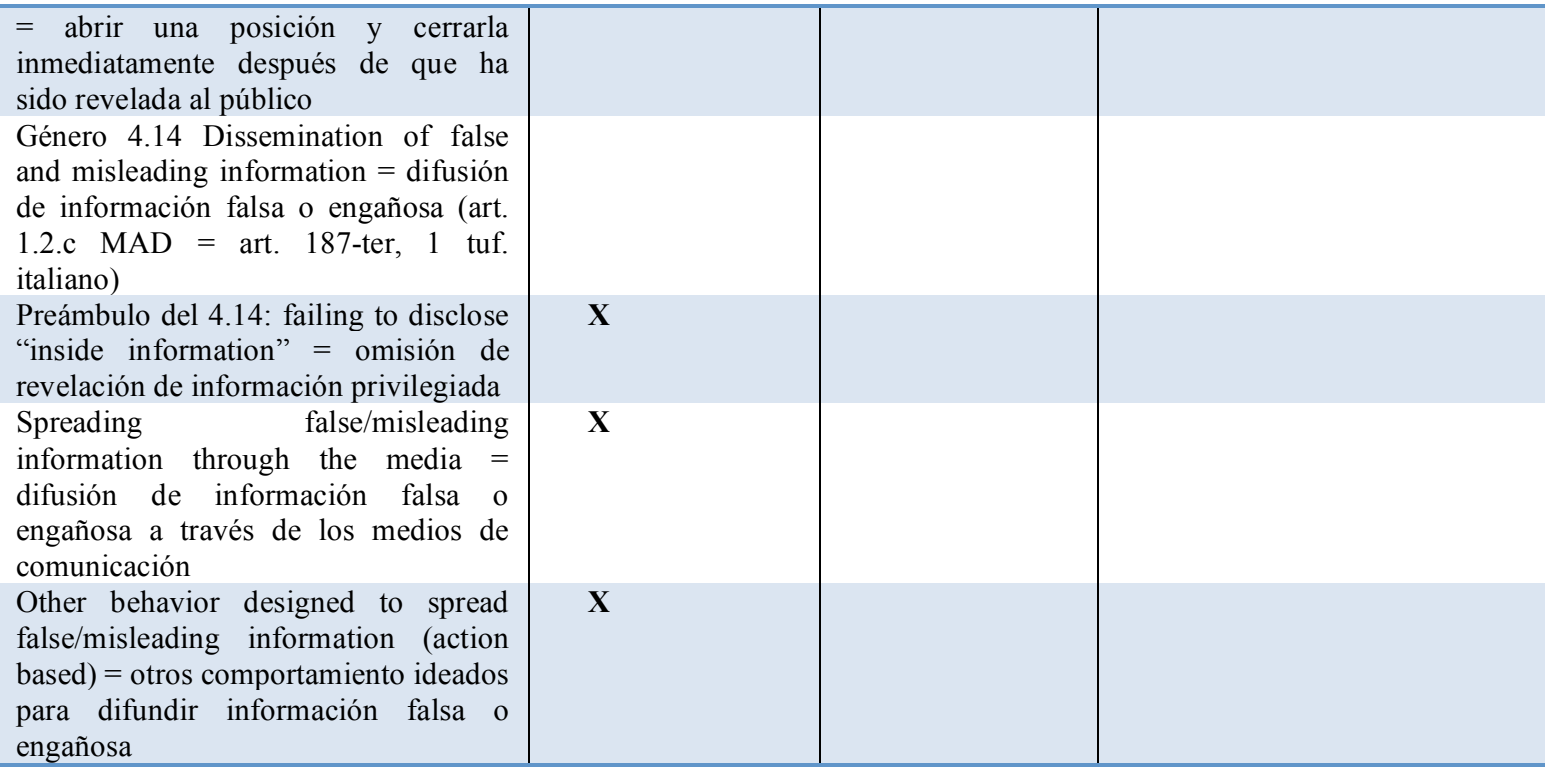

\section{Colocando la manipulación en su contexto: las funciones del mercado de oferta pública de valores y la lesividad de la manipulación. Hacia una reconstrucción de los intereses jurídicos en juego.}

Una correcta caracterización del fenómeno de la manipulación supone un correcto acercamiento al contexto en el que la conducta se coloca. De esta forma podrán apreciarse adecuadamente sus efectos. Una descripción general del mercado de oferta pública de valores se ha ofrecido en la primera sección de este trabajo. Toca ahora intentar una reconstrucción funcional de los intereses tutelados. En ese marco, se buscará aclarar el sentido de conceptos con frecuencia usados por la doctrina especializada para caracterizar los intereses o bienes jurídicos en juego en este contexto. Se procurará esclarecer representaciones usuales como funcionalidad del mercado de capitales, $^{132}$ integridad informativa del mercado de valores o correcto funcionamiento de los mecanismos de formación de los precios. ${ }^{133}$

132 Cfr. VOGEL, “\$\$20a, 38-40b,”cit. nota n 79, pp. 1672 y ss., aludiendo a la Funktionsfähigkeit der Kapitalmärkte; en otro contexto alude también a un bien jurídico supra-individual más "concreto", cual la "fiabilidad y veracidad de la formación de los precios en la bolsa y el mercado" (=Zuverlässigkeit und Wahrheit der Preisbildung an Börsen und Märkten: op. cit., pp. 762 y ss.).

${ }^{133}$ Con variantes afines, idea recurrente en la doctrina italiana: por todos, PEDRAZZI, Cesare, "Turbativa dei mercati (voce)", en: AA.VV., Digesto - Discipline Penalistiche, Torino: UTET, 1999, pp. 421-432 y SEMINARA, Sergio, "I reati di aggiotaggio", en: PEDRAZZI, Cesare; ALESSANDRI, Alberto; FOFFANI, Luigi; SEMINARA, Sergio; SPAGNOLO, Giuseppe, Manuale di diritto penale dell'impresa, Bologna: Monduzzi, 2000, pp. 635-663. En sentido similar, OTTO, Harro, Anmerkungen zum strafrechtlichen Schutz des Finanzwesens und der Handelsgesellschaften (Art. 49-56), en: TIEDEMANN (Coord.), Wirtschaftsstrafrecht in der Europäischen Union (Freiburg-Symposium), Köln: Heymanns, 2002, pp. 353367; y FOFFANI, Luigi, "Delitos Bancarios y Bursátiles”, en: TIEDEMANN, Klaus (Dir.); NIETO, Adán (Coord.), Eurodelitos. El Derecho Penal económico en la Unión Europea, Cuenca: Universidad de Castilla La Mancha, 2004, pp. 109-117, p. 115, aludiendo a la "seriedad en la formación de los precios en interés del correcto funcionamiento de los mercados organizados de capitales". 
LONDOÑO, Fernando. "Ilícito de manipulación bursátil: fenómeno y lesividad. Aspectos de política sancionatoria".

\subsection{Las funciones del mercado de oferta pública de valores.}

Tres funciones del mercado de valores deben ser consideradas especialmente para una adecuada reconstrucción de las expresiones de lesividad de la manipulación bursátil: ${ }^{134}$

a. Función de flujo, movilización, asignación, colocación o captación de capitales, desde las unidades en superávit (ahorro) hacia las unidades en déficit (emisores). Como se indicara en la primera sección de este trabajo, constituye la función central del mercado de oferta pública de valores, y es desempeñada por el denominado mercado primario o mercado de primera emisión. Esta función es desplegada también por el mercado de capitales de carácter bancario. Sin embargo, el mercado de oferta pública de valores lleva adelante esta función con una intensidad y democraticidad particulares. ${ }^{135}$

b. Función de pricing o correcta colocación de los capitales. En la medida que la colocación de capitales se desenvuelve de manera eficiente, es decir, en correspondencia con las exigencias y posibilidades de las unidades en déficit y en surplus, puede decirse que el mercado de capitales asume una correcta función de pricing; a saber, de asignación de valor. Si la función anteriormente descrita (flujo de capitales) obedece a una lógica cuantitativa, ésta función obedece a una lógica cualitativa. En este sentido, se trata de una dimensión caracterizadora de la función de flujo de capitales, pues éstos pueden fluir de manera eficiente o de manera ineficiente. Que lo hagan de manera eficiente depende del correcto funcionamiento de esta variable. Algunas consecuencias de un flujo ineficiente allí donde se introduce una hipótesis de fraude en el mercado- han ya sido esbozadas de manera sintética supra 2.4, especialmente a partir de la explicación de Easterbrook y Fischel.

c. Función de Liquidez. El mercado de valores debe también permitir que los participantes puedan "entrar y salir" de él con facilidad, recuperando así el poder adquisitivo al que renunciaron al invertir en el mercado. ${ }^{136} \mathrm{El}$ nivel de inversión de capitales sería menor si

\footnotetext{
134، These functions are stated to be (1) direction and facilitation of the flow of capital into industry, (2) liquidity and continuity of prices, (3) adjustment of prices to the market schedule of going interest rates and to “investment worth",", AA.VV., "Market Manipulation” (1937), cit. nota ${ }^{\circ} 105$, p. 625, nota 5, con referencia a la obra de John Maynard Keynes, The General Theory of Employment interest and money, 1936, pp. 150164. Considérense además PERDUE, "Manipulation of futures", cit. nota ${ }^{\circ} 74$, pp. 349-352, con referencia alas funciones del mercado de futuros (pricing information y allocation function). En fin, con un carácter más amplio -referido a los mercados de capitales en general- igualmente cfr. KOSLOWSKI, The Ethics of Banking, cit. nota $\mathrm{n}^{\circ} 20$, pp. 34 y 40-41, con alusión a las funciones de suministro de capitales y de ahorro (depósito), que aquí consideramos en el marco de la primera de las funciones mencionadas. En un pasaje sucesivo, el autor menciona la función de liquidez como un sub-propósito del mercado de capitales (op. cit. p. 40). En fin, el autor menciona también la función del mercado por el control corporativo, la que puede considerarse como una externalidad del mercado mismo, principalmente en contextos de estructuras societarias de propiedad difusa o public companies. A través de dicho mercado los inversionistas pueden controlar y poner presión en las gerencias para que ofrezcan rendimientos aceptables.

${ }^{135}$ Cfr. KOSLOWSKI, The Ethics of Banking, cit. nota $\mathrm{n}^{\circ} 20$, pp. 41-42, considerando el mercado de capitales como el mecanismo de distribución de capitales más acorde con una sociedad democrática, por sobre otros dos modelos posibles (la distribucion de recursos mediante decisiones de asignación adoptadas por (i) Bancos o (ii) por un Gobierno en el marco de una economía centralizada).

${ }^{136}$ Para más detalles, véase la primera sección de este trabajo.
} 
Polít. crim. Vol. 8, № 15 (Julio 2013), Art. 3, pp. 64 - 127.

[http://www.politicacriminal.cl/Vol_08/n_15/Vol8N15A3.pdf]

éstos corriesen el riesgo de quedar inmovilizados o no fuese posible modificar o liquidar las posiciones con una cierta comodidad. Esta función es desempeñada por el mercado secundario. Cabe considerar aquí el rol de inversionistas de corto plazo, intermediarios, "hacedores de mercado" (market makers) y especuladores en general, todos quienes otorgan liquidez al sistema. ${ }^{137}$

\subsection{Atributos o cualidades del mercado de capitales.}

Las funciones recién descritas se enlazan a su vez con atributos o cualidades del mercado de valores. Así, el flujo de capitales y la liquidez están directamente asociadas a la potencia del mercado; a saber, a la mayor o menor capacidad de movilización/captación de capitales, en términos de volumen. Por su parte, la función de pricing está directamente asociada a la fidelidad o integridad del mercado, e indirectamente conectada con el volumen o potencia del mercado. ${ }^{138}$ Un mercado íntegro -que ejecute eficientemente la tarea de asignación de valor- tiende a ser también un mercado voluminoso, potente. ${ }^{139}$

\subsection{Los presupuestos de las funciones del mercado de valores: los factores institucionales y sociológicos que condicionan o dinamizan el despliegue de las funciones. ${ }^{140}$}

Si funciones y cualidades del mercado de valores son, respectivamente, flujo/ liquidez/ pricing; y volumen/integridad, ¿cuáles son los factores que condicionan el rendimiento de dichas funciones y el grado de desarrollo de dichos atributos?

Estos factores dinámicos, de naturaleza institucional o sociológica, pueden sintetizarse del siguiente modo:

(a) Libertad y democraticidad. Con estos conceptos se quieren ilustrar los factores determinantes del grado de apertura del mercado, la accesibilidad y grado de participación en el mercado de valores. El modelo supone un grado importante de igualdad, pues sin un mínimo de igualdad de condiciones, ${ }^{141}$ entonces las facilidades de acceso paritario dejarían de ser reales y con ello disminuiría el interés en la participación. ¿Pues qué atractivo puede suscitar un "juego" en el que las posibilidades de victoria resulten sistemáticamente defraudadas (por una injustificada falta de paridad), no obstante las razonables expectativas iniciales? Evidentemente se trata de una aspiración, de un diseño ideal del modelo. Se captará la estrecha conexión entre este factor y el infra descrito como confianza-optimismo.

\footnotetext{
${ }^{137}$ En cuanto a la importante contribución a la función de liquidez llevada a cabo por la especulación, cfr. KOSLOWSKI, The Ethics of Banking, cit. nota $n^{\circ} 20$, pp. 42-43.

138 Es decir, indirectamente: a través de la confianza y de la eficiencia en la asignación de capitales.

${ }^{139}$ Cfr. LA PORTA/LÓPEZ-DE-SILANES/SHLEIFER, "What Works", cit. nota ${ }^{\circ} 27$.

140 Sobre el ideal de mercado que inspira al modelo y los presupuestos sociológico-culturales, cfr. Niebuhr y su definición del protestantismo liberal: la exaltación y confianza en los hombres píos e inteligentes: NIEBUHR, Reinhold, Il destino e la storia, Milano:Rizzoli, 1999, pp. 20-21.

141 Imagínense las consecuencias para el modelo en un supuesto de participantes que controlaran los resultados de la actividad bursátil, reduciendo los márgenes de riesgo o aleatoriedad estructural (manipuladores) o bien que irremediablemente ganaran antes o mejor que los demás intervinientes en el mercado (insiders). Cfr. al respecto, LOSS/SELIGMAN, Securities Regulation, cit. nota ${ }^{\circ}$ 62, Cap. 10-A. En sentido similar, cfr. KOSLOWSKI, The Ethics of Banking, cit. nota ${ }^{\circ} 20$, p. 53.
} 
LONDOÑO, Fernando. "Ilícito de manipulación bursátil: fenómeno y lesividad. Aspectos de política sancionatoria".

(b) Competitividad meritocrática. Si la participación en el mercado de valores se describiese como un juego, ¿cuáles serían las habilidades o destrezas individuales requeridas para jugar lo bien? Si el objetivo o interés prevalente de este "juego" es la generación de riqueza, entonces las destrezas requeridas por el modelo saltan a la vista: la captación del valor de inversión, el hallazgo del razonable valor de un determinado título o instrumento y la elaboración de la mejor prognosis posible sobre el signo y entidad de su variación a mediano y largo plazo. ${ }^{142}$ Ello supone un intento razonable de reducción de la incertidumbre o bien de valoración del riesgo de inversión. Se trata en definitiva del hallazgo de un valor "externo", intersubjetivamente válido. ${ }^{143}$ Lo anterior supone un esfuerzo (trabajo) de descubrimiento constante.

Ya desde este prisma es posible reprochar las "destrezas" anti-competitivas de manipuladores. ¿Por qué esas "destrezas" no son bienvenidas? Porque sólo el tipo de destrezas antes descritas da lugar a movimientos sinérgicos, poniendo "el juego" en contacto con "lo real"; es decir, al servicio de la búsqueda individual de la captación de mayor valor, y redundando ello en una situación deseable para el interés común. Como ya se ha explicado en la primera sección de este trabajo (cfr. supra 1.1), el interés común se ve realizado a partir de la conexión entre ahorro en inversión, la que -en la medida que se verifica con eficiencia- da lugar a una correcta asignación de los recursos, con los ulteriores mayores beneficios en un plano macroeconómico, social. En este sentido, puede hablarse de un modelo meritocrático, pero orientado a la comunidad: comunitariamente responsable.

Por el contrario, las destrezas del manipulador no permiten alinear su interés individual con el interés común; o mejor aún, dichas destrezas son representativas de un interés individual limitado, incompleto. Así, no puede reconocerse un interés individual satisfactorio o deseable desde el punto de vista del interés común, en el caso de quien, por ejemplo, por la vía de una manipulación informativa, dificulta, retrasa o impide la captación de la real situación financiera del emisor o de su mercado, dando pie a las consecuentes disfuncionalidades en el plano de la eficiencia en la asignación de los recursos financieros. Vale aquí reiterar la explicación aportada por Easterbrook y Fischel a propósito de un supuesto más general; a saber, el del impacto lesivo (harm) del fraude en la economía:

"Las fuentes de daño [harm] corresponden a las respectivas reducciones en la eficiencia distributiva [allocative efficiency] de la economía. Así, una incompleta o inexacta entrega de información relativa a las inversiones, conduce a las personas a invertir en los proyectos equivocados; se gastarán más recursos de los necesarios para producir bienes y servicios. Por otra parte, una incompleta o inexacta entrega de información puede enviar señales erróneas sobre el riesgo, y esto distorsiona la posibilidad de elección entre inversión y consumo". 144

\footnotetext{
${ }^{142}$ La razonable minimización de la incertidumbre o riesgo de inversión. Por cierto, en el marco de un modelo de riesgo estructural, no completamente controlable. Cfr. al respecto, PERRONE, "Información", cit. nota ${ }^{\circ}$ 18, p. 1.

${ }^{143}$ KOSLOWSKI, The Ethics of Banking, cit. nota ${ }^{\circ} 20$, p. 35.

${ }^{144}$ EASTERBROOK/FISCHEL, The Economic Structure, cit. nota n 102, p. 324: "The (...) sources of harm are related reductions in the allocative efficiency of the economy. One is that incomplete or inaccurate disclosure about investments leads people to invest in the wrong projects. They will spend "too much" in
} 
Polít. crim. Vol. 8, № 15 (Julio 2013), Art. 3, pp. 64 - 127.

[http://www.politicacriminal.cl/Vol_08/n_15/Vol8N15A3.pdf]

(c) Confianza, optimismo. El tercer factor es de naturaleza subjetiva e intangible, pero no por ello menos real ni menos incidente. ${ }^{145}$ Fundado en los anteriores dos factores, en parte los supera. En efecto, este factor supone la consideración -más o menos razonable- de elementos no sólo intrínsecos al mercado (el valor del título, la situación del emisor, la situación del mercado para el título, etc.), sino también la de aspectos extrínsecos: así, una buena/mala opinión de los inversionistas sobre el estado general de la nación o de la economía mundial puede reflejarse en la valoración de un aspecto intrínseco. En este nivel se insertan también los elementos eventualmente irracionales o infundados del optimismo o del pesimismo.

En extrema síntesis, es posible conjugar estos factores de manera de apreciar su incidencia en las funciones y cualidades del mercado supra descritas. Así, la competitividad y la democraticidad son factores (o deberían serlo) de la confianza/optimismo. La democraticidad del mercado es factor principal de su potencia en términos de mayor volumen. A su vez, la confianza de los inversionistas es factor de la potencia en términos de mayor volumen. La competitividad meritocrática del modelo es factor principal de la integridad informativa del mercado; es decir, aparece como factor de una eficiente asignación de los capitales (pricing). ${ }^{146}$

resources to produce goods and services. The other is that incomplete or inaccurate disclosure can send the wrong signals about risk, and this distorts the choice between investment and consumption" (el destacado es del autor).

${ }^{145}$ En el preámbulo de la Directiva MAD (considerando 12) el legislador europeo le asigna un rol fundamental en el plano del interés protegido por la legislación sobre abusos de mercado, hasta el punto de constituirla en el interés de enlace entre la regulación de la manipulación y la del abuso de información privilegiada. Sin apelación a dicha dimensión global del interés de protección asociado a la confianza, no resulta evidente una nota común entre dichas figuras en el plano de la lesividad. Lo anterior, desde ya porque en principio no es posible afirmar que una afectación de la eficiencia en la asignación de los recursos acontezca en el caso del abuso de manipulación bursátil. Un enlace entre ambas figuras - en el plano del desvalor de resultado - es pues posible de advertir desde una perspectiva consecuencial, sistémica: a partir de las negativas consecuencias que quepa esperar de la tolerancia y difusión de ambas conductas. Ya en el plano del desvalor de acción, puede identificarse un punto de enlace en la (parcial) supresión de la incertidumbre (aleas) intrínseca en la operatoria del modelo, lo que tanto el manipulador como el insider ejecutan, recurriendo a destrezas no del todo compatibles con el tipo de valores que vivifican el sistema. Un muestra eficaz del desvalor implícito en ambas conductas (abuso de información privilegiada y manipulación bursátil) se desprende de una figura penal tradicional pero poco desarrollada entre nosotros: a saber, la hipótesis del número 6 del art. $470 \mathrm{CP}$ chileno, que sanciona "a los que con datos falsos u ocultando antecedentes que le son conocidos celebraren dolosamente contratos aleatorios basados en dichos datos o antecedentes". Por lo que se refiere a la figura de manipulación bursátil, un desarrollo ulterior de estas ideas puede hallarse infra en las conclusiones de este trabajo (sección cuarta). Por lo que se refiere al desvalor de acción implícito en el abuso de información privilegiada, considérese en esta línea la perspectiva planteada por KOSLOWSKI, The Ethics of Banking, cit. nota ${ }^{\circ} 20$, pp. 53 y ss. En lo demás, cfr. notas n ${ }^{\circ} 16$ y 156 del presente trabajo.

${ }^{146}$ Como se podrá apreciar en seguida, existe en todo caso un relativo trade-off o costo de oportunidad entre integridad informativa y potencia del mercado. Cfr. al respecto, AVGOULEAS, The Mechanics, cit. nota $\mathrm{n}^{\circ}$ 59, p. 192, dando cuenta del trade-off entre market transparency y liquidity. 
LONDOÑO, Fernando. "Ilícito de manipulación bursátil: fenómeno y lesividad. Aspectos de política sancionatoria".

\subsection{Los vehículos materiales de los factores que condicionan la funcionalidad del mercado de valores.}

Los mencionados factores dinámicos no operan por "irradiación en el vacío", sino que lo hacen a través de los elementos o "partículas fundamentales" de todo sistema de mercado de valores: la información y las operaciones de mercado (trading).

La conexión entre los factores y atributos del mercado y dichos elementos vehiculares es la siguiente:

La información es directamente tributaria de la fidelidad/integridad. ${ }^{147}$ La información puede referirse (a) al instrumento financiero (ya directamente [=a.1], ya por referencia a su emisor [=a.2], o bien (b) al mercado (ya al específico mercado del instrumento [=b.1], ya a las condiciones del mercado (o de otros mercados) en general [=b.2]).

Este conjunto o marco de informaciones constituyen el input de las operaciones de mercado (trading). En efecto, ellas aparecen en la explicación inmediata de buena parte de las operaciones del mercado de referencia. De ahí la idea -expuesta supra 1.3, c.3)- de que el precio refleja la información disponible en un determinado momento. ${ }^{148}$

Por su parte, las operaciones de mercado (trading) -el vehículo inmediato de todos los factores antes descritos- son directamente tributarias de la potencia del mercado; e indirectamente -en cuanto las conductas humanas son siempre susceptibles de una lectura, generando con ello información - tributarios de la fidelidad/integridad del mercado. Es decir, las operaciones de mercado se explican en razón de la información, pero a su vez son fuente de información. Que un agente calificado del sector se desprenda de una parte importante de los títulos de un emisor, puede decirnos algo sobre la situación del emisor. Por cierto, una correcta lectura de la operación supone el dominio y la coordinación de determinada información (=conocimiento). En síntesis: hay información asociada a las operaciones del mercado, tanto en el input como en output de las mismas.

Ahora estamos en condiciones de describir el "tejido conectivo" del mercado: el mercado aparece como una instancia de intercambios o propuestas de intercambios. Por su parte, los intercambios, como toda acción humana, responden a motivaciones o razones. A su vez, ellas están fundamentalmente determinadas por conocimientos (informaciones), pero también por necesidades (siempre contingentes) y expectativas más o menos razonables (no necesariamente fundadas en informaciones).

\footnotetext{
${ }^{147}$ Cfr. FAMA, "Efficient Capital Markets", cit. nota ${ }^{\circ}$ 39, pp. 383 y ss.; GILSON/KRAAKMAN, "The Mechanism", cit. nota ${ }^{\circ}$ 39, pp. 549 y ss.; FAMA, Eugene, "Efficient Capital Markets: II", J. Fin. (1991), vol. 46 , p. 1575 y ss.

${ }^{148}$ Cfr. FAMA, "Efficient Capital Markets ", cit. nota n ${ }^{\circ}$ 39, pp. 383 y ss.; GILSON/KRAAKMAN, "The Mechanism", cit. nota ${ }^{\circ} 39$, pp. 549 y ss. Mayores detalles supra, 1.3, c3).
} 
Polit. crim. Vol. 8, № 15 (Julio 2013), Art. 3, pp. 64 - 127.

[http://www.politicacriminal.cl/Vol_08/n_15/Vol8N15A3.pdf]

\subsection{Algunas conclusiones preliminares.}

Se puede llegar así a una conclusión preliminar, de enlace entre funciones (3.1), cualidades (3.2), factores dinámicos (3.3) y vehículos del mercado (3.4): el mercado será tendencialmente más eficiente en el desempeño de su función (cuantitativa) de flujo de capitales (supra 2.1.a), en la medida que la información y las operaciones sean mayores. ${ }^{149}$ Será por su parte más eficiente en el desempeño de su función (cualitativa) de pricing o correcta asignación de capitales (supra 2.1.b), en la medida que las informaciones sean mejores y las operaciones aparezcan basadas en informaciones correctas y motivadas en legítimas razones de intercambio; es decir, allí donde no obedezcan a lógicas de manipulación (general o especial).

Pero con dicha conclusión no se avanza mucho si no se ponderan ciertas particularidades ya esbozadas en la caracterización con la que se cerró el apartado anterior.

Pues bien, a esta altura debería resultar evidente la ambigüedad de los vehículos de los factores condicionantes de la eficiencia del sistema. Expresado en términos más precisos: dichos vehículos -informaciones y operaciones- son realmente funcionales sólo en la medida que obedezcan a los presupuestos (competitivo-meritocráticos) que favorecen la integridad y la potencia del mercado. En otras palabras, la información transmitida puede ser, o no, verdadera, así como el trading puede ser, o no, representativo de un razonable interés de intercambio. Aquí la componente competitivo-meritocrática aparece como fundamental y resulta caracterizada por su mayor o menor vinculación con lo real; es decir, por su mayor o menor afinidad a las variables que contribuyen a que el "juego se juegue bien".

La anotada ambigüedad de los vehículos nos ofrece el siguiente cuadro:

(a) Unos mismos vehículos (informaciones y operaciones) pueden aparecer como funcionales o como disfuncionales. Un vehículo puede ser portador de la materia que alimenta al mercado (=trigo), así como de aquella que lo envenena (=cizaña).

(b) La identificación de los portadores de disfuncionalidad no es fácil o inmediata, pues su expresión externa es prácticamente en todo equivalente a los vehículos funcionales. La fuente de su disfuncionalidad se halla en una dimensión interna, en el contenido. En consecuencia, su identificación requiere de una verificación a partir del dato real.

(c) Tratándose de información, su verificación supone un contraste con una situación objetiva (o intersubjetivamente válida).

(d) Tratándose de operaciones, su verificación supone un contraste con una intención subjetiva incompatible con la racionalidad de mercado. Dicha falta de racionalidad revela una ausencia de información compatible con lo real. Este punto se vincula con el tratado

149 Cfr. GILSON/KRAAKMAN, "The Mechanism", cit. nota n ${ }^{\circ}$ 39, pp. 549 y ss., describiendo los mecanismos de la eficiencia del mercado (=MOME=mechanisms of market efficiency). 
LONDOÑO, Fernando. "Ilícito de manipulación bursátil: fenómeno y lesividad.

Aspectos de política sancionatoria".

supra en el excurso del apartado 2.6.2., a propósito de la dificultad de la distinción entre operaciones manipulativas y operaciones lícitas, idóneas para alterar los precios.

(e) Adicionalmente -y para ratificar la complejidad- es posible identificar vehículos preliminarmente disfuncionales -en cuanto a lo menos controladores-y que sin embargo colocados en determinados contextos pueden resultar funcionales. Así, por ejemplo, el fenómeno de la estabilización correctamente ejecutada en el mercado de primera emisión (cfr. supra 2.3.5), así como ciertas prácticas aceptadas en el mercado o AMP (= accepted market practices), como se les conoce por su sigla en inglés en el contexto europeo. Considérense incluso los wash trades aceptados en ciertos mercados europeos, bajo determinados parámetros. ${ }^{150}$

\subsection{Breve corolario aplicativo, en materia de diseño de una política sancionatoria.}

A partir de las constataciones anteriores - especialmente las contenidas en las letras (a), (d) y (e) -se llega al primer núcleo problemático en una perspectiva de diseño de una política criminal o administrativo-sancionatoria; a saber, la constatación de un relativo trade-off entre prohibición/sanción y rendimiento del mercado. Se trata del mismo costo de oportunidad presente en la parábola del trigo y la cizaña, implícito en el punto (a) del apartado precedente. En concreto, la prohibición y sanción de conductas disfuncionales conlleva una dosis de riesgo de disuasión de conductas funcionales, por efecto de la overdeterrence. $^{151}$ Qué dosis de riesgo en concreto, es algo que dependerá de la razonabilidad del diseño normativo y de las características del propio mercado y de sus intervinientes. En consecuencia, se trata de elaborar una política sancionatoria tal, que permita detectar tanta cizaña como sea posible (=manipulaciones distorsionadoras o limitadoras de la libertad del mercado), en modo compatible con la mayor cosecha de trigo posible (=flujo de informaciones, especulaciones lícitas ${ }^{152}$ y operaciones funcionales, todas las cuales favorecen la potencia e integridad al mercado). Un inadecuado filtro normativoinstitucional correría el riesgo de atajar el trigo, o bien, para evitar lo anterior, de dejar crecer demasiada cizaña.

\section{Conclusiones. Propuesta de reconstrucción del fenómeno manipulativo (mecanismos y lesividad). Aspectos de política sancionatoria.}

A partir de lo expuesto en los apartados anteriores, finalmente se está en condiciones de ofrecer una reconstrucción sintética del fenómeno manipulativo y de su lesividad, basada en una perspectiva de competitividad meritocrática, comunitariamente responsable.

El objetivo del modelo enlaza con la idea de "juego jugado bien”. La lectura de la violación de las reglas del juego aparece así como una alteración de las condiciones de paridad. Esta alteración de las condiciones se ve ya comprometida en su dimensión formal, con ocasión de la manipulación general, entendida como control. De allí el carácter preliminarmente

\footnotetext{
${ }^{150}$ Cfr. supra 2.6.1, especialmente nota $\mathrm{n}^{\circ} 103$ relativa la valuation transaction en el mercado de valores vienés.

${ }^{151}$ En este sentido, cfr. PERDUE, "Manipulation of futures", cit. nota ${ }^{\circ} 74$, p. 392.

${ }^{152}$ Cfr. supra 3.1.c, especialmente nota $n^{\circ} 137$.
} 
Polít. crim. Vol. 8, № 15 (Julio 2013), Art. 3, pp. 64 - 127.

[http://www.politicacriminal.cl/Vol_08/n_15/Vol8N15A3.pdf]

disfuncional de estas conductas. Por otra parte, dada una presunta racionalidad del modelo (su configuración conforme a reglas adecuadas y funcionales), la violación de las reglas resulta también indiciaria de una lesión ulterior, ya en el plano sustantivo. Allí aparece la manipulación especial como paradigma disfuncional, en cuanto distorsionadora del objeto de las destrezas requeridas por el modelo. Dicho en términos más concretos: aparece la manipulación especial como perturbadora de la racionalidad con la que se distribuyen los recursos; por tanto, como afectadora de la eficiencia distributiva de los recursos financieros (allocative efficiency), a su turno asociada a la función de pricing.

Así se llega a una comprensión sintética de la connotación normativo-sistemática ${ }^{153}$ de la manipulación general/especial, entendida como control/desviación: tipicidad en la violación de las reglas (=manipulación general o control) y exclusión de la antijuridicidad de dicha violación en caso de funcionalidad de la misma (por ejemplo, estabilizaciones permitidas y otras AMP). Por su parte, la exclusión de la antijuridicidad nunca parece poderse afirmar en casos de distorsión (=manipulación especial).

En cuanto a los fundamentos para la tipicidad de la mera violación de las reglas (manipulación general o manipulación-control), su lesividad ha sido ya puesta en evidencia: la alteración de las condiciones de paridad, el incremento del riesgo de desviación en la eficiente distribución de los recursos, el detrimento de la confianza y, con todo ello, la eventual disminución del volumen y liquidez del mercado. Lo anterior, en razón al aumento de los costos, a partir del incremento de los niveles de desconfianza.

En cuanto a la lesividad de la manipulación especial o manipulación-distorsión, corresponde a todo lo anterior, sumada una efectiva lesión de la eficiencia distributiva; es decir, un efectivo detrimento en el plano de la fidelidad e integridad del mercado.

Considérese en seguida la racionalidad anti-económica (y no institucional o de tutela) ${ }^{154}$ de toda manipulación lesiva. No hay en dicha racionalidad motivos de inversión o intercambio, sino el mero interés en el efecto colateral en el precio, cual externalidad del intercambio. ${ }^{155}$ Esta falta de racionalidad económica coincide con la introducción de información disociada del valor de inversión predicable del título o instrumento financiero. Puede decirse que esta situación de la manipulación lesiva constituye -desde el punto de vista de la eficiencia distributiva del mercado de capitales- el polo opuesto del abuso de información privilegiada. Es decir, lo que en éste redunda, como externalidad, en iluminación (aunque a partir de un abuso), ${ }^{156}$ en aquella redunda en opacidad.

Más allá de la genérica antijuridicidad de las conductas de manipulación, la prohibición de las mismas obedece a un criterio de conservación de los atributos del mercado bursátil, así como ha sido diseñado originalmente. Ha sido en efecto construido como un sistema

\footnotetext{
${ }^{153}$ En el marco de un modelo tripartito de teoría del delito.

${ }^{154}$ Racionalidad operativa en las estabilizaciones permitidas, no antijurídicas.

${ }^{155}$ PERDUE, "Manipulation of futures", cit. nota $\mathrm{n}^{\circ} 74$, pp. 345 y ss.

${ }^{156}$ Sólo en este muy limitado sentido podría darse razón a José Miguel Ried, al argumentar que no es la transparencia el interés o bien jurídico afectado por el uso de información privilegiada (RlED, "Fundamentos de la prohibición", cit. nota $n^{\circ} 16$, pp. 451-452). En lo demás, cfr. supra nota $\mathrm{n}^{\circ} 145$.
} 
LONDOÑO, Fernando. "Ilícito de manipulación bursátil: fenómeno y lesividad. Aspectos de política sancionatoria".

competitivo e inteligente (competitividad cualitativa), en el que los participantes se esfuerzan por conocer o anticipar el valor actual y potencial de los bienes intercambiados, de manera de poder maximizar las utilidades de las operaciones y de la inversión en general. ${ }^{157}$ De esta forma el conocimiento y la capacidad de adquirir conocimiento se colocan aquí como fuente de riqueza. A su vez, esta idea de un mercado competitivo e inteligente responde a exigencias de interés común. En la medida que los participantes individuales buscan y transmiten conocimientos fiables sobre los emisores o instrumentos del caso, entonces el sistema en su conjunto resulta más eficiente en la distribución de los recursos financieros. En efecto, ellos se destinan preferentemente hacia las unidades más eficientes en la generación de riqueza. Ello tiene un evidente reflejo a nivel colectivo. Ahora estamos en condiciones de reformular el postulado anterior: el conocimiento aparece como una fuente de riqueza individual (de los participantes del mercado), a la vez que comunitaria.

En definitiva, el presupuesto institucional de este diseño es la meritocracia competitiva, pero comunitariamente responsable. La lealtad en el ejercicio de la competencia -es decir, aquella que se ejerce valiéndose de las destrezas correctas- está implícita en la idea misma de mérito. Así, los out-put de la competencia no ceden sólo en beneficio del portador del mérito, sino del contexto social o comunitario en el que éste ejerce su competencia.

El mérito se vincula de este modo a lo real, a la búsqueda de conocimiento real. La captación de lo real -en este contexto- significa, por ejemplo, la correcta identificación de la situación financiera, económica y de mercado de un emisor de valores cotizados en bolsa. La captación de lo real se asocia a la correcta ponderación del valor de inversión de un determinado título o instrumento bursátil, como reflejo de la situación del propio título, del emisor, del mercado y del entorno económico-político, así como percibida por los evaluadores-participantes, intersubjetivamente. En esta dimensión, lo distorsionador y lo abusivo (la manipulación lesiva, en sus diversas modalidades) aparece como lo no-real, cual vehículo inidóneo para la correcta captación de lo real; más aún, como un vehículo propulsor de confusión. No en vano, en derecho italiano la tipología en estudio figura en ocasiones asociada a la voz turbativa. ${ }^{158}$

Bajo la perspectiva aquí asumida, la manipulación aparece, en una dinámica de juego, como la conducta de quien, recurriendo a destrezas desalineadas con los presupuestos del modelo y su consecuente marco de reglas, explota una ocasión de provecho individual, restringiendo las posibilidades de provecho común. La particularidad de esta conducta es que las destrezas se emplean aquí en una tentativa de alteración de los precios, lo que supone una posible ocasión de provecho individual (primer objetivo del juego jugado bien), pero prescindiendo del despliegue de aquellas destrezas inherentes al diseño del juego o modelo; es decir, prescindiendo de aquellas (únicas) destrezas cuyo ejercicio permite la realización coordinada de intereses individuales y comunes. Pues en el contexto que nos

\footnotetext{
${ }^{157}$ Cfr. KOSLOWSKI, The Ethics of Banking, cit. nota ${ }^{\circ} 20$, p. 35.

${ }^{158}$ PEDRAZZI, "Turbativa dei mercati”, cit. nota $\mathrm{n}^{\circ} 133$, pp. 421-432. Igualmente PEDRAZZI, Cesare, Problemi dell'aggiotaggio, Milano, 1958; reedición en PEDRAZZI, Cesare, Diritto Penale IV, Scritti di diritto penale dell'economia, Milano: Giuffrè, 2003, pp. 3-97.
} 
Polít. crim. Vol. 8, № 15 (Julio 2013), Art. 3, pp. 64 - 127.

[http://www.politicacriminal.cl/Vol_08/n_15/Vol8N15A3.pdf]

ocupa, sólo el ejercicio de la destreza cognitiva empleada en la correcta captación del valor, compatibiliza la realización de intereses individuales y comunes.

Considérense bajo este prisma las siguientes observaciones de Wendy C. Perdue, a propósito de los presupuestos y destrezas del mercado de futuros:

"Un mercado de futuros produce un precio digno de confianza en la medida que ofrece a quienes allí transan un incentivo para buscar y analizar con precisión toda la información disponible. Ese trading informado es esencial para el funcionamiento del mercado y debe como tal ser estimulado. Por el contrario, no contribuyen al funcionamiento eficiente del mercado, los operadores que buscan lucrar, no ya a partir de su habilidad especial para predecir los precios, sino mediante su habilidad para alterar el precio de mercado. Dicha conducta debe ser considerada ilícita."159

Así, la trasgresión de la reglas ha de caracterizarse como la tentativa de conquista de un objetivo individual con destrezas diversas a las esperadas o empleadas por los demás participantes (information seekers) y en todo caso incompatibles con la realización del objetivo común. Evidentemente no se trata sólo de una cuestión formal o limitada a un problema de disparidad de armas (desigualdad); pues si las reglas tienen un sentido material, funcional a la persecución de objetivos comunes (como lo tienen las reglas orientadas a la fidelidad informativa), entonces su trasgresión resulta efectivamente lesiva.

A partir de estas consideraciones puede asentarse una conclusión adicional en el plano de la lesividad del fenómeno manipulativo: las modalidades de mero control (no directamente asociadas a la distorsión/falsedad) lesionan cuanto menos la dimensión de la competitividad meritocrática (=desigualitario uso de "habilidades"); por su parte, las modalidades asociadas a la infidelidad informativa (distorsión) suponen además una lesión a la dimensión de la eficiencia en la asignación de los recursos financieros. En este contexto se insertan ya en propiedad las dos formas de manipulación que desde el inicio de este trabajo se han identificado: manipulación general (violación de las reglas, lesiva para las condiciones de paridad y, por tanto, para la confianza en el sistema); y manipulación especial (violación no sólo de las reglas, sino alteración del out-put del sistema, con la consecuente afectación de las condiciones de eficiencia en la asignación de los recursos).

Ahora bien -sentada la dimensión de la lesividad- si se introducen adicionalmente variables en clave de prevención y costo/beneficio, tradicionales en este contexto conforme a un paradigma de agente racional (a saber, capacidad "auto-disuasiva" de la conducta en

\footnotetext{
${ }^{159}$ PERDUE, "Manipulation of futures", cit. nota $\mathrm{n}^{\circ}$ 74, pp. 391-392. Puede resultar útil transcribir el pasaje íntegro en ingles, incluyendo un pasaje previo que puede resultar clarificador del contexto: "This article advances a definition of manipulation premised on the belief that the proper goal of a manipulation prohibition is to ensure the proper functioning of the futures market. In this regard, [it] begins with Holbrook Working's definition of "the perfect futures market" as "one in which the market price would constitute at all times the best estimate that could be made, from currently available information, of what the price would be at the delivery date of the futures contracts.". A futures market produces a reliable price by providing an incentive to traders to seek out and analyze accurately all available information. Such informed trading is essential to the operation of the market and should be encouraged. In contrast, traders who seek to profit, not through their superior ability to predict future prices, but by their ability to alter the market price, do not contribute to the efficient operation of the market. Such conduct should be considered illegal.".
} 
LONDOÑO, Fernando. "Ilícito de manipulación bursátil: fenómeno y lesividad. Aspectos de política sancionatoria".

función de sus costos inherentes o self-deterrence y riesgo de "disuasión excesiva" de la prohibición de la conducta u over-deterrence), ${ }^{160}$ pueden entonces delinearse algunas posiciones generales en materia de política sancionatoria.

Así, de las modalidades asociadas al mecanismo de injerencia en los precios descritas supra 2.6, aquellas basadas en formas activas de engaño o falsedad (a.1; fraud-based) aparecen como prioritarias de cara a una prohibición/sanción administrativa o penal. En efecto, además de su alto índice de lesividad (conforme a todo lo expuesto supra), ellas presentan un relativamente bajo costo en fase de comisión (baja self-deterrence), al tiempo que su prohibición y persecución ofrece bajos índices de riesgo de disuasión excesiva (baja overdeterrence).

Prescindiendo de las modalidades comisivas, las conductas de manipulación especial (distorsión) ejecutadas en el mercado primario, resultan particularmente lesivas y, por tanto, fuertemente necesitadas de prohibición/sanción. ${ }^{161}$ Lo anterior, en cuanto es en dicho mercado en el que se materializa la conexión entre ahorro e inversión. Por lo demás, la afectación de la confianza en el modelo se verifica aquí con especial intensidad, en la medida que las posibles manipulaciones ejecutadas en el mercado primario (incluyendo las falsedades de prospecto en las que incurren los emisores) serán necesariamente obra o contarán con el aval de actores principales: emisores, underwriters, auditores, calificadoras de riesgo y/o -dados los volúmenes allí transados- grandes inversionistas.

En un plano distinto -necesitado de un alto estándar de sutileza y fragmentariedad persecutoria- se colocan las modalidades comisivas de incidencia en los precios mediante abuso de posición de mercado, descritas supra 2.6 (a.2; market power), pues al tiempo que algunas de estas hipótesis (especialmente aquellas operativas mediante corners o squeezes en mercados de derivados) presentan un alto índice de auto-disuasión (dados los costos del denominado burying the corpse effect), ${ }^{162}$ su prohibición y persecución ofrece un nivel mayor de riesgo de disuasión excesiva (considerando el carácter preliminarmente lícito de las operaciones reales en un mercado). Esta última característica también es compartida por los esquemas de manipulación puramente basados en operaciones reales y que inciden en el precio de modo directo, sobre la base de un poder de mercado ejercido en compras o ventas reales, según se ha descrito supra 2.6 (b, actual trade). Lo anterior, considerando especialmente las dificultades probatorias para distinguirlas de las operaciones reales lícitas, idóneas para alterar los precios. ${ }^{163} \mathrm{En}$ fin, las manipulaciones omisivas -aquellas consistentes en la no entrega de una información debida y que, de ser conocidas por el

\footnotetext{
${ }^{160}$ Cfr. POSNER, Richard, "Optimal Sentences for White-Collar Criminals", Am. Crim. L. Rev. (1980), vol. 17, pp. 409 y ss.; COOTER, Robert, "Prices and Sanctions”, Colum. L. Rev. (1984), Vol. 84, p. 1523 y ss.; COFFEE Jr., John. C., "Corporate Crime and Punishment: a Non-Chicago view of the economics of criminal sanctions", Am. Crim. L. Rev. (1980), vol. 17, pp. 419 y ss.

${ }^{161}$ Como por ejemplo, las falsedades ideológicas descritas y sancionadas en la letra f) del art. 59 de la $L M V$ chilena.

${ }^{162}$ En cuanto al "efecto de entierrro del cuerpo", cfr. por todos, PIRRONG, "Commodity Market", cit. nota ${ }^{\circ}$ 80, p. 955: "Market participants refer to this postdelivery price collapse as the "burying the body (or corpse)" effect".

${ }^{163}$ Véase los dicho supra, en excurso de apartado 2.6.2.
} 
Polit. crim. Vol. 8, № 15 (Julio 2013), Art. 3, pp. 64 - 127.

[http://www.politicacriminal.cl/Vol_08/n_15/Vol8N15A3.pdf]

público tendrían un impacto en el precio de los respectivos valores- ${ }^{164}$ merecen un tratamiento punitivo cauteloso, sólo a título de infracción de la regla de revelación continua de información (mandatory disclosure), ${ }^{165}$ posiblemente subsidiaria de la eventual sanción por explotación de información privilegiada en dicho contexto. ${ }^{166}$

\footnotetext{
${ }^{164}$ Cfr. supra nota $\mathrm{n}^{\circ} 64$, con especial referencia a la hipótesis prevista en la legislación alemana, $W p H G$ parag. 20 a (1) 1). Nótese que se trata de casos de entera omisión, y no de falsedades cometidas mediante comunicaciones o revelaciones incompletas o tendenciosas (en las que se "omite" un trazo de información verdadera o clarificadora del contexto).

${ }^{165}$ Cfr., a título ejemplar, el art. 10 de la $L M V$ chilena.

${ }^{166}$ Más allá de los problemas probatorios en un escenario de tipos construidos sobre la base de dolo directo, la equiparación entre una omisión de información y manipulación, en el sentido de injerencia, parece no dar en el blanco. La figura abre además un escenario de riesgo de intromisión desmedida en las esferas de decisión del emisor, tendencialmente ya colmada con la mandatory disclosure y la sanción de su infracción.
} 
LONDOÑO, Fernando. "Ilícito de manipulación bursátil: fenómeno y lesividad.

Aspectos de política sancionatoria".

\section{BIBLIOGRAFIA}

AA.VV., "Illegality of Stock Market Manipulation (Note)", Colum. L. Rev. (1934), vol. 34, pp. 500 y ss.

AA. VV., "Market Manipulation and the Securities Exchange Act (Comment)", Yale L.J., n. 46 (1937), pp. 624 y ss.

AA. VV., "Regulation of Stock Market Manipulation (Comment)", Yale L.J., n. 56 (1947), pp. 509 y ss.

AA. VV., "Manipulation of the Stock Markets under the Securities Laws (Note)", U. Pa. L. Rev., n. 99 (1951), pp. 651 y ss.

AGGARWAL, Rajesh; PURNANANDAM, Amiyatosh; WU, Guojun, "Underwriter Manipulation in Initial Public Offerings", $S S R N$, 2005, disponible en www.csom.umn.edu/Assets/62572.pdf o en http://papers.ssrn.com.

AGGARWAL, Rajesh K.; WU, Guojun, "Stock Market Manipulation - Theory and Evidence", SSRN, 2003, disponible en http://papers.ssrn.com/sol3/papers.cfm?abstract id=474582

AKERLOF, George, "The Market for "Lemons": Quality Uncertainty and the Market Mechanism”, 84 Q. J. Econ. (1970), pp. 488-500.

ALLEN, Franklin; GALE, Douglas, "Stock-Price Manipulation”, Rev. Fin. Stud. (1992), n. 5, pp. 503-529.

ALLEN, William T, "Securities Markets as Social Products: The Pretty Efficient Capital Market Hypothesis", 28 Iowa J. Corp. L., pp. 556 y ss.

AVGOULEAS, Emilios, The Mechanics and Regulation of Market Abuse. A legal and Economic Analysis, Oxford: Oxford University Press, 2005.

BANNER, Stuart, Anglo-American Securities Regulation. Cultural and Political Roots. 1690-1860, Cambridge: Cambridge University Press, 1998.

BERLE, Adolf A. Jr., "Liability for Stock Market Manipulation", Colum. L. Rev., n. 31 (1931), pp. 264 y ss.

393 y ss.

BÖCKENFORDE, Ernst-Wolfgang, Stato, costituzione, democracia, Milano: Giuffrè, 2006.

BOGNETTI, Giovanni, Introduzione al diritto costituzionale comparato: il metodo, Torino: Giappichelli, 1994.

, L'apporto della comparazione alla scienza giuridica / contributi originali di Giovanni Bognetti, (Ed. R. Sacco), Milano: Giuffrè, 1980.

CHATTERJEA, Arkadev; JARROW, Robert, "Market Manipulation, Price Bubbles, and a Model of the U.S. Treasury Securities Auction Market", The Journal of Financial and Quantitative Analysis, 1998-Jun, Vol. 33, pp. 255-289.

COFFEE Jr., John C., "Market Failure and the Economic Case for a Mandatory Disclosure System”, 70 Virginia Law Review 717 (1984).

, "Corporate Crime and Punishment: a Non-Chicago view of the economics of criminal sanctions", Am. Crim. L. Rev. (1980), vol. 17, pp. 419 y ss.

COMITÉ DE REGULACIÓN Y AUTORREGULACIÓN DE LAS BOLSAS DE COMERCIO DE SANTIAGO Y ELECTRÓNICA DE CHILE, Reglas para prevenir y combatir el uso de información privilegiada y la manipulación de mercado, abril de 
Polít. crim. Vol. 8, № 15 (Julio 2013), Art. 3, pp. 64 - 127.

[http://www.politicacriminal.cl/Vol_08/n_15/Vol8N15A3.pdf]

2009.

Disponible

en

http://www.bolsadesantiago.com/Normativas\%20Comite $\% 20$ Regulacion/Reglas $\% 20$

sobre $\% 20$ informaci $\% \mathrm{C} 3 \% \mathrm{~B} 3 \mathrm{n} \% 20$ privilegiada.pdf.

COOTER, Robert, "Prices and Sanctions", Colum. L. Rev. (1984), Vol. 84, pp. 1523 y ss.

COX, James; HILlMAN, Robert W; LANGEVOORT, Donald C., Securities Regulation, Cases and Materials, New York: Aspen, 2001 (3a. ed.), cap. 10-12.

EASTERBROOK, Frank H.; FISCHEL, Daniel, "Mandatory Disclosure and the Protection of Investors", 70 Virginia Law Review 669 (1984).

, The Economic Structure of Corporate

Law, Cambridge: Cambridge University Press, 1991.

EASTERBROOK, Frank H., "Monopoly, Manipulation, and the Regulation of Futures Markets", The Journal of Business, Vol. 59 (1986), n. 2, pp. 103-127.

ETCHEBERRY, Alfredo, Derecho Penal. Parte Especial, Tomo IV, $3^{\text {a }}$ ed., Santiago: Editorial Jurídica de Chile, 1998.

FAMA, Eugene, "Efficient Capital Markets: a Review of Theory and Empirical Work", J. Fin. (1970), vol. 25, pp. 383 y ss. (disponible digitalmente en stuwww.uvt.nl) , "Efficient Capital Markets: II", J. Fin. (1991), vol. 46, pp. 1575 y ss.

FELIXSON, Karl; PELLI, Anders, "Day end returns - stock price manipulation”, Journal of Multinational Financial Management (1999), Vol. 9, pp. 95-127.

FINNERTY, John D., "Short Selling, Death Spiral Convertibles, and the Profitability of Stock Manipulation", SSRN, 2005, disponible en http://papers.ssrn.com/sol3/papers.cfm?abstract id=687282.

FISCHEL, Daniel; ROSS, David; "Should the Law Prohibit "Manipulation" in Financial Markets?", Harv. L. Rev., n. 105 (1991), pp. 503 y ss.

FOFFANI, Luigi, "Delitos Bancarios y Bursátiles", en: TIEDEMANN, Klaus (Dir.); NIETO, Adán (Coord.), Eurodelitos. El Derecho Penal económico en la Unión Europea, Cuenca: Universidad de Castila La Mancha, 2004, pp. 109-117.

FRIEDMAN, Richard D., "Stalking the squeeze: understanding commodities market manipulation", Mich. L. Rev., n. 89 (1990), pp. 30-68.

GARCÍA, Gonzalo, "Modelo de protección en normas administrativas y penales que regulan el abuso de Información Privilegiada en la legislación chilena". Polit. crim. Vol. 8, No 15 (2013), Art. 2, pp. 23 - 63.

GILSON, Ronald; KRAAKMAN, Reinier, "The Mechanism of Market Efficiency", $V a . L$ Rev. (1984), vol. 70, pp. 549 y ss.

HANSMANN, Henry; KRAAKMAN, Reinier, "The End of History for Corporate Law", Georgetown Law Journal, vol. 89 (2001), pp. 439 y ss. (disponible también en versión digital como paper en SSRN).

HART, Herbert L.A., The Concept of Law, Oxford: Oxford University Press, 1994.

HERNÁNDEZ, Héctor, "La punibilidad de la colusión (secreta) de precios en el derecho chileno". Polit. crim. Vol. 7, No 13 (Julio 2012), Art. 4, pp. $147-167$.

HERTIG, Gerard; KRAAKMAN, Reiner; ROCK, Edward, "Issuers and Investor Protection", en: KRAAKMAN, Reiner; DAVIES, Paul; HANSMANN, Henry; HERTIG, Gerard; HOPT, Klaus; KANDA, Hideki; ROCK, Edward (Dirs.), The Anatomy of Corporate Law. A Comparative and Functional Approach, New York: Oxford University Press, 2004, sección 8. 
LONDOÑO, Fernando. "Ilícito de manipulación bursátil: fenómeno y lesividad.

Aspectos de política sancionatoria".

JARROW, Robert. A., "Derivative Security Markets, Market Manipulation, and Option Pricing Theory", The Journal of Financial and Quantitative Analysis (1994), Vol. 29, pp. 241-261.

, "Market Manipulation, Bubbles, Corners, and Short Squeezes", The Journal of Financial and Quantitative Analysis, 1992-Sep., Vol. 27, pp. 311-336.

JENNINGS, Richard W; MARSH Jr., Harold; COFFEE Jr. John. C.; SELIGMAN, Joel, Securities Regulation, Cases and Materials, New York: Matthew Bender, 1998 (8a. ed.), cap. 11 y 18, pp. 673 y ss y 1582 y ss.

JIANG, Goulin; MAHONEY, Paul G.; MEI, Jianping, "Market manipulation: a comprehensive study of stock pools", Journal of Financial Economics (2005), vol. 77, pp. 147-170.

KOSLOWSKI, Peter, The Ethics of Banking. Conclusions from the financial crisis, Dordrecht: Springer, 2011.

KUMAR, Praveen; SEPPI, Duane J., "Futures Manipulation with 'Cash Settlement", The Journal of Finance, 1992-Sep., Vol. 47, pp. 1485-1502.

LA PORTA, Rafael, LÓPEZ-DE-SILANES, Florencio; SHLEIFER, Andrés, "What Works in securities laws?", The Journal of Finance, vol. XVI, N. 1, 2006.

LOSS, Louis; SELIGMAN, Joel, Securities Regulation, versión digital Lexis.com, 2004 (3a. ed.), cap. 10.

LUHMANN, Niklas, Sistema Giuridico e Dogmatica Giuridica, Bologna: Il Mulino, 1978.

MAHONEY, Paul, "The Stock Pools and the Securities Exchange Act", J. Fin. Econ., n. 51 (1999), pp. 343 y ss.

MARKHAM, Jerry W., "Manipulation of Commodity Futures Prices -- The Unprosecutable Crime", Yale J. Reg., n. 8 (1991), pp. 281 y ss.

MATHIAS, James, "Manipulative Practices and the Securities Exchange Act", U. Pitt. L. Rev. (1936), n. 3, pp. 7 y ss.

MATUS, Jean Pierre. "Acerca de la actual falta de punibilidad en Chile de los acuerdos de precios". Polit. crim. Vol. 7, No 14 (Diciembre 2012), Art. 3, pp. 318 - 356.

McDERMOTT, Edward T., "Defining Manipulation in Commodity Futures Trading: The Futures 'Squeeze'”, Nw. U.L. Rev. (1979), vol. 74, pp. 202 y ss.

MENGONI, Luigi, Ermeneutica e dogmatica giuridica, Milano: Giuffrè, 1996.

MERRICK Jr., John J., NAIK, Narayan Y., YADAV, Pradeep K., "Strategic trading behavior and price distortion in a manipulated market: anatomy of a squeeze", Journal of Financial Economics (2005), vol. 77, pp. 171-218.

MOORE, James M.; WISEMAN, Frank M., "Market Manipulation and the Exchange Act", U. Chi. L. Rev., n. 2 (1934), pp. 46 y ss.

MOOSMAYER, Klaus, "Straf- und bußgeldrechtliche Regelungen im Entwurf eines Vierten Finanzmarktförderungsgesetzes, Wistra (2002), n. 5, pp. 161-170.

MUCCIARELLI, Francesco, "Aggiotaggio", en: ALESSANDRI, Alberto (Dir.), Il nuovo diritto penale delle società, Milano: Ipsoa, 2002, pp. 421-440.

MUSCO, Enzo, I nuovi reati societari, Milano: Giuffrè, 2001, pp. 175 y ss.

MYERS, Stewart C.; MAJLUF, Nicholas [sic] S., "Corporate Financing and Investment Decisions When Firms Have Information that Investors Do Not Have", 13 J. Fin. Econ. (1984), pp. 187-221.

NIEBUHR, Reinhold, Il destino e la storia, Milano: Rizzoli, 1999. 
Polít. crim. Vol. 8, № 15 (Julio 2013), Art. 3, pp. 64 - 127.

[http://www.politicacriminal.cl/Vol_08/n_15/Vol8N15A3.pdf]

NOVAK, Michael, The Spirit of Democratic Capitalism, Lanham: University Press of America, 1991.

ONADO, Marco, Mercati e intermediari finanziari, Bologna: Il Mulino, 2000.

, Economia e regolamentazione del sistema finanziario, Bologna: Il Mulino, 2004.

OTTO, Harro, Anmerkungen zum strafrechtlichen Schutz des Finanzwesens und der Handelsgesellschaften (Art. 49-56), en: TIEDEMANN, Klaus (Coord.), Wirtschaftsstrafrecht in der Europäischen Union (Freiburg-Symposium), Köln: Heymanns, 2002, pp. 353-367.

PARDOW, Diego, "La experiencia chilena disuadiendo ilícitos corporativos", Revista Derecho Público Iberoamericano, N. 1 (2012), pp. 55-83.

PEDRAZZI, Cesare, Problemi dell'aggiotaggio, Milano, 1958; reed. en Diritto Penale IV, Scritti di diritto penale dell'economia, Milano: Giuffrè, 2003, pp. 3-97.

, "Turbativa dei mercati (voce)", en: AA.VV., Digesto - Discipline Penalistiche, Torino: UTET, 1999, pp. 421-432.

PERDUE, Wendy C., "Manipulation of futures markets: redefining the offense", Fordham L. Rev., n. 56 (1987), pp. 345 y ss.

PERRONE, Andrea. "Información en el mercado de valores y tutela del inversor". Polit. Crim. Vol. 4, No 7 (Julio 2009), Art. 7, pp. 197-229 (1-33). [http://www.politicacriminal.cl/Vol_04/n_07/Vol4N7A7.pdf]

PIRRONG, Craig, "Commodity Market Manipulation Law: A (Very) Critical Analysis and a Proposed Alternative", Wash. \& Lee L. Rev., n. 51 (1994), pp. 945 y ss.

POSER, Norman, "Stock Market Manipulation and Corporate Control Transactions", $U$. Miami L. Rev., n. 40 (1986), pp. 671 y ss.

POSNER, Richard, "Optimal Sentences for White-Collar Criminals", Am. Crim. L. Rev. (1980), vol. 17, pp. 409 y ss.

RlED, José Miguel, "Fundamentos de la prohibición del uso de la información privilegiada en Chile: una visión crítica", Revista Chilena de Derecho (2004), № 31.3, pp. 439463.

ROSENBLUT, Verónica, "E1 denominado caso "Schwager": análisis de histórica condena por uso de información privilegiada y manipulación bursátil”, Revista Jurídica del Ministerio Público, N. 46, marzo 2011, pp. 185-209.

SEMINARA, Sergio, "I reati di aggiotaggio", en: PEDRAZZI, Cesare; ALESSANDRI, Alberto; FOFFANI, Luigi; SEMINARA, Sergio; SPAGNOLO, Giuseppe, Manuale di diritto penale dell'impresa, Bologna: Monduzzi, 2000, pp. 635-663.

SCHMITZ, Roland, "Der strafrechtliche Schutz des Kapitalmarkts in Europa", ZStW (2003), n.115, pp. 501-538.

SORGENFREI, Ulrich, "Zum Verbot der Kurs- oder Marktpreismanipulation nach dem 4. Finanzmarktförderungsgesetz", Wistra (2002), n. 9, pp. 321-331

SORGENFREI, Ulrich, §§ 20a, 38 I nr. 4, 39 WpHG (Comentario), en: PARK, Tido (Coord.), Kapitalmarkt Strafrecht. Handkommentar, Baden Baden: Nomos-VerlagGes, 2004, pp. 210-270.

STEINBERG, Marc I., Understanding securities law, New York: Lexis Nexis, 2001 (3a. ed.).

THEL, Steve, "\$ 850,000 in Six Minutes -- The Mechanics of Securities Manipulation", Cornell L. Rev., n.79 (1994), pp. 219 y ss. 
LONDOÑO, Fernando. "Ilícito de manipulación bursátil: fenómeno y lesividad. Aspectos de política sancionatoria".

TIEDEMANN, Klaus, Wirtschaftsstrafrecht: Besonderer Teil, Köln: Heymanns, 2006. , "Tecnica legislativa nel diritto penale economico”, Riv. Trim. Dir. Pen. Ec. (2006), pp. 4 y ss.

TRIPMAKER, Stefan, "Der subjective Tatbestand des Kursbetrugs", Wistra (2002), n. 8, pp. 288-292.

TWENTIETH CENTURY FUND, INC., The Security Markets, New York: The Fund, 1935, cap. 13, pp. 443-508.

VAN BOMMEL, Jos, "Rumors", The Journal of Finance, 2003-Aug., vol. LVIII, No. 4, pp. 1499-1519.

VAN SMITH, Preventing the Manipulation of Commodity Futures Markets: To Deliver or Not to Deliver, Hastings L.J. (1981), n. 32, pp. 1569 y ss.

VOGEL, Joachim, "Kurspflege: Zulässige Kurs- und Marktpreisstabilisierung oder strafbzw. ahndbare Kurs- und Marktpreismanipulation? ”, WM (2003), n. 51-52, pp. 24372445.

, $\S \S 20 a, 38-40 b$ (kommentar), en: ASSMANN, H.D.; SCHNEIDER, U.H., Wertpapierhandelsgesetz Kommentar, Köln: Otto Schmidt, 2006, pp. 727 y ss. y 1669 y ss.

ZIOUVAS, Dimitris, "Das Neue Recht gegen Kurs- und Marktpreismanipulation im 4. Finanzmarktförderungsgesetz”, en ZGR (2003), pp. 113 y ss.

ZIOUVAS, Dimitris; WALTER, Tonio, "Das neue Börsenstrafrecht mit Blick auf das Europarecht - zur Reform des $\S 88$ BörsG -", WM (2002), n. 29, pp. 1483-1488. 